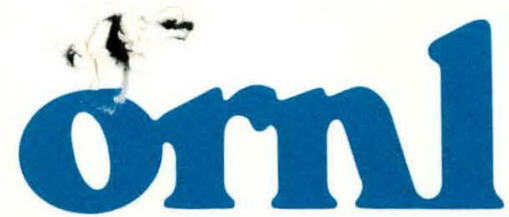

\section{OAK RIDGE NATIONAL LABORATORY}

UNION CARBIDE

NUREG-CR-1482

ORNL/NUREG/TM-395

\title{
Nuclear Power Plant Simulators: Their Use in Operator Training and Requalification
}

OPERATED BY

UNION CARBIDE CORPORATION FOR THE UNITED STATES DEPARTMENT OF ENERGY

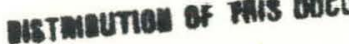

Prepared for the U.S. Nuclear Regulatory Commission Office of Nuclear Regulatory Research Under Interagency Agreement DOE 40-551-75 


\section{DISCLAIMER}

This report was prepared as an account of work sponsored by an agency of the United States Government. Neither the United States Government nor any agency Thereof, nor any of their employees, makes any warranty, express or implied, or assumes any legal liability or responsibility for the accuracy, completeness, or usefulness of any information, apparatus, product, or process disclosed, or represents that its use would not infringe privately owned rights. Reference herein to any specific commercial product, process, or service by trade name, trademark, manufacturer, or otherwise does not necessarily constitute or imply its endorsement, recommendation, or favoring by the United States Government or any agency thereof. The views and opinions of authors expressed herein do not necessarily state or reflect those of the United States Government or any agency thereof. 


\section{DISCLAIMER}

Portions of this document may be illegible in electronic image products. Images are produced from the best available original document. 
THIS PAGE

\section{WAS INTENTIONALLY LEFT BLANK}




\section{Printed in the United States of America. Available from National Technical Information Service U.S. Department of Commerce 5285 Port Royal Road, Springfield, Virginia 22161}

\section{Available from}

GPO Sales Program

Division of Technical Information and Document Control U.S. Nuclear Regulatory Commission Washington, D.C. 20555

This report was prepared as an account of work sponsored by an agency of the United States Government. Neither the United States Government nor any agency thereof, nor any of their employees, makes any warranty, express or implied, or assumes any legal liability or responsibility for the accuracy, completeness, or usefulness of any information, apparatus, product, or process disclosed, or represents that its use would not infringe privately owned rights. Reference herein to any specific commercial product, process, or service by trade name, trademark. manufacturer, or otherwise, does not necessarily constitute or imply its endorsement, recommendation, or favoring by the United States Government or any agency thereof. The views and opinions of authors expressed herein do not necessarily state or reflect those of the United States Government or any agency thereof. 
NUREG/CR--I482

TI85 015919
NUREG-CR- 1482

ORNL/NUREG/TM-395

Category Distribution RI

Contract No. W-7405-eng-26

Engineering Physics Division.

NUCLEAR POWER PLANT SIMULATORS:

THEIR USE IN OPERATOR TRAINING AND REQUALIFICATION

\section{Prepared by}

Center for Nuclear Studies

Memphis State University

Memphis, Tennessee

for

Oak Ridge National Laboratory under ORNL Subcontract No. 7688

Manuscript Completed - June, 1980

Date Published - July 1980

This Work Performed for

Nuclear Regulatory Commission under

DOE Interagency Agreement 40-551-75

NRC Fin No. B0421-8

OAK RIDGE NATIONAL LABORATORY

Oak. Ridge, Tennessee 37830

operated by

UNION CARBIDE CORPORATION

for the

DEPARTMENT OF ENERGY
DisclalMER

This book was prepared as an account of work sponsored by an agency of the United States Government, warranty. express or implied, of assumes any legal liabitity or resoonsibility for the accuracy. complteteness. Of usetuiness of any information. apparatus. product. or process disclosed. Or represents that its use would not inftinge privately owned rights, Reference herein to any specific commercial product, process, Or service by trade name, trademark, manufocturer, or otherwise, docs
not necassarily constitute or imply is endorsement, recommendation, or favoring oy the Uniteo States Government or any agency thereof. The views and opinions of authors expressed herein do not necesserily state or reflect those of the United States Government or any egency thereof. 


\section{THIS PAGE \\ WAS INTENTIONALLY \\ LEFT BLANK}


Survey performed by:

Donald K. Baer

Christopher C. Francis

John M. Winders

CNS/MSU

CNS/MSU

CNS/MSU

Report written by:

D. W. Jones

Donald K. Baer

Christopher C. Francis

Director, CNS/MSU

CNS/MSU

CNS/MSU

Report revised and edited by:

Paul M. Haas

Lorraine S. Abbott

Richard L. Dietz

Program Manager, ORNL

ORNL

CNS/MSU

\section{DISCLAIMER}

This report was prepared as an account of work sponsored by an agency of the United States Government. Neither the United States Government nor àny agency thereof, nor any of their employees, makes any warranty, express or implied, or assumes any legal liability or responsibility for the accuracy. completeness. or usefulness of any information, apparatus, product, or process disclosed, or represents that its use would not infringe privately owned rights. Reference herein to any specific commercial product, process, or service by trade name, trademark, manufacturer, or otherwise docs not nccessarily constitute or imply its endorsement, recommendation, or favoring by the United States Government or any agency thereof. The views and opinions of authors expressed herein do not necessarily state or reflect those of the United States Government or any agency thereof. 


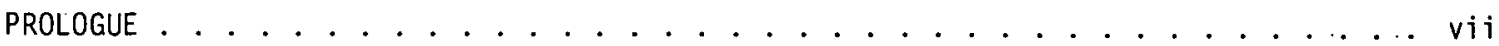

ABSTRACT . . . . . . . . . . . . . . . . . . . . . . $\mathrm{ix}$

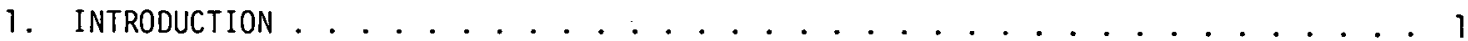

1.1. Background and History of U.S. Nuclear Power Plant Simulators and Their Use in Training Programs......................... 1

1.2. Purpose of this Study. . . . ... . . . . . . . . . . . . . . . 2

1.3. Early Results. . . . . . . . . . . . . . . . . . . . . 3

1.4. Sources of Information ....................... 4

2. BRIEF REVIEW OF PERTINENT TMI-2 EVENTS AND OPERATOR ACTIONS. . . . . . . . . . . . 6

3. EXISTING NUCLEAR POWER PLANT SIMULATOR CAPABILITIES. . . . . . . . . . . . . . . 8

3.1. Generic Characteristics and General Capabilities of:Existing Simulators. . 8

3.1.1. Training Features. . . . . . . . . . . . . . . . 9

3.1.2. Initial Conditions..................... 12

3.1.3. Systems Simulated. .................... . 13

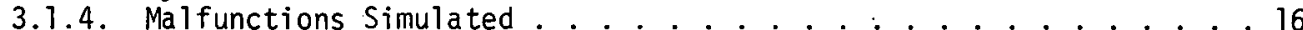

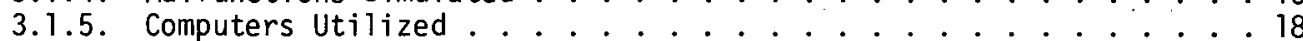

3.2. Issues About Simulator Capabilities Raised by TMI-2. . . . . . . . . . 18

3.2.1. Capability for Multiple Failures................. . 18

3.2.2. Capability to Fail Selected Components in the Simulator. . . . . . 19

3.2.3. Ability to Model Saturated Conditions in the Primary Loop (of PWRs)........................ . . 19

3.2.4. Capabilities for Training on How to Control Pressurizer Level. . . 20

3.2.5. Capability to Introduce Passive as Well as Active Failures . . . . 20

3.2.6. Training on Achieving Natural Circulation. . . . . . . . . . . . . 20

3.3. Conclusions and Recommendations on Simulator Capabilities. . . . . . . 21

4. SIMULATOR TRAINING PROGRAMS. . . . . . . . . . . . . . . . . . . . . 24

4.0. Introduction ...........................24

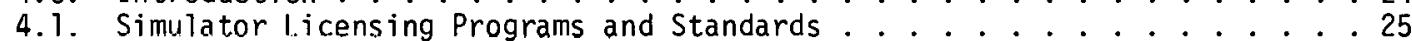

4.1.1. Culd License Training Programs . . . . . . . . . . . . . . . . 25

4.1.2. Hot License Training Programs. ... . . . . . . . . . . . . 28

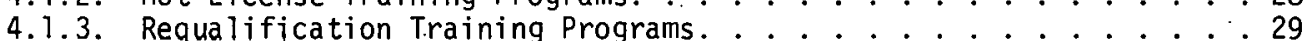

4.2. Issues About Simulator Training Programs Raised by TMI-2 . . . . . . . . 30

4.3. Systems Approach to Training.. . . . . . . . . . . . . . . . . . . . . 32

4.4. Conclusions: Major Problems and Recommendations on the Use of

Simulators in the Nuclear Industry . . . . . . . . . . . . . . . 33

5. PROPOSED PROCEDURES FOR SELECTING EQUIPMENT MALFUNCTIONS FOR SIMULATION. . . . . 36

5.1. Development of General Screening Criteria. . . . . . . . . . . . . 37

5.1.1. Malfunctions That Comprise Safety-Related Events . . . . . . . . 37

5.1.2. Malfunctions That Occur Frequently . . . . . . . . . . . . . 38

5.1.3. Malfunctions That Are Precursors to Safety-Related Events. . . . 38

5.1.4. Malfunctions That Result in Plant Outage........... 39

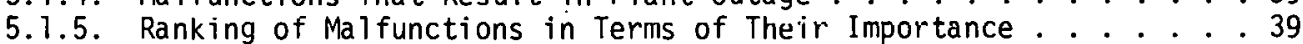




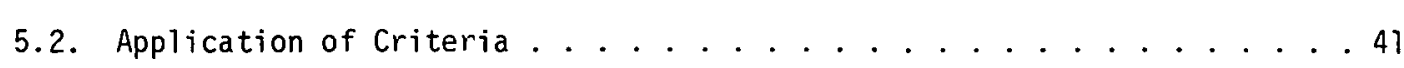

5.2.1. Sources of Data .................. . . . . . 41

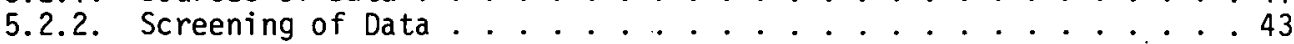

5.2.3. Comparisons with ANSI/ANS-3.5 ............... 45

5.3. Conclusions and Recommendations ................. . . 48

App. A. SYSTEMS AND MALFUNCTIONS SIMULATED FOR PWR PLANTS, . . . . . . . . . A- . .

App. B. SYSTEMS AND MALFUNCTIONS SIMULATED FOR BWR PLANTS. . . . . . . . . . B-1

App. C. OUTLINE OF TVA COLD LICENSE TRAINING PROGRAM FOR PWR OPERATORS : . . . . . C-1

App. D. JOB DIMENSIONS FOR NUCLEAR REACTOR OPERATORS ........... . . . .

App. E. LIST OF MALFUNCTIONS EXPERIENCED AT PWR POWER PLANTS . . . . . . . . . E- E

App. F. LIST OF MALFUnCTIONS EXPERIENCED AT BWWR POWER PLANTS . . . . . . . . F F-1

App. G. CLASSIFICATION OF PWR MALFUNCTIONS BY PROPOSED SCREENING METHOD. . . . . G-

App. H. CLASSIFICATION OF BWR MALFUNCTIONS BY PROPOSED SCREENING METHOD. . . . . H-1

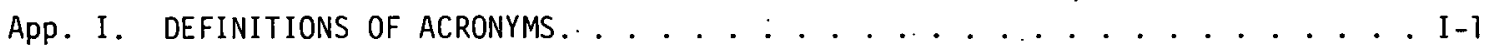


All analyses of the March 28, 1979, incident at Unit 2 of Three Mile Island have concluded that if the nuclear power plant operators had refrained from taking certain actions, the damage to the plant would have been greatly lessened. While these actions have been attributed to many factors, including misleading instrument readings and. deficiencies in the control room design, questions have also arisen about the preparedness of the operators for the abnormal conditions comprising the TMI-2 event. Inevitably, the training methods of the nuclear industry have been compared with those of other industries, particularly with those used by the comercial airline industry to train pilots, and it has been suggested that the nuclear industry's methods have been inadequate.

An important facet of pilot training, of course, is the use of simulated flight conditions to which the trainee is required to respond. During the last decade a significant portion of the training of nuclear power plant operators has also been conducted with simulators. With one exception, the simulators are plant-specific and include control panels that duplicate the control panels of a particular plant. Working at the controls, the trainee observes the responses of the "plant" to his commands, the "plant" being a computer programmed to simulate the responses of the real plant systems.

With simulators playing such a prominent role in operator training, the adequacy of operator training is directly related to the capabilities of the simulators and also to the manner in which-the simulators are used. So that questions related to simulator training could be addressed on the basis of the latest available information, the Nuclear Regulatory Commission's Division of Reactor Safety Research requested Oak Ridge National Laboratory to conduct a survey of the capabilities of U.S. nuclear power plant simulators and also to review the use of simulators in existing operator training programs. ORNL was also requested to determine whether the types, of malfunctions that occurred at TMI-2 were simulatable and, moreover, whether they had been simulated, or should have been simulated, during any of the training programs. In addition, NRC requested that the available standards for simuiator design and use be studied, and, finally, that recommendations be made for improvements in simulators and simulator training programs.

The project was subcontracted by ORNL to the Center for Nuclear Studies at Memphis State University (CNS/MSU), which includes on its staff several individuals who are experienced both in the operation of reactors and in the training of reactor operators. It is the CNS/MSU report, reviewed and modified by ORNL, that is presented here. 
This report presents the results of a study performed for the Nuclear Regulatory Commission to evaluate the capabilities and use of nuclear power plant simulators either built or being built by the U.S: nuclear power industry; to determine the adequacy of existing standards for simulator design and for the training of power plant operators on simulators; and to assess the issues about simulator training programs raised by the March 28, 1979, accident at Three Mile Island Unit 2. Nuclear plant simulators have generally used state-of-the art technology for the time at which they were designed, and their general scope and fidelity. has been satisfactory for most of the anticipated training needs. The PWR simulators can duplicate the multiple malfunctions that occurred at TMI-2; however, improvements in the existing technology would probably be required to model the saturated conditions that developed in the TMI-2 coolant system or to model balance-of-plant systems, should such capability be ruled to be desirable. The NRC has no specific requirements for using simulators in training programs; however, the NRC recognizes that training on simulators both reduces power plant down time and allows training in handling programmed malfunctions. It therefore accepts successful completion of approved simulator training programs by both cold and hot license candidates as fulfilling the requirements for reactor operator experience and it endorses the ANSI/ANS standard covering simulator training programs (No. 3.1). It has not endorsed the ANSI/ANS standard for the simulators themselves (No. 3.5), except indirectly by accepting training programs using simulators that meet the ANSI/ANS-3.5 standard. The nuclear industry has voluntarily met the requirements of both ANSI/ANS-3.1 and ANSI/ANS -3.5 and has also developed additional standards. While this is commendable, it is the conclusion of this study that both ANSI/ANS standards should be expanded, strengthened, and endorsed by the NRC; that simulator training should be required; and that a well-defined regulatory structure for simulators and simulator training programs should be developed. The most obvious deficiency in the present standards is the absence of a methodology and data base to comprehensively and objectively assess the relative importance of specific malfunctions and thereby define the most important exercises to be included in a training program. This deficiency was considered to be sufficiently serious that the present study was expanded to include the development of a preliminary methodology and to illustrate its application. 


\section{INTRODUCTION}

\subsection{Background and History of U.S. Nuclear Power Plant Simulators} and Their Use in Training Programs

The first U.S. nuclear power plant simulator was built by the General Electric Company at Morris, Illinois, to train operators for Dresden.2, a Boiling Water Reactor operated by Commonwealth Edison Company. This simulator went into service in 1968 and was followed in 197.0 by the first Pressurized Water Reactor simulator constructed in Lynchburg, Virginia, by the Link Division of Singer Company. The PWR simulator was for Babcock and Wilcox's use in training operators for the Rancho Seco Power Plant of the Sacramento Municipal Utility District in California. Before these simulators became available, all reactor operator licensing candidates received their training on actual nuclear power plants and each trainee was required to perform at least two reactor startups. However, since two startups for an operating crew can cause a $2 \%$ loss in the on-1ine availability of a nuclear power plant, it was soon realized that the nuclear industry would have to turn to simulators for training their operator license candidates. Among other advantages, simulators offered the opportunity to train for emergency situations that were unlikely to be encountered during training on an actual plant.

The industry's decision to use simulators was affirmed when the federal government ruled in 1969 that successful completion of an approved simulator training program would fulfill the requirements for operating experience for cold license candidates (those applying for licenses prior to the initial fuel loading of the reactor). Later, in 1971, the government also ruled that simulator training was acceptable for hot license candidates (those applying for licenses after initial criticality). At the same time the American National Standards Institute and the American Nuclear Society Standards Committee Working Group ANS-3.1 began developing an American National Standard for Selection and Training of Nuclear Power Plant Personnel (ANSI/ANS-3.1) and an American National Standard for Nuclear Power Plant Simulators (ANSI/ANS-3.5). ANSI/ANS-3.1, which includes training on simulators, has becn endorscd by the Nuclcàr Regulatory Commission's Guide 1.8. MNSI/ANS-3.5 has not been officially endorsed by the Nuclear Regulatory. Commission. However, in most cases the simulator training standards specified in ANSI/ANS-3.1 cannot be met unless the simulators meet the standards specified in ANSI/ANS-3.5. Thus, in effect, ANSI/ANS-3.5 has been adopted.as an official standard.

Today, 20 nuclear power plant simulators (NPPSs) either have been built or are under construction. Of these, 13 simulate PWR plants and seven simulate BWR plants (see Tables 3.1 and 3.2 in Section 3). At the time this study was performed, only 10 of the PWR simulators and three of the BWR simulators had actually gone into service; however, all are scheduled for operation by 1981 . 
The leading manufacturer of nuclear power plant simulators is the Singer Company, which has constructed nine of the PWR simulators and six of the BWR simulators. Three of the PWR simulators were constructed by Electronics Associates, Inc., including one for a standardized PWR plant (SNUPPS), and one by Westinghouse (the simulator for Commonwealth Edison's Zion-1 plant). As mentioned above, General Electric constructed the BWR simulator for the Dresden plant. General Electric is, of course, the only U.S. vendor of the BWRs themselves, whereas three different companies, Babcock and Wilcox, Westinghouse, and Combustion Engineering, supply PWRs.

Simulator training is currently provided by the four Nuclear Steam Supply System (NSSS) vendors and is also available at four utility-operated training facilities. An intensive marketing effort by the NPPS vendors plus an increasing recognition of the training value of simulators has led to the current trend of each utility building a simulator for each type of plant it operates. However, this is a lengthy process (the minimum time for simulator construction is about two years), as well as costly, and some utilities have elected to contract for simulator training at an existing site rather than purchase a site-specific simulator. Thus, many operators have been and are being trained on simulators that do not represent precisely the plants they will operate, and the need for site-specific simulators has become a subject of continuing controversy.

In addition to being used for both cold and hot license training programs, simulators are increasingly being used for biennial requalification programs for operators. A typical cold license training program lasts two years, the first year largely being devoted to class instruction and the second year to on-the-job (simulator) training. Hot license and requalification programs require less șimulațor time; however, since only thrce or four trainees can effectively participate in a training class, training time usually must be scheduled at least a year in advance. As more simulators are constructed, more simulator time will become available to each trainee, which, as discussed throughout this report, is a desirable goal. (Currently NPPS owners charge premium rates of $\$ 400$ to $\$ 700$ per hour to cover the costs of facility amoritization and to support the maintenance and training staffs.)

\subsection{Purpose of this Study}

With simulator training comprising such an important role in the overall preparation of the nation's nuclear power plant operators, the March 28, 1979, accident at Unit 2 of Metropolitan Edison's Three Mile Island power station immediately prompted questions about the adequacy of simulators in duplicating the operation of a nuclear plant and its potential malfunctions, as well as questions about the training procedures employed. So that it would be informed of the latest innovations and have a consistent set of data 
that would allow the simulators and training methods to be intercompared, the Nuclear Regulatory Commission's Division of Reactor Safety Research asked Oak Ridge National Laboratory to review the capabilities and use of the various simulators. ORNL, in turn, subcontracted the project to the Center for Nuclear Studies at Memphis State University (CNS/MSU), which has on its staff a number of individuals who have worked as nuclear power plant operators themselves, and who have also served as instructors in simulator training programs and in some cases as developers of the training programs.

As originally conceived, the NRC work statement for the project listed the following objectives:

(a) Survey and make recommendations for improving nuclear power plant simulators -- both those existing and those planned.

(b). Survey and make recommendations for improving current practices in the training of nuclear power plant operators -- both in their initial training and in their requalification.

(c) Study specific issues related to simulators and their use in training that have been raised by investigations of the TMI-2 accident, e.g. were the malfunctions and events that occurred simulatable and had they been anticipated in training programs? Also, review and assess other studies related to the TMI-2 incident, including NRC Report NUREG-0560 ("Staff Report on the Generic Assessment of Feedwater Transients in Pressurized Water Reactors Designed by the Babcock and Wilcox Company, May 1979); General Accounting office Letter B-127945 (to Senator Richard S. Schweiker, May 15, 1979); and information reports SECY-79-330 through SECY-79-330F prepared for the NRC commissioners.

(d) Review and assess current standards for nuclear power plant simulators and for the use of the simulators (ANSI/ANS-3.1 and ANSI/ANS-3.5).

\subsection{Early Results}

Preliminary studies performed early in the project centered on item (c) above, and it soon became apparent that:

(1) The nuclear training industry was undergoing dramatic and traumatic changes as a result of the TMI-2 accident, and it would therefore not be possible to collect accurate and up-to-date information, especialiy on training practices. 
(2) Definitive answers to some of the questions raised would require in-depth' studies of each simulator's software and hardware, as well as each training program, and this was beyond the scope of the work statement.

(3) All training programs share a common deficiency in that no consistent methodology or set of criteria exists for selecting the malfunctions to be simulated. As a result, there is considerable variability in the selection of training exercises and little objective basis for confidence that the "most important" events are being simulated. The lack of accepted criteria for selecting malfunctions was felt to be symptomatic of a more fundamental problem: the nuclear training industry has not generally employed a comprehensive, formal methodology for designing operator training programs as have some other high-technology industries.

These preliminary findings were reported to the NRC on July 20, 1979, and it was subsequently decided that while the study should continue along the general lines proposed earlier, i.e., reviewing existing simulator capabilities and training programs, it should concentrate on the problem of criteria for selecting malfunctions. Thus, throughout the study the questions that became dominant were: Are the "most important" malfunctions being simulated? How can one determine which are the most important? What should be the basis for selecting malfunctions to be emphasized in simulator training? Etc.

Consistent with this format, Chapters 3 and 4 discuss findings and recommendations about current simulator capability and current use of simulators in training programs. These chapters are. preceded by Chapter 2, which briefiy summarizes the TMI-2 accident sequence, highlighting the events and actions most applicable to the study. Chapter 5 then describes the efforts to resolve the questions cited in the preceding paragraph and to establish a systematic basis for "ranking" malfunctions.

\subsection{Sources of Information}

To complete this study, the MSU/CNS relied heavily on the extensive experience of staff members in power plant operations and operator training and selection. Specific information was gathered from numerous sources of different types including:

(1) NRC Records. Information on specific systems and malfunctions simulated at each training facility was obtained from records on file in the NRC Operator Licensing Branch, Washington, D. C.

(2) Simulator Bid Specifications. Information on the capabilities of the simulators was obtained from their bid specifications.

(3) Simulator Development Studies. Information on the design and analysis of simulator training programs had been prepared previously by the CNS/MSU staff during. simulator development studies. 
$\checkmark$

(4) Simulator Training Staffs. The CNS/MSU staff communicated directly with the simulator training staffs to discuss their training procedurês and simulator capabilities.

(5) Site Visits. Site visits were made to both of the BWR training facilities in operation and to one PWR training facility. (Prior to this survey, CHS/MSU staff members had visited or otherwise contacted almost all the training facilities in the United States, and they themseives had received training on two of the PWR simulators.)

(6) Plant Specifications. Technical specifications for the particular nuclear power plants being simulated also provided information on systems and operational parameters.

(7) Licensee Event Reports (LERS). Information on specific malfunctions that have occurred at nuclear power plants was obtained from LERs. The ORNL Nuclear Safety Information Center provided 20,000 LERs, of which approximately 3000 were analyzed by the CNS/MSU staff. The data accumulated were used to compare the contents of training exercises, i.e., the malfunctions simulated, to operating experience.

(8) Nonnuclear Simulator Data. Data on simulators and training programs by nonnuclear agencies were also solicited, and information was provided by the Maritime Administration, the U.S. Air Force, the FAA Control Tower Operator Training Facilities, and NASA. 


\section{BRIEF REVIEW OF PERTINENT TMI-2 EVENTS AND OPERATOR ACTIONS}

Objective (c) of the NRC work statement specified that issues raised by the investigation of the TMI-2 accident should be examined with respect to their relevance to simulator capabilities and/or simulator training procedures. Without attempting to give a detailed account of the accident, for clarification of later discussions it is helpful to recall the following pertinent events and operator actions:

(1) The TMI-2 incident was initiated at approximately 4:00 AM by the tripping of a series of pumps supplying feedwater to the steam generators. The tripped pumps caused the steam turbine and the electric generator it powered to immediately shut down. With no feedwater (secondary coolant) removing its heat, the primary coolant increased in temperature and expanded. Compressed steam in the top of an adjacent pressurizer tank caused a pilot-operated relief valve (PORV) to open to relieve the pressure, and steam and water began flowing out of the coolant system into a drain tank in the containment building. The pressure in the reactor vessel continued to rise, however, and at $8 \mathrm{sec}$ following the initial pump trip, the reactor scrammed.

(2) At some time short of $14 \mathrm{sec}$ into the accident, auxiliary feedwater pumps began running, but valves that were blocked (in violation of operating procedures) prevented the reinstitution of feedwater flow. Control panel lights indicating that the valves were closed were unnoticed by the operators until 8 min into the accident, at which time the valves were opened. The ultimate impact of the delay in establishing auxiliary feedwater has been debated; some investigators suggest that if the valves had been open, the reactor coolant temperature may have remained relatively stable long enough to correct the initial problem and reinitiate primary feedwater flow. Others say the basic core transient thermal hydraulic response would nol have been significantly affected, and the failure to recognize and stop the loss of coolant through the PORV was the critical problem. All agree that regardless of the direct impact, the loss of auxiliary feedwater complicated the operators' response and caused an added distraction. With regard to training issues, questions raised focus on how effectively operators are and can be trained to anticipate and respond to transient events that are complicated by inoperative safety equipment, events that are initiatec with key equiprient in an off-normal (out of specification) condition, and events that do not progress as predicted in safety analysis beciuse of unanticipated equipment or operator failures.

(3) At $t=13 \mathrm{sec}$, pressure in the primary coolant dropped sufficiently for the PORV to close; however, it remained open. The control panel lamp indicated closure, but it reflects only the valve solenoid state and not the physical closure of the valve. As noted above, the failure to recognize that the relief valve had not seated and that the upstream block valve should be closed until more than two hours into the event was critical.

(4) Between 1 and 4 minutes into the event, the pressurizer level instrumentation indicated a rapidly rising pressurizer level. The operators interpreted this as an 
indication of increasing core coolant inventory, which is the correct inference for norma 1 (single-phase) core conditions. Because they feared the pressurizer would go "solid," at $t=4.0$ minutes they throttled the high-pressure injection (HPI) system flow, which had initiated on low coolant pressure at about $t=2$ minutes. Had the operators correctly interpreted the reactor coolant system readouts, they would have realized that voias had formed in the primary system. Their failure to correctly interpret the different instrument readings raises further questions about operator training on and fundamental understanding of system transient response under two-phase conditions (i.e., both steam and water), especially with respect to interpretation of pressurizer level indications.

(5) An hour into the accident, with the inconsistency of the high pressurizer level reading and a lower pressure reading from the coolant system still unresolved, the presence of a two-phase coolant caused the four reactor coolant pumps to begin vibrating severely. Fearing damage to the pumps, the operators turned two of them off after 15 min, and 27 min later turned the other two off. The forced flow of cooling water through the core was thus terminated. By this time, the core apparently had become uncovered and had heated to the point that some of the zirconium alloy fuel cladding. was reacting with water to produce hydrogen, some of which must have begun escaping through the open PORV into the containment building.

(6) At 6:22 AM, it was recognized that the PORV was probably open and the block valve between the PORV and the pressurizer was then closed. The loss of coolant stopped and the coolant pressure began to rise; however, the core remained uncovered. At 6:54 AM the operators turned on one of the reactor coolant pumps, but again shut it down ( $19 \mathrm{~m} / \mathrm{n}$ later) because of high vibrations.

(7) At 7:20 AM, an alarm indicated high radiation readings within the containment building. Almost simultaneously the operators turned on the HPI pumps, but for only 18 min. At 8:00 AM the containment building automatically isolated due to increased pressure in the building. However, it was not totally isolated since the operators could and did pump water from the containment building to the auxiliary building.

(8) At 8:26 AM the operators once again turned on the HPI pumps and left them on. Evidence indicates it took about $2 \mathrm{hr}$ to cover the core again.

(9) Later, the TMI-2 staff attempted to establish natural circulation cooling of the core. Attempts were complicated by a gas bubble that had formed in the top of the reactor and by gas bubbles and steam circulating in the primary system. Attempting to depressurize the system somewlial, they opened the block valve and reduced the high pressure injection. Coolant again drained from the. system and the core again became uncovered, but the length of time is unknown. The depressurization attempt ended at 3:00 PM. (In the meantime, at 1:50 PM, an unrecognized hydrogen gas explosion occurred in the containment building.) The difficulty in establishing natural circulation flow raises questions about. nperator training for and the capability of existing simulators to represent these unanticipated conditions. 


\section{EXISTING NUCLEAR POWER PLANT SIMULATOR CAPABILITIES}

The current edition of ANSI/ANS-3.5 (American National Standard for Nuclear Power Plant Simulators) was approved by the American National Standards Institute, Inc., on January 29, 1979. The objectives of the standard are: (1) to estabiish minimum requirements for nuclear power plant simulators to be used in operator training and requalification programs, and (2) to establish minimum criteria for the degree of simulation, performance, and functional capability of the control room instrumentation and controls. As noted in Chapter 1, NRC does not directly endorse ANSI/ANS 3.5, but it effectively has been the accepted standard.

ANSI/ANS-3.5 considers a nuclear power plant simulator primarily as a device for initial and requalification training of nuclear power plant operators and therefore the simulator is to be capable of simulating the operation of the reference plant continuously and in real time. The standard further requires that the extent of simulation be sufficient to allow the operator (or trainee) to participate fully in appropriate plant evolutions and appropriate transients, and it specifies maximum differences permitted between the control room indications of the simulator and those of the reference plant. Minimum requirements are also established for the control room environment and instructor interface, and for the identification of systems which must be simulated. This survey attempted to accumulate and compare information on existing simulators and assess capabilities from the general perspective of these existing requirements and generic characteristics, as well as from the perspective of concerns relative to the TMI-2 accident. The discussions that follow are divided according to these two perspectives.

\subsection{Generic Characteristics and General Capabilities of Existing Simulators}

Generic characteristics useful for describing a nuclear power plant simulator are:

(a) Training features - the options and degree of control available to the instructor in guiding and monitoring the trainee's performance.

(b) Initial conditions - sets of parameter variables that describe the plant conditions at some specified point in time or in a specified operating mode.

(c) Systems simulated - systems (reactor coolant, reactor control, etc.) whose responses can be duplicated on the simulator.

(d) Malfunctions simulated (either preprogrammed or otherwise simulatable) specific malfunctions that might occur within a system or interacting systems of a nuclear power plant.

(e) Computers utilized - the individual or multiple computers utilized by the simulators and an assessment of their capabilities. 
了

These five parameters have been used to intercompare the 20 NPPSs now in service or soon to be in service. The comparisons are summarized in Tables 3.1 and 3.2 and discussed below:

\subsubsection{Training Features}

Specific training features of all of the simulators could not be rigidly categorized because, in some cases, several possibilities exist for achieving the same result. In general, the newer simulators have more definable features. All the simulators, however, appear to have enough training features to satisfy the training needs curreritly defined by ANSI/ANS-3.1. The features required for a particular simulator are specified in the initial bid specifications. Typical features are:

(a) Real time - The normal mode of operation of the simulator is in real time so that the timely response of the power plant is represented as the controls are manipulated by the trainee.

(b) Fast time - To reduce time spent in waiting for uneventful changes in plant conditions to take place, the instructor may set the progress of the simulator to typically 10 times real time.

(c) Slow time - To examine more carefully the response of control room instrumentation during transients, the instructor may reduce the progress of the simulation to typically $1 / 10$ of real time.

(d) Freeze - To allow time for instructor-student discussion of specific points, the instructor can depress a freeze button to stop the evolution of the simulator in real time.

(e) Snapshot - To retain information for future examination, the instructor may obtain a printout of plant conditions at any specific time and/or request that the data be stored.

(f) Backtrack - To discuss particular indications of the control room instrumentation at any given time, the instructor may freeze the simulator and backtrack in predefinable increments of time to a specific pnint in time.

(g) Recall - After a specific set of plant conditions has been stored in the computer, the instructor may recall that set of conditions at any time for display on the control room instrumentation.

(h) Replay - The simulator may be stopped, backtracked to a specific point, and a particular evolution replayed for the trainee's study.

(i) Cry wolf - The instructor may activate false alarms throughout the training exercise to test the ability of the trainee in interpreting control room indications.

(j) Condition override - The instructor may intercept signals from the computer to the control board and either negate the signals or increase or decrease their values in order to introduce faise indications of instruments being monitored by the trainee (an important feature available on modern simulators). 
Table 3.1. PHR Simulators in the United States

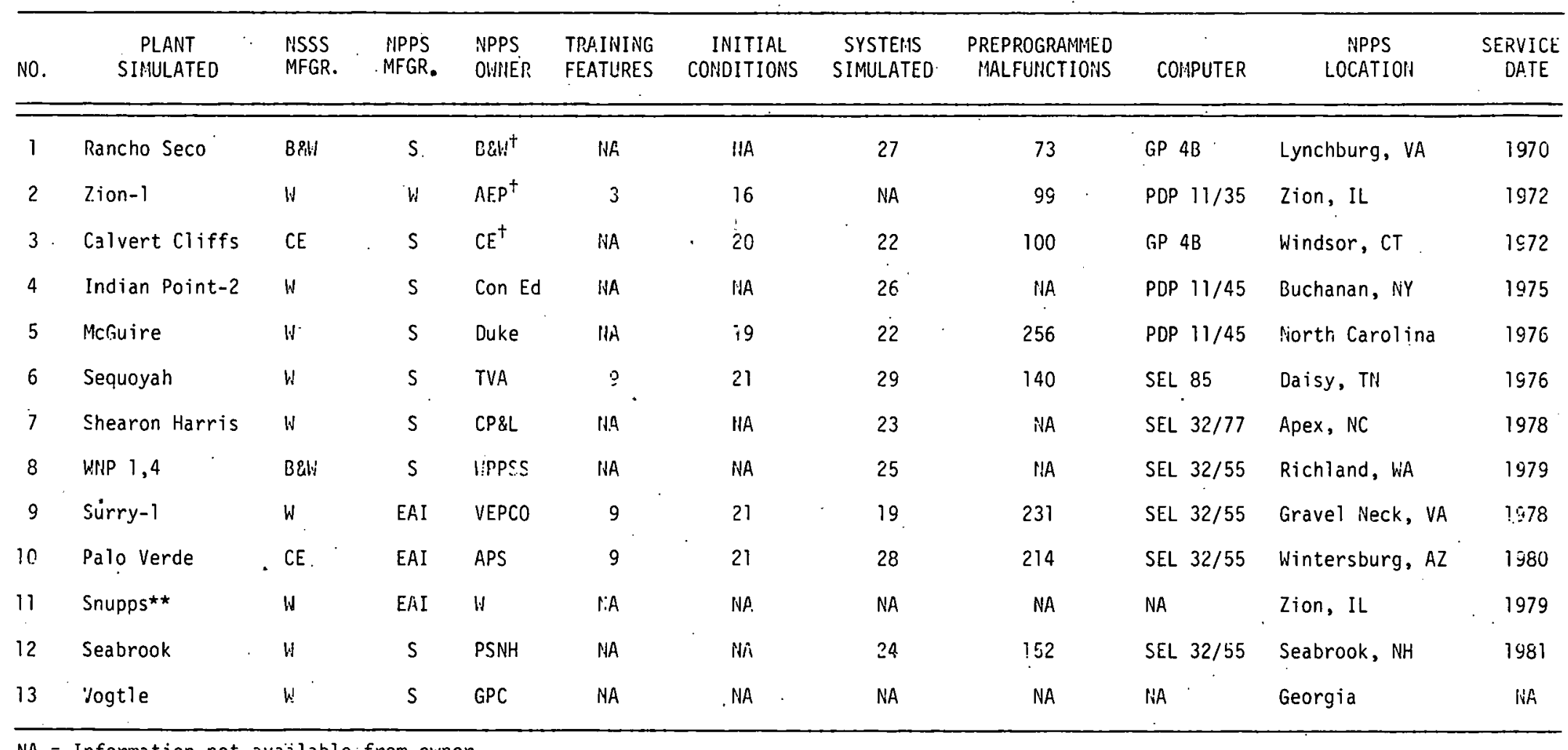

$N A=$ Information not available from owner.

${ }^{\dagger}$ Constructed for commercial training by NSSS vendors.

**Standard Nuclear Power Plant System. 
Table 3.2. BIMR Simulators in the United States

\begin{tabular}{|c|c|c|c|c|c|c|c|c|c|c|c|}
\hline NO. & $\begin{array}{c}\text { PLAIIT } \\
\text { SIMULATED }\end{array}$ & $\begin{array}{l}\text { NSSS } \\
\text { MFGR. }\end{array}$ & $\begin{array}{l}\text { NPPS } \\
\text { MFGR. }\end{array}$ & $\begin{array}{l}\text { NNPS } \\
\text { OWNER }\end{array}$ & $\begin{array}{l}\text { TRAINING } \\
\text { FEATURES }\end{array}$ & $\begin{array}{l}\text { IPITIAL } \\
\text { CONDITIONS }\end{array}$ & $\begin{array}{l}\text { SYSTEHS } \\
\text { SIMULATED }\end{array}$ & $\begin{array}{l}\text { FREPROGRAIMIED } \\
\text { MALFUNCTIONIS }\end{array}$ & COMPUTER & $\begin{array}{c}\text { NPPS } \\
\text { LOCATION }\end{array}$ & $\begin{array}{c}\text { SERVICE } \\
\text { DATE }\end{array}$ \\
\hline 1 & Dresden-2 (BWR;3) & GE & GE & $\mathrm{GE}^{\dagger}$ & 3 & 21 & 33 & 107 & GEP 4020 & Morris, IL & 1968 \\
\hline 2 & Browns Ferry (BWR/4) & GE & $S$ & TVA & 9 & 18 & 47 & 149 & SEL 85 & Daisy, TW & 1976 \\
\hline 3 & Susquehanna (BNR/4) & GE & S & PP\&L & 6 & 26 & 34 & 100 & SEL jáji5s & Berwick, PA & 1979 \\
\hline 4 & Black Fox (BWR/6) & GE & $s$ & $\mathrm{GE}^{+}$ & 6 & 26 & 27 & $14 \hat{2}$ & SEL $32 ; 55$ & Inola, OK & 1980 \\
\hline 5 & Perry (B'NR/G) & GEE & $S$ & $\mathrm{GE}^{+}$ & HA & NA. & 25 & iIA & SEL $32 ; 55$ & Inola, ok & 1980 \\
\hline 6 & Limerick (BWR/4) & GE & $S$ & GP & NA & NA & 31 & NA & SEL $32 / 55$ & Pottstowr, PA & 1980 \\
\hline 7 & Hartsville & GE & $S$ & GF & 6 & 26 & $27^{\circ}$ & 142 & SEL $32 / 5 E$ & Pottstown, PA & 1980 \\
\hline
\end{tabular}

NA = Information not available from owner.

${ }^{\dagger}$ Constructed for commercial training by NSSS veridors.

DEFINITIONS:

NISS = Nuclear Steam Supp y System $^{-1}$

NPPS = Nuclear Fower Plan: Simulator

\section{Vendors}

$G E=$ General Electric

$E \& W=$ Babcock and Wilcox

$k^{\prime}$ = Westinghouse

C.E = Combustion Engineering

$\mathrm{E}=$ = Combustion Engineering

EAI = Electronic Associates, Inc.

TVA = Tennessee Valley Authority

PP\&L = Pennsylvania Power and Light Company.

GP $=$ General Public Utilities

AEP $=$ American Electric Power

CON ED = Consolidated Edison Co.

DUKE = Duke Power Company

CP\&L = Carol ina Power and Light Company

VEPCO = Virginia Electric and Power Company

WPPSS = Washington Publ ic Power Supply System

APS = Arizona Public Service Company

PSNH = Public Service Company of New Hampshire

$\mathrm{GPC}=$ Georgia Power Company

\section{Computers}

PDP = Programming Data Processor of Digital Equinment Corporation (DEC)

GP, GEP = General Precision Company (1ater became DEC)

$S E L=$ Systems Engineering Laboratory 
(k) Diagnostics - Simulators may also include a software package which allows the performance of the student to be monitored and analyzed for later discussions.

ANSI/ANS-3.5 requires a number of these features, in particular, items (a) through (f). As indicated in Tables 3.1 and 3.2, a maximum of nine training features were identified for any one simulator. However, several simulators were being updated to include additional capabilities.

The increased number of features available in modern simulators is indicative of advances in computer hardware and software and, presumably, of increased demands by the training industry for greater flexibility and for more realistic and more comprehensive simulation. These advances have made the simulator a more powerful tool for instruction in emergency operations, and there has been some progress in not simply running "canned" exercises but instead using more realistic simulation of "unpredicted" accident sequences. It is difficult to assess how much progress has been made, especially at any given simulator site. Software development normally continues to evolve after the simulator is operational. Improvements and modifications are made more or less continuously by the operating staff or, as is more likely, by the simulator vendor staff. Even if this were not the case, a thorough understanding of the capabilities and limitations of a particular simulator would require an in-depth study of simulator software, hardware and the reactor systems being modeled. The conclusion from the general review performed is that the simulator hardware and software (as indicated by available training features) are not the limiting factors to more effective training at the present time. Rather, it is the utilization of.simulators in training programs -- the time spent and the manner in which training exercises are developed and carried out -- that can be substantially improved. (Simulator utilization is the subject of Chapter 1.) This does not say that there are nut some definite areas for improvement in simulator capability, such as those highlighted by TMI-2. These are indicated in subsequent sections of this chapter. The point is simply that better usage of existing capability is felt to be more critical and more readily effected.

\subsubsection{Initial Conditions}

Each simulator has a variety of preprogrammed initial condition (IC) sets so that a particular training exercise may begin at any one of a number of points in time from cold or hot startup to full power and shutdown of the reactor. Table 3.3 presents typical IC sets for a PWR simulator (specifically for the TVA Sequoyah Nuclear Power PIant Simulator at Daisy, Tennessee).

ANSI/ANS-3.5 requires that each simulator have at least 20 IC sets. As indicated in Tables 3.1 and 3.2, all of the BWR and most of the PWR simulators for which data were available have at least 20 . However, any specific set of plant conditions may be programmed simply by operating the simulator to a particular point, freezing the variables, 
$\bullet$

backtracking if necessary, taking a snapshot, and storing the data in one of several unfilled IC sets (see Table 3.3). Thus the instructor may even program abnormal plant conditions for the starting point of an exercise. All simulators surveyed appear to have this capability. and all simulators also have several spare IC sets for insertion of new initial conditions by the instructor.

Owing to the lack of change in the normal mode of plant operation, IC sets have changed little over the past decade. Our study indicates that the number of IC sets available should satisfy most training needs in the foreseeable future, and revisions or improvements in this parameter are not seen as a major concern. The reason for investigating this parameter was to assess the flexibility of software and hardware to see whether training exercises could be made less rigid and more realistic. For example, could trainees be introduced to exercises with the reactor system in an off-normal condition? The conclusion from the survey is that the existing simulation have sufficient capacity and flexibility in establishing IC sets to accommodate anticipated training needs, and major revisions or improvements in this area are not recommended.

\subsubsection{Systems Simulated}

Typically, U.S. PWR simulators include modeling of approximately 20 to 30 systems. BWR simulators include approximately 25 to 50 systems. These numbers vary because of basic differences in design and because of differing terminology and categorization schemes for systems (or subsystems). Appendices $A$ and $B$, which detail specific malfunctions that can be simulated with PWR and BWR.simulators, respectively, indicate that 18 major generic systems are modeled.* However, these data may be incomplete since they were derived largely from bid specifications, and, moreover, information was not available for all simulators. On the other hand, the data collection was not intended to be a detailed investigation of the rapabilities of any one simulator and should not be used in that manner. Rather, it should be used for general intercomparisons, to suggest trends, and to provide an indication of the scope of simulation currently available. The general findings from examination of this information and from follow-up discussions with persons experienced in operator training and accident analysis are discussed below.

3.1.3.1. Scope of Simulation. The primary source of information on systems to be simulated is probably the Final Safety Analysis Report (FSAR) and the current scope of simulation, i.e., the number of systems modeled and the detail of modeling, appears to be generally adequate for simulation of abnormal events included in FSARs, to the extent that analyses of those events are typically carried out. However, the TMI-2 event has emphasized that accident scenarios can extend well beyond the time-frame and complexity of the typical FSAR analysis when compounded by unanticipated equipment and/or operator failures.

*See Section 3.1.4 for discussion of malfunctions. 
Table 3.3. Typical Sets of Initial Conditions for PWR Simulators*

\begin{tabular}{|c|c|c|c|c|c|c|c|}
\hline $\begin{array}{c}\text { Initial } \\
\text { Condition } \\
\text { Set }\end{array}$ & $\begin{array}{l}\text { Temperature } \\
\text { (of })\end{array}$ & $\begin{array}{l}\text { Pressure } \\
\text { (psia) }\end{array}$ & $\begin{array}{c}\text { Power } \\
\text { Level } \\
\text { (\% Ful1) }\end{array}$ & $\begin{array}{l}\text { Xenon } \\
\text { Level }\end{array}$ & $\begin{array}{c}\text { Critical } \\
\text { Status } \\
.(\Delta k / k)\end{array}$ & $\begin{array}{l}\text { Fuel } \\
\text { 8urnup } \\
\text { Status } \\
\text { (\% Max.) }\end{array}$ & Comnents \\
\hline 1 & 70 & 15 & 0 & 0 & $\begin{array}{l}10 \% \text { sub- } \\
\text { critical }\end{array}$ & 0 & \\
\hline 2 & 70 & 15 & 0 & 0 & $\begin{array}{l}1 \% \text { sub- } \\
\text { critical }\end{array}$ & 0 & 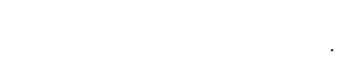 \\
\hline 3 & 300 & Horm & 0 & 0 & $\begin{array}{l}1 \% \text { sub- } \\
\text { critical }\end{array}$ & 0 & \\
\hline 4 & 565 & Ilorm & 0 & 0 & $\begin{array}{l}1 \% \text { sub- } \\
\text { critical }\end{array}$ & 0 & \\
\hline 5 & Norm & Norm & 0 & 0 & Critical & 0 & \\
\hline 6 & Norm & Horm & 10 & 0 & Critical & 0 & Turbine not yet on line \\
\hline 7 & Norm & Norm & 20 & 0 & Critical & 0 & $\begin{array}{l}\text { Turbine on line, steady- } \\
\text { state condition }\end{array}$ \\
\hline 8 & Norm & Norm & 50 & $\mathrm{EQ}^{+}$ & Critical & 0 & Steady-state conditions \\
\hline 9 & liorm & Norm & 100 & EO & Critical & 0 & Steady-statc conditions \\
\hline 10 & Norm & llorm & 0 & $75 \%$ peak & Critical & 0 & Xenon increasing \\
\hline 11 & 565 & Norm & 0 & 0 & $\begin{array}{l}1 \% \text { sub- } \\
\text { critical }\end{array}$ & 40 & \\
\hline 12 & 565 & llorm & 0 & $\begin{array}{l}\text { Increasing } \\
\text { from } \mathrm{E} ?\end{array}$ & $\begin{array}{l}1 \% \text { sub- } \\
\text { critical }\end{array}$ & 40 & Hot startup condition \\
\hline 13 & 565 & Horm & 0 & 0 & $\begin{array}{l}1 \% \text { sub- } \\
\text { critical }\end{array}$ & 40 & $\begin{array}{l}\text { Hot reactor coolant } \\
\text { system, cold turbine }\end{array}$ \\
\hline 14 & Norm & Norm & 50 & $\begin{array}{l}\text { En for } \\
100 \% \text { power }\end{array}$ & Critical & 40 & Steady-state conditions \\
\hline 15 & Horm & Norm & 100 & EO & Critical & 40 & Steady-state conditions \\
\hline 16 & 350 & 400 & 0 & Increasing & $\begin{array}{l}1 \% \text { sub- } \\
\text { critical }\end{array}$ & 40 & $\begin{array}{l}\text { Normal shutdown, cool- } \\
\text { down after full-power run }\end{array}$ \\
\hline 17 & Norm & Nlorm & $0^{\circ}$ & $75 \%$ peak & Critical & 40 & Xenon increasing \\
\hline 18 & 350 & 400 & 0 & $c$ & $\begin{array}{l}1 \% \text { sub- } \\
\text { critical }\end{array}$ & $8 n$ & \\
\hline 19 & Norm & Norm & 0 & $75 \%$ peak & Critical & 80 & Xenon decreasing \\
\hline 20 & Norm & Norm & 10 & 0 & Critical & 80 & Turbine not yet on line \\
\hline $\begin{array}{l}21 \\
22-30^{+}\end{array}$ & Norm & Norm & 100 & EQ & Critical & 80 & Steady-state conditions \\
\hline
\end{tabular}

* Specifically for the Sequoyah Polver Plant Simulator operated by TVA.

${ }^{+} \mathrm{EQ}=$

"Unfilled initial condition set for insertion of new initial conditions by instructor and/or for storing data on the plant conditions at a particular point. 
Determination of how much, if any, and in exactly what way the current scope of simulation needs to be extended is not simple and will require additional study. There are some obvious suggestions for improvement that result from TMI-2, such as more complete modeling of saturated conditions in a PWR primary system. However, it seems that a much more comprehensive review of accident sequences is called for, i.e., one that will consider compounded failures and extended accident sequences and also examine the need for modeling additional systems (such as balance-of-plant systems). The potential needs identified by systems and safety analysts in such a study would then have to be balanced with the many other requirements for operator training and examined within the constraints of current computer capability and mathematical modeling techniques before decisions can be made as to future requirements for the scope of plant simulation.

\subsubsection{Simulator Fidelity. The responses of simulated nuclear power plant} systems are required by ANSI/ANS-3.5 to be the same as the responses of the actual systems during normal operation from hot and cold startup to full power loading, during maneuvers throughout the power range; during the occurrence of malfunctions and recovery of the systems, and during plant shutdown and cooldown. ANSI/ANS-3.5 requires that the operator shall not observe differences between the control room indications for the simulator and reference plant that are greater than those allowed by specified performance criteria (the specified tolerance limits on the parameter being monitored are typically $\pm 2 \%$ ). Although NRC has no formal written requirement endorsing or augmenting ANSI/ANS-3.5, our survey indicates that the industry has voluntarily met this requirement. Our survey also indicates that detailed verification of simulator fidelity is. left to the owner as a part of acceptance testing. In view of the importance of simulator training to the operator licensing process, it is recommended that, as a minimum, NRC conduct regulatory reviews of these acceptance tests.

The extent to which simulators can meet the standards and the fidelity of the simulation of systems and their interaction is determined largely by the degree of accuracy afforded by the mathematical modeling techniques and by the capabilities of the computers used. Typically, a system response is calculated from an equation that requires a series solution. The accuracy of the simulation depends upon the number of terms and/or rate of convergence of the series, which in turn determines the time needed for the calculation. However, the simulation must be in real time, which requires from one to eight updates of instrumentation per second. These counteracting requirements place limitations upon the number of systems that can be simulated and the accuracy attainable with a given computer.

These historic limitations involving computer execution time, input/output interface speed and bulk storage requirements still exist despite refinements and increased sophistication. There have been no fundamental innovations in hardware or software during the decade of use of NPPSs to overcome the limitations. Earlier simulators stored data in tabular form in the computer memory and used these data to reproduce system responses. Stored tables may be interpolated with a high degree of accuracy, but they limit the scope and range of the simulation. Later simulators tend to employ dynamic modeling of system 
response. Dynamic modeling affords an extension in simulation to a wide range of system variables, but it requires more time than for interpolation of tables. Complete use of dynamic modeling for more complex physical states, such as two-phase flow, will probably tax the state of technology in both computer capability and mathematical modeling techniques.

3.1.3.3. System Interaction. Mathematical models of systems are usually modularized and isomorphic with plant subsystems. This allows update of the simulator software in modular fashion, but requires performance standards on system interactions which must be reflected in simulator software. Neither ANSI/ANS-3.5 nor NRC places specific requirements on the degree of "system interactiveness," but a high degree is necessary to achieve the standards set in the simulation of overall plant evolutions. Apparently this approach has been successful, but the potential advantages of defining specific criteria for interaction should be examined.

3.1.3.4. Requirements for Updating. Frequently, detailed documentation of the plant systems and equipment to be simulated is not available before the nuclear plant and/or simulator is completed and placed in commercial operation. Thus the simulator design may be based on interim data with plans to update it after the initial cold license training is complete. ANSI/ANS-3.5 requires that this update be performed within 18 months after the reference plant begins commercial operation and that the simulator be. maintained such that compliance is always satisfied. These requirements could result in revisions of simulator software. There apparently is no rigorous and methodical auditing program by NRC to assure compliance with these suggested requirements for updating. Similarly, there are no rigorous procedures for periodic auditing reviews of simulator capabilities as they are modified throughout their lifetime. It is felt that the industry and the NRC (with its very limited number of staff available) have made a conscientious effort to maintain the fidelity of the simulator as plant design and parameters change. However, it is suggested that benefits and costs of a formal program of mandatory reviews be carefully considered by NRC along with the above recommended consideration of an initial acceptance review program.

\subsubsection{Malfunctions Simulated}

ANSI/ANS-3.5 requires that a simulator be capable of simulating at least 75 emergency and/or abnormal. conditions that result from malfunctions. Twenty-one abriormal and emergency conditions are specified. Each of the generic accidents that is analyzed in the reference plant's FSAR and results in observable indications on control room instrumentation must be provided and each shall be considered as a single malfunction.

In the early simulators, the selection of malfunctions to be simulated within the various plant systems was based entirely on the reference plant FSARs and general engineering analyses of potential system failures. Later, plant operating experience guided the selection of malfunctions and, over the years, the number of generic 
malfunctions preprogrammed for both PWR and BWR simulators has grown considerably. Specific malfunctions that can be simulated are presented in Appendices A and B for PWR and BWR simulators, respectively.

Appendices $A$ and $B$ list single equipment malfunctions in the individual systems of specific reference plants. The instructor may combine these to introduce multiple failures via signals from his console. On most simulators the instructor can insert or remove 10 to 20 malfunctions and, in some simulators, he may also vary the severity of the maifunction as well as control or preset the time at which each malfunction is to occur. Thus, he has the option of activating the malfunctions in sequence or simultaneously. Also, with some simulators the instructor may renew the malfunction tableau either partially or completely at any tillie during the exercise.

With the recently innovated "condition override" (see Section 3.1.1), the instructor may also intercept signals en route between the control panel and the computer and negate the signal or, in the case of a variable parameter, change the magnitude. With this option, an almost unlimited number of malfunctions can be introduced during a training exercise. Similarly, the "cry wolf" feature allows the instructor to insert spurious alarms that appear on the control panel, indicating to the operator trainee that a malfunction has occurred, when, in fact, it has not. The "cry wolf" feature is a valuable training aid in teaching the trainee to cope with false alarms, and it either is available or may be duplicated in one way or another on essentially all simulators.

Because of the modular nature of system and malfunction modeling, it is possible to redefine and modify any malfunction with a minimum of difficulty. It is also possible to introduce new malfunctions and, in fact, most simulators include some systems for which no malfunctions have been preprogrammed. Thus, on-going training programs can be modified to take advantage of new developments and this is a versatility that should be retained for all new simulators. It is important to remember, however, that the instructor must assume the responsibility for programming the additional exercises and that current practice limits the available time such that most of it must be devoted to training for normal operations. Thus, he could be expected to include only those malfunctions which he considers to be the most important and the most likely to be encountered during normal operations. It is entirely possible that the malfunctions that are in fact the most important are neither preprogrammed nor anticipated by the instructor. Certainly the wide variety of preprogrammed malfunctions for the different simulators listed in Appendices $A$ and $B$ does not indicate a consensus on which malfunctions should be preprogrammed. As nuled previously, this lack of uniformly applied criteria for selecting the malfunctions and/or systems to be modeled was recognized early in the study as a major deficiency in simulator design and use, and most of the subsequent work was devoted to providing a basis for such criteria. Once established and accepted, these criteria will also provide a consistent basis for review of existing simulators to determine specific needs for improvement. That is not possible at this time without an agreed upon standard for determining which specific malfunctions should be simulated. 


\subsubsection{Computers Utilized}

In general, simulation of a large system requires that:. (1) a large data base be stored; (2) several calculations be performed simultaneously; and (3) input sense lines and output indicators be operated simultaneously. So that the calculations do not interfere with data taking and data display, different processors must communicate very quickly. The early simulators utilize 16-bit machines limited to a single-processor capability (see Tables 3.1 and 3.2), but the latest simulators use 32-bit machines with multiprocessor capability -- specifically the Systems Engineering Laboratory-32/55 computer. These new computers can share memory between processors with access times for the shared memory being 1ittle more than that within each processor. As a result, the speed with which data can be handled has increased considerably (nearly an order of magnitude) and the fidelity and scope of simulation has been greatly improved.

A major criterion for a simulator computer is that the iteration rates with which output signals drive an instrument be such that the operator shall experience no noticeable instrumentation response differences between the simulator control room and the plant control room. Normal iteration rates are 1, 2, 4, or 8 iterations per second, the actual rate required for each system being dependent upon the ability of the operator to discern transient behavior from plant instrumentation. Thus, a critical step in achieving a high degree of fidelity in simulation is the optimization of solution rates. This involves a balance between higher order integration formulas and iteration rates. This balance is especially. important in the case of transient behavior of a system. A review of the state-of-the-art of mathematical modeling techniques is well beyond the scope of this study. However, it is apparent that major improvements such as incorporation of sophisticated transient two-phase flow models for simulation in real time will push if not exceed current capabilities of hardware and software.

\subsection{Issues About Simulator Capabilities Raised by TMI-2}

The TMI-2 event raised a number of specific questions about current simulator capabilities which were examined in the early phase of this study. The questions of immediate concern to NRC and the related survey findings are summarized below.

\subsubsection{Capability for Multiple Failures}

The concern was whether existing simulators have the capability to accommodate nultiple failures, either simultaneously or in succession, such as those that occurred at TMI-2. But more generally, could the simulators accommodate any desired combination of preprogrammed events? In general, the answer is that existing simulators can indeed accommodate multiple failures but that (a) the selection of "logical" combinations of events to form a worthwhile training exercise essentially is the responsibility of the instructor at the console, and (b) the constraints on training time are such that instructors have little time to illustrate possible combinations of failures. 


\subsubsection{Capability to Fail Selected Components in the Simulator}

The question was whether and to what extent simulators can selectively "fail" individual components, say key safety equipment, during the course of an event. Can instructors control the input/output from individual components to further complicate, or initiate, an accident sequence? This capability does exist to some degree in all simulators and to a much greater degree in more recent simulators, particularly those with software equivalent to the "condition override" feature. Examination of Appendices $A$ and $B$ shows that many of the preprogrammed malfunctions are primarily component failures. In addition, many key components can be "failed," or "degraded," during the simulated exercises. For example, the relief valve leakage at TMI-2 could be simulated in all PWR simulators surveyed, and the condensate pump failure could be simulated in most of them. Some types of failures of pressurizer level instrumentation are simulated, though the response of the pressurizer with a saturated reactor coolant system is not directly simulatable. The closure of the auxiliary feedwater valves is not normally simulated directly, but loss of auxiliary feedwater flow could be simulated in most PWR simulators by failing the pumps. Thus, the individual component failures that occurred at TMI-2 could be simulated simultaneously or sequentially at most PWR simulators, and obviously, simulation of the many problems suggested by the TMI-2 event has been and will be receiving a great deal of emphasis. It seems that the more important question is again the basis for deciding which of the virtually limitless combinations of component failures should be emphasized in training. This is the subject of Chapter 5 of this report.

\subsubsection{Ability to Model Saturated Conditions in the Primary Loop (of PWRs)}

Prior to the TMI-2 event, little or no thought was given by the nuclear training industry to modeling in a training simulator the response of a PWR primary loop with saturated conditions. In general, operation of safety systems is assumed to preclude vapor formation in the primary system. The possibility for a slowly developing loss-ofcoolant accident proceeding unrecognized for a considerable time period without adequate core cooling was considered as not credible and/or the consequences were assumed to be bounded by those of the large LOCA.

Since the TMI-2 event, most of the PWR simulator operators have attempted to reproduce, with varying degrees of success, the significant effects on plant monitors that would result from a saturated primary coolant. However, none can truly model twophase primary coolant flow and its interactive effects on the many associated reactor systems. Nccuratc and thorough models of two phasc flow in a PWR systcm following a transient are still in developmental stages. Computer codes in use are large and (relatively) very time-consuming for use in dynamic modeling with real-time simulation. The extent to which saturated conditions need to be modeled in current or future highfidelity simulators should be determined by experts in both safety analysis and reactor operations and training, and these needs must be balanced with the existing capabilities of software and hardware. 


\subsubsection{Capabilities for Training on How to Control Pressurizer Level}

Pressurizer level control and instrumentation is certainly included in all PWR simulators, and malfunctions related to pressurizer level can be simulated. The actual practices and emphasis in training on pressurizer level control is a question of the use of existing simulator capability and is discussed in Chapter 4. Prior to TMI-2 there was no training in interpretation of and little interest in simulating pressurizer level. indications with voids in the primary system. The need for improving simulator software and the extent of improvement necessary to provide realistic modeling of the pressurizer under such conditions needs to be addressed as part of expert review suggested in item 3.2.3 above.

\subsubsection{Capability to Introduce Passive as Well as Active Failures}

Passive failures are those that do not have significant consequences (and hence are undetected) until a demand is placed on the failed item. The closed auxiliary feedwater valves in the TMI-2 event are an excellent example. Another typical example is the failure of a starting circuit for a diesel generator. As seen in Appendices $A$ and $B$, and discussed in item 3.2.2 above, the modern simulators generally do have the capability to selectively simulate failure of key safety equipment and to then override signals from the failed equipment. Thus, they could simulate unavailability of selected items because of passive failures. All existing simulators can fail some of the key safety systems, completely and/or partially, after initiation. The extent, i.e., the number of items which can be failed, and the versatility of the software to perform the simulation varies somewhat from site-to-site. A more detailed review of software would be necessary to identify specific capabilities. Again, the question of how effective training has been and can be depends more on the optimum use of existing capability rather than development of more sophisticated software or hardware.

\subsubsection{Training on Achieving Natural Circulation}

Training on achieving natural circulation in a steady-state mode is a routine part of training exercises. Operators are taught to recognize the difference in core parameters (primarily RCS $\Delta \mathrm{T}$ ) between natural and forced circulation and to recognize symptoms of loss of natural circulation. Generally, the emphasis on achieving natural circulation is secondary; that is, achieving steady-state natural circulation is one aspect of a particular training exercise whose primary function might be, for example, operation in a particular reactor mode. The problem with achieving natural circulation when there are significant voids present in the primary system was not considered in training prior to the TMI-2 event. Certainly, it should be possible to "force" key readouts to simulate the effects of attaining or losing natural circulation under such conditions, but accurate physical modeling does not now exist. The need to include such modeling and the difficulty of doing so are questions that need to be addressed by NRC and the training industry as part of the review suggested in item 3.2.3. 


\subsection{Conclusions and Recommendations on Simulator Capabilities}

Two major conclusions of a general nature have been derived from this survey of simulator capabilities:

(1) Improved Usage of Simulators Needed. Although there are specific areas for improvement of simulator capability, the more immediate and more substantial benefits are to be derived from improved usage of simulators in training programs.

(2) Methodology Needed for Ranking Malfunctions. A general deficiency in the design of simulators and simulator training exercises is the lack of a supporting methodology and data base to comprehensively and objectively assess the relative importance of specific malfunctions and thereby define exercises to be included in training. This deficiency is felt to be indicative of a more fundamental problem of a lack of rigorous methodology for delineating specific training goals and corresponding requirements and performance criteria. This more basic problem is an issue of the use of simulators rather. than simulator capability and is discussed further in Chapter 4 . With regard to the lack of criteria for selection of malfunctions, it is recommended that the industry and NRC move to provide the comprehensive and objective studies of potential accident sequences and malfunctions which are necessary to provide the data base for continually upgrading operator training. In the interim, it is suggested that a subjective but consistent "ranking" system such as described in Chapter 5 of this report can be used as a uniform basis for evaluating and improving existing programs.

Other conclusions and recommendations related to simulator capability are:

(3) Simulator Flexibility Generally Satisfactory; Criteria Needed. The flexibility and degree of control provided for the instructor by existing simulator computer software (as indicated by training features) have been increasing somewhat over the past decade and are considered generally satisfactory to meet most of the demands for more flexible training that have been highlighted by the TMI-2 event. There are specific exceptions, and each simulator needs to be examined in depth to identify those exceptions and improve its capabilities. Such an in-depth examination was beyond the scope of this survey. More importantly, it is felt that some consistent criteria for "adequacy" need to be established before specific needs for updating can be identified.

(4) Initialization Conditions Satisfactory. The number of IC sets and flexibility of manipulating initial conditions is alsn sonsidered to be generally satisfactory to meet anticipated training demands. The existing simulators can perform, with varying degrees of flexibility, exercises for which the plant is initialized in an off-normal or out-ofspecification condition. As is the case with other parameters of concern, judgement of "adequacy" without specific performance criteria is totally. subjective and was not attempted on a site-by-site basis. 
(5) Scope and Fidelity of Simulation at State-of-the-Art. The scope and fidelity of simulation are limited by the conflicting demands on computer software and hardware discussed in Sections 3.1.3.1 and 3.1.3.2. The judgement from the survey is that nuclear simulators are utilizing state-of-the-art hardware and software. There is an obvious lag time in following the rapidly advancing computer technology, but we did not identify any major advances currently in use in other industries that are not being used in the nuclear industry. Again, without the benefit of specific requirements or criteria for simulators, the judgement of adequacy is entirely subjective, and our judgement is that the general scope and fidelity is satisfactory for most of the anticipated training needs. There are, however, specific major exceptions, such as the potential need to model saturated conditions in the PWR primary system or the possible need to incorporate models for major balance-of-plant systems, as has been suggested. These specific questions will have to be examined in depth by experts in safety analysis and operator training. Given the demand, improvements in such specific areas may or may not be able to be accommodated with relatively minor modifications. Serious modeling of either saturated conditions or balanceof-plant systems will probably require major improvements in existing simulator capabilities, and possibly in existing technology.

In considering these major modifications, it is essential to retain the perspective that these are training simulators, and not tools for analysis of accident progression. The functional requirements for the scope and fidelity of simulators must be based on specific training objectives. Despite the impact of TMI-2, it may not be desirable to incorporate exterisive modeling changes or to greatly expand the scope of simulation in order to precisely model phenomena which are apt to occur with an extremely low frequency.

(6) Strengthened Regulatory Framework by NRC Necessary. A fact that became apparent early in the study is that the NRC has not had a well-defined regulatory framework for design, qualification or review of simulators or their use in operator training. There is no specific NRC requirement to use a simulator in training, though admittedly their use has been encouraged. (As discussed in Chapter 4, the latest version of ANSI/ ANS-3.1, which was issued in draft August 27, 1979, does include such a requirement.) There is no NRC standard for minimum performance and no official endorsement of the minimum requirements in ANSI/ANS-3.5. Acceptance testing of simulators is left largely to the owner; there is no formal, clearly delineated simulator qualification acceptance program by NRC. Verification of updating and continued review of modifications also are not covered by written, well-defined regulatory requirements. There is no requirement for certification of instructors. (Again, the August 27, 1979 version of ANSI/ANS-3.1 does require licensing of instructors who train licensed operators).

It is recognized that both the NRC, which has had an extremely limited staff available, and the industry have done a commendable job of maintaining minimum requirements for simulators. The costs and practical difficulties of establishing a comprehensive regulatory and enforcement process and staff are also recognized. These factors need to be 
considered in any study of how the regulatory process should be formalized and strengthened.

It is recommended that, as a minimum, NRC develop a standard, or strengthen and endorse ANSI/ANS-3.5, which will improve minimum requirements for scope and fidelity, specify requirements for acceptance testing by the industry, and include requirements. for initial and periodic review to ensure accurate simulation of the plant being simulated. Guidelines for selection of malfunctions should be included as part of the standard, and the possibility of using the subjective ranking system in Chapter 5 or a similar process should be carefully considered. 


\section{SJMULATOR TRAINING PROGRAMS}

\subsection{Introduction}

The statutory requirement that operators of nuclear power facilities must demonstrate their qualifications and hold licenses was established by the U.S. Atomic Energy. Act of 1954. Title 10 of the Code of Federal Regulations, Part 55, specifies the procedures and criteria for the issuance of the licenses and governs the regulatory program of operator licensing. Individuals may be granted a license prior to initial fuel loading at the facility (cold license) or after initial criticality (hot license). Requalification is required biannually. For cold license applicants 10 CFR 55 requires previous operating experience at a comparable reactor, but completion of an approved training program that utilizes a full-scope simulator is recognized by NRC as satisfying this requirement. Hot license candidates must participate in a minimum 3-month period of on-the-job training. As part of the training, they are required to manipulate the reactor controls through five reactivity changes under the direct supervision of a licensed operator. Performance of these manipulations in an approved simulator is accepted by NRC. Thus, while simulators are not specifically required by 10 CFR 55, their use is encouraged by NRC since they offer the opportunity to meet 1 icensing requirements without affecting plant operation.

In addition, NRC's Nuclear Regulatory Guide 1.8 endorses ANSI/ANS-3.1, "The American National Standard for Selection and Training of Nuclear Power Plant Personnel," which outlines the qualifications and responsibilities of nuclear plant personnel and gives guidelines for training programs. Prior to the TMI-2 event this standard did not specifically require the use of simulators, though. simulator training was recognized as one way of meeting some of the solection and training requireinitils. A revlsed version of ANSI/ANS-3.1 that was issued in draft form on August 27, 1979, includes specific require. ments for using simulators in cold license, hot license and requalification programs. It specifies a minimum list of plant evolutions and requires an examination on the simulator, including power operation with malfunctions and startup. A significant change, in our opinion, is a requirement that training instructors themselves be licensed. The revised version also expands and strengthens other areas of operator selection and training not directly related to the use of simulators, for example, educational and "time-in-grade" requirements for different staff positions. To date, NRC has not officially endorsed the revised version, but it is anticipated that major revisions such as these in operator selection and training practices will be required by NRC, either directly or through endorsement of an industry standard. The review of existing simulator training programs performed for this study necessarily predates these changes, and therefore may no longer be totally accurate. 


\subsection{Simulator Licensing Programs and Standards}

As stated in Section 1, current simulator programs to train operators for cold licenses, hot licenses, and requalification licenses are conducted by four NSSS vendors and by four training centers operated by utilities. With one exception (SNUPPS), the simulators are plant-specific; however, they are used to train operators for plants other than the plants the simulators represent. As has been noted, the trend now is to build a simulator for each new plant, but in the meantime NPPS owners make their facilities and programs available to others. Representative training programs and the corresponding standards are discussed briefly below.

\subsubsection{Cold License. Training Programs}

Candidates for cold licenses begin training at least 24 months prior to fuel loading. The first year of their training is primarily classroom work while the second year is largely on-the-job training. Time that becomes available as the result of slippage in startup dates is normally used for writing procedures, etc. Individuals with no previous experience are required to complete all phases of the training program, while those with acceptable prior experience are placed in the program at appropriate points.

Title 10 of the Code of Federal Regulations, Chapter 1; Part 55, requires that trainees for cold licenses have extensive actual operating experience at a reactor comparable to the nne they will operate. As stated earlier, however, the NRC ruled in 1969 that applicants who successfully complete an approved simulator training program will have met this requirement. And, of course, the latest edition of ANSI/ANS-3.1 requires simulator training.

A typical 24-month training sequence for cold license candidates is presented in Table 4.1, which shows that two of the training programs involve the use of a training simulator. The first, the operator training program, consists of about 3 months of combined classroom and simulator control room training, while the second, the refresher program, consists of four days of control room training and a 1-day exailiration. The operator training program is essentially the same for both BWR and PWR reactors. It may involve shift work similar to an actual work situation, with trainees spending a total of typically 88 to 140 hours on the simulator. Of this, about $30 \%$ of the time 1 s spent in learning how to cope with abnormal and emergency conditions.

Westinghouse has a simulator training program for PWR cold 1 icense candidates which, as indicated in Table 4.2, consists of 8 weeks of combined classroom instruction and simulator operation. The first 7 working days are spent on the day shift acquiring background knowledge for the Zion Unit 1 simulator. The next 27 working days are spent on a normal four-shift operation during which the day shifts are spent in class and the swing and mid-shifts are spent on the simulator. The final 7 days are spent in studying and taking an examination for the Zion station. During operation of the simulator, 
trainees are divided into groups of three, and they alternate the positions of shift supervisor, senior control operator, and control operator. Each trainee gains about 30 hours experience in each position.

Table 4.1. Typical Cold License Training Sequence

Training Program

Months Before Fuel Loading

$\begin{array}{lllllllllllllllllllllllll}24 & 23 & 22 & 21 & 20 & 19 & 18 & 17 & 16 & 15 & 14 & 13 & 12 & 11 & 10 & 9 & 8 & 7 & 6 & 5 & 4 & 3 & 2 & 1 & 0\end{array}$

Fundamentals $\times \times \times \times \times$

Technology

Observation

Operator Training*

On-the-job

$x \times \times \times \times \times \times \times \times \times \times \times \times \times$

Refresher*

*On simulator.

Table 4.2. Westinghouse Simulator Training Program for PWR Cold License Candidates* ( 8 weeks)

\begin{tabular}{|c|c|c|c|c|c|c|c|c|c|}
\hline Shift & & SS & SS & SS & SS & SS & SS & SS & SS \\
\hline Day & LLLLL & LI & & & & & & EEE & \\
\hline Swing & \multicolumn{4}{|c|}{ SSSSSSS } & \multicolumn{5}{|c|}{ SSSSSSS } \\
\hline Mid & . & & & SSSSS & & & 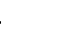 & & \\
\hline
\end{tabular}

$*_{L}=$ Lecture, $S=$ Simulator, $E=$ Examination, $S S=$ Saturday, Sunday.

A Babcock \& Wilcox training program for PWR cold license candidates also consists of 8 weeks of combined classronm and simulator operation (see Tablc 4.3). The first 5 weeks are split between the classroom and simulator operation. During the next 2 weeks, the trainees work in shifts on the simulator, spending approximately equal time as shift supervisor, control operator, and assistant control operator, for a total of approximately 100 hours of simulator training. The last week involves study and an examination designed to simulate the NRC license examination.

Table 4.3. Babcock and Wilcox Simulator Training Program for PWR Cold License Candidates* ( 8 weeks)

\begin{tabular}{llllllllll}
\hline Shift & & SS & SS & SS & SS & SS & SS & SS & SS \\
\hline Day & LLLLL & LLLLL & LLLLL & LLLLL & LLLLL & & & EEEEE \\
Swing & SSSSS & SSSSS & SSSSS & SSSSS & SSSSS & SSSSS & & \\
Mid & & & & & & & & & \\
\hline
\end{tabular}

${ }^{*} \mathrm{~L}=$ Lecture, $S=$ Simulator, $E=$ Examination, $S S=$ Saturday, Sunday. 
General Electric has a cold license training program for BWR reactors that is somewhat longer than the lestinchouse and Babcock \& Wilcox frograms for PWR reactors. A total of 12 weeks is divided between classroom instruction and simulator operation, with each trainee receiving 140 hours of training in the control room following the basic outline given in Table 4.4. During simulator operation, trainees are divided into groups of 3 or 4 in which each trainee rotates from one position to another, receiving approximately equal time in each position. The simulator portion of the training is accomplished by spending 4 hours on the simulator and 4 hours in seminars at the nearby Dresden Power Plant.

- Table 4.4. General Electric Simulator Training Program for BWR Cold License Candidates* (Last 10 weeks of 12.)

\begin{tabular}{|c|c|c|c|c|c|c|c|c|}
\hline Shift & SS & SS & SS & SS & SS. & SS & SS & SS \\
\hline Day & LLLLL & & . & LLLLLL & . & & LLLLLL & $\overline{\text { EEEEE }}$ \\
\hline Swing & . & SSSSSSS & & & SSSSSSS & & . & \\
\hline Mid & & & SSSSSSS & . & & SSSSSSS & & \\
\hline
\end{tabular}

$\star L=$ Lecture, $S=$ Simulator, $E=$ Fxamination, $S S=$ Saturday, Sinday.

A TVA simulator training program for both PWR and BWR cold license candidates is. 12 weeks in length (see Table 4.5). The first 4 weeks are devoted to classroom lectures, and the 5 th through the 11 th weeks are divided between classroom lectures and simulator training exercises. The last week is devoted to study and certification examinations. Simulator instruction is limited to no more than four trainees in the control room at any one time, and the trainees rotate from one position to another.

Table 4.5. TVA Simulator Training Program for PWR and BWR Cold License Candidates* (Last 10 weeks of 12)

\begin{tabular}{|c|c|c|c|c|c|c|c|c|c|}
\hline Shift & SS & $\mathrm{S}$ & SS & SS & SS & SS & SS & SS & SS \\
\hline Day & LLLLL & LLLLL & SSSSSSS & & SSSSSSS & & SSSSSS & & \\
\hline Swing & & & & SSSSSSS & & SSSSSSS & $\cdot$ & & \\
\hline Mid & & & & & & & & & \\
\hline
\end{tabular}

${ }^{\prime} L=$ Lecture, $S=$ Simulator, $E=$ Examination, $S S=$ Saturday, Sunday.

In general, the classroom phase of each program complements the simulator control room training. [xerciscs to be performed on the simulator are described in the classroom and include the operation and characteristics of the systems involved as well as the plant response to be expected. Simulator exercises vary from one facility to another, but a typical example of a simulator training exercise is startup from "cold shutdown." The sequence of events might be as follows: 
1. Startup of plant from cold shutdown.

(a) Shift performs precritical checkouts.

(b) Instructor inserts malfunction (continuous rod movement with no demand during criticality approach). Shift must take appropriate action.

2. Instructor reinitializes plant to $10 \%$ power.

(a) Shift places turbine and generator. in service and increases power to $30 \%$.

(b) Instructor inserts malfunction (trip. of one reactor coolant pump). Shift must take appropriate action.

3. Instructor reinitializes plant to full power.

(a) Shift obtains heat balance.

(b). Instructor inserts malfunction (loss of all a-c power). Shift must take appropriate action.

Training programs at the different training facilities were reviewed by the CNS/MSU staff in some detail, and, overall, were found to be very complete in their coverage of subject material. The 12-week cold license training program of TVA is outlined in Appendix $C$ of this report to provide a more detailed and complete perspective.

In summary, cold license simulator training includes the following characteristics:

(a) Training is limited to three or four trainees in the rontrni ronm at one time.

(b) Actual time on the simulator varies between 88 and 140 hours at the four facilities surveyed.

(c) Trainees work in shifts as they would during actual power plant operations.

(d) The total training time varies from 8 to 12 weeks.

\subsubsection{Hot License Training Programs}

ANSI/ANS-3.1-1978 requires on-the-job training for hot $i$ icense candidates that involves manipulation of the nuclear power plant controls during day-to-day operation and during at least two training startups and shutdowns of the reactor. An appropriate reactor simulator may be used in this training and in such cases the need to perform startups and shutdowns on the reactor may be eliminated. If not already eligible by experience and previous training, related technical training is also required.

Information Report SECY-79-330E (July 30, 1979), prepared for the NRC Commissioners, specifies that to be eligible to sit for a hot license examination, a candidate must have a minimum of 500 hours of classroom training. On-the-job training must be at least of 
three months duration and include five reactivity changes, two of which may be startups performed on a simulator. A minimum time of one week is specified for simulator training, which includes training in abnormal and emergency operations, as well as performing reactor startups.

Actual hot license programs vary among utilities and are influenced by the availability of plant-specific training, cost, and the experience and previous training of the candidates. Since trainees participate in actual plant operations as auxiliary or assistant control room operators, company philosophy with regard to the scope of simulator training needed by a particular candidate also becomes a factor. Thus, it has been found that a hot-license simulator program may vary from two to six weeks in duration and may include any number of various training exercises. For this reason, no attempt is made here to catalog either generic or specific characteristics of a typical program.

It is to be expected that more specific requirements for use of simulators in hot license programs will focus attention on the importance of plant-specific simulators in training and the rieed for defining criteria by which the adequacy of simulation can be judged. Of equal importance is the emphasis which should be placed upon specific exercises in which trainees will participate. These exercises should reflect those accident scenarios that are the most important in terms of probability of occurrence and safety value for the particular plant operated by the trainee. Definition of a method such as the procedure proposed in Chapter 5 would allow an estimate to be made for the total number of exercises in which operators should participate. This total number could also be a consideration in defining the frequency with which requalification should take place.

\subsubsection{Requalification Training Programs}

Appendix $A$ of 10 CFR55 requires an on-going, comprehensive requalification program in order for licenses to ensure continued competence. At least ten reactivity manipulations and a demonstration of satisfactory understanding of all apparatus in areas for which an individual is licensed must he completed during each two-year period. A simulator may be used if the simulator reproduces the general operating characteristics of the facility involved and if the arrangement of instrumentation and controls of the simulator are similar to the facility involved.

During the two-year term of an operator or senior operator, the individual will typically spend about one week per year in intensive training at a simulator facility as part of an overall requalification program. Exercises and drills to be performed are selected on the basis of the specific needs of the licensees involved and include simulated abnormal and emergency operations. The apparent objective during this training is to retune skills that have not been frequently exercised during normal reactor plant operation. Control manipulations which are acceptable for purposes of requalification are listed in ANSI/ANS-3.1. 
When comparing the use of simulators in nuclear retraining programs to retraining programs of other industries, it was found that requirements were more stringent and retraining more frequent for pilots in the commercial airlines industry. Aircraft simulator programs have clearly defined, objective, personnel performance criteria which are well understood by each pilot undergoing training and poor performance could result in withdrawal of a pilot's license. Such is generally not the case in the nuclear industry.

It should be noted that personnel engaged in requalification training are already licensed and have actual plant operating experience. Thus, even minor differences between simulator and plant can have a significant impact on the effectiveness of simulator training in such programs. In some cases, depending upon the attitudes of licensees toward accepting training on a simulator that does not correctly reproduce responses they have observed in their actual plant, the value of the simulator could be rendered totally ineffective. Requirements for plant-specific simulation, therefore, appear to be more important for effective requalification programs than for initial training.

The revised draft of ANSI/ANS-3.1 would require that a simulator be used to fulfill portions of the requalification training program for those evolutions where the simulator is capable of simulating continuously and in real time plant operations of the referenced facility. The standard would also require specific control manipulations which include a total of 27 malfunctions or events. Some of these manipulations would be required on an annual basis and others over a two-year period. Loss of coolant, loss of feedwater, failure of the reactor coolant/volume control system, and other key issues identified in the TMI-2 analysis have been included in the list of control manipulations. However, the proposed revision does not define acceptable performance criteria other than for the written examinations.

\subsection{Issues About Simulator Training Programs Raised by TMI-2}

In the initial discussion and statement of work for this survey, NRC identified a number of specific and general questions or issues that had been raised during investigations of the TMI-2 event, and several that involved questions of simulator (hardware and software) capabilities were discussed in Section 3.2:

(1) Inclusion of multiple failures,

(2) Failure of selected components,

(3) Modeling of saturated conditions in the primary loop,

(4) Training on how to control pressurizer leve?,

(5) Training on passive failures,

(6) Training on achieving natural circulation. 
It was pointed out in the discussion of Section 3.2 that a need exists for improving simulator capabilities if serious modeling of two-phase flow and the impact of void formation on later phases of the accident sequence are to be accommodated, but that for the other issues, the problemi is more the availability of time for all the training needs and assessment of priorities as to what should be included. Generally, selected failure and multiple failure of components can be accommodated, but which of the many possible failures and combinations should be emphasized? What basis exists for an instructor to determine logical event sequences? Pressurizer level instrumentation is part of the control room display, and interpretation is part of many existing exercises. After TMI-2, it would be hard to argue that training exercises should not place greater emphasis on interpretation of and control of the pressurizer level, in particular on recognition of the atypical relationship between the pressurizer level and the core level when voids exist in the primary system. But how much emphasis? And what other training should be deemphasized, if necessary, to accommodate an increase in training in this or other areas? This question of determining priorities becomes more difficult when one realizes that many of the abnormal events and conditions that are of greatest "visibility" from a viewpoint of accident consequence are very rare. There is a danger of overemphasizing training in specific areas, especialiy in the aftermath of an event like TMI-2, at the expense of other necessary training. Furthermore, much of the total training time available must be spent on training for normal operation.

Thus, there are practical limits on how much time can be spent on training for abnormal events, and these need to be considered in deciding the contents and emphasis of simulator training exercises. Much of the concern of NRC in initiating this study involved directly or indirectiy these general problems of the availability of time and the emphasis of existing training programs. Should each utility be required to have its own simulator? 'Do the utilities give enough attention to training their operators for abnormal conditions? Should simulator training be mandatory? Should there be a regulatory guide which includes required malfunctions, and, if so, which malfunctions shouid be included? All of these questions, which were asked by NRC as this study was initiated, touch on the fundamental problem that has been referred to previously as a lack of a consistent methodology in the nuclear training industry to define training objectives, priorities, and specific requirements and criteria.

Nuclear training personnel generally have not been given the support of a comparative assessment of accident sequences for their plant, such as a comprehensive risk assessment would provide. There is no consistent basis for deciding which initiating events, complicating multiple failures, etc. are the "most important." More fundamentally, there has been no comprehensive consistent methodology used to design training programs. This is discussed further in the following section. 


\subsection{Systems Approach to Training}

Training organizations in a number of other fields that require highly skilled and highly trained personnel, e.g., military and commercial pilots, and more recently, ship masters in the maritime industry, have employed a comprehensive formal methodology referred to as a "systems approach" to training. The methodology involves a systematic definition of the specific objectives to be attained in the training program (or a particular aspect of a program such as simulators), followed by a cost-effectiveness evaluation and trade-off analyses among the varying characteristics of the different elements of the complete training system. The methodology provides a structured framework for computing and assessing information, much of which is subjective, evaluating it objectively, and providing objective criteria for decisions.

A basic element of the approach is a thorough task analysis, which provides the behavioral data base necessary to define the specific objectives. The task analysis examines the system goals and functions, the specific requirements or demands placed on the operator, and the performance shaping factors that affect operator performance. Required skills, knowledge, and behavioral characteristics are identified. From these, entry level and training requirements are derived and each element of the training program is examined to determine what provides the optimum means for meeting the different goals, and the entire training program is structured to accomplish specific training objectives. Criteria for acceptable performance are specified as objectively as possible and delineated clearly so that each trainee knows what will be required. Examples of some of the dimensions encompassed by the job of reactor operator, which are a necessary part of a thorough task analysis, are listed in Appendix D.

In general, the nuclear industry has not wade use of task analyses or a comparable formal methodology. This does not mean a priori that nuclear training programs are "inferior" to those in other industries or that the fundamental problems addressed by such a formal methodology have not been addressed in the nuclear industry. What does appear to be true is that the decisions made on training in the nuclear industry tend to be made more on a subjective basis. The behavioral characteristics, the objectives to be met by each element of training, and the criteria for selection and satisfactory performance all tend to be subjectively defined on the basis of "experience." Often this experience is in plant operation rather than professional education and training or human factors, and often key considerations, such as definition of required simulator training programs or simulator specifications, are made more on the basis of what has been done previously than on the needs of the particular program being designed. The use of a systematic methodology that includes a task analysis performed by a multi-disciplinary team composed of persons with experience in plant and control room design, plant operation, human factors, and education and training, etc. would provide an objective basis for designing a complete training program, including a simulator and a simulator training program to meet the training objectives in the most effective and economic manner. It would 
also provide a basis for defining performance and licensing criteria which are necessary for an effective and equitable regulatory process. The use of a systems approach to training is highly recommended. At a minimum, it is recommended that the NRC and the industry examine carefully the use of this approach in other industries and assess the potential applicability and benefits to nuclear industry training.

\subsection{Conclusions: Major Problems and Recommendations on the Use} of Simulators in the Nuclear Industry

The primary conclusion from this review of simulator usage in the nuclear industry is that simulators are not. being utilized in an optimum manner. The use of simulators in the nuclear industry has grown historically without the benefit of either a systematic methodology or a comprehensive regulatory structure. As a result, simulator requirements and simulator training programs are specified largely by subjective judgement of training staff and utility management, possibiy in conjunction with the simulator vendor. There are many practical constraints that limit the amount of time available for training on abnormal events, and there is little objective, systematic basis for deciding priorilies. Simulators are not required, and many utilities train their operators on simulators that are not exact replicas of their own plant. The effectiveness of such training has been questioned for some time, but there are few hard data to support either viewpoint, and we have identified no research program in progress to address this question. (The use of simulators to perform general human factors research and obtain data on operator performance has not been emphasized in this report, but it is certainly another area in which other industries have made more effective use of simulators than has the nuclear industry.) Finally, criteria for acceptable performance on a simulator are not, in general, objectively derived and clearly specified. Therefore, they have not been rigidly and objectively applied in the licensing process or in a management review process. By contrast the U.S. Air Force has a very much systemized rating system for each pilot trainee in which performance criteria are clearly delineated. The performance of the trainee, and later the pilot, is regularly evaluated in simulator training and actual flight and records of performance are maintained. It is not obvious that a comparable system is attainable or even desirable for nuclear plant operators, but there is a need for a more systematic approach to evaluating performance and defining performance criteria for operator licensing. There is also a need for continued research in the development of performance monitoring systems for simulators.

The following recommendations are made to address these problems:

(a) Simulator Training Should Be Required. Expanded use of simulators for training nuclear plant operators should be encouraged by NRC and the industry. The most effective means for NRC to promote simulator training is to provide incentives or to require simulator training in the licensing process. Both are recommended. 
(b) Use of Systems Approach Should Be Encouraged. The expanded use of simulators recommended above should not be carried out arbitarily or without a thorough analys is of training programs, in particular simulator training programs, using a systematic approach comparable to that discussed in Section 4.3. The successes and failures of other industries in using the systems approach should be examined, and applicable methods should be adopted by the nuclear industry. Certainly it seems that a formal task analysis, or an equivalent assessment by a team of persons qualified in the appropriate disciplines, should be carried out for each plant or generic type of plant. The existing programs should be evaluated and future programs should be designed on the basis of the more objective criteria derived from such an analysis.

(c) Interim Use of Subjective Ranking Procedure Is Needed. For existing simulators, some procedure is needed to develop priorities for potential abnormal events in order to decide which should be included in the list of malfunctions and emphasized in training. The ranking procedure discussed in Chapter 5 is one proposed scheme; others may be suggested by NRC anci/or industry.

(d) A Well-Defined Regulatory Structure Should Be Developed. Either through direct specification of regulations or guidelines or by endorsement of industry standards, a comprehensive and clearly defined regulatory process should be defined which specifies mịnimum requirements for simulators and simulator training (and indeed, all aspects of operator programs). Specific attention should be given to the use of simulators in licensing operators: there should be a definition and clear delineation of performance criteria (as objective as possible) and of acceptable performance to obtain and maintain a license. Standards and requirements should be defined, and the industry and operators should be assured that if those requirements are met, a license will be granted/maintained, and if they are not met, it will not. That is, the subjectivity involved in the current operator licensing process should be minimized.

(e) Human Factors Research with Simulators Recommended. Much of the data necessary for human factors experts to quantitatively assess operator performance is not available and can be obtained from studies using simulators. The NRC and the industry should encourage research in these areas.

(f) Improvements in Related Areas Necessary. There are a number of recommendations that should be made concerning aspects of operator training that are not directly related. to the use of simulators, but became apparent during this study. These include:

(1) The use of risk assessment methods as part of the reactor licensing process should be encouraged and expanded. Such analyses provide a more rigorously defined accident sequence for training as well as an objective criterion - risk - for determining the priority each event should be given. 
(2) Procedures need to be. improved. Other investigators have been pointing out the great need for developing concise, clear procedures for normal as well as abnormal procedures. One area that clearly needs attention is the (intra-plant) standardization of nomenclature. Equipment labels for a given plant should be consistent in all documentation - including drawings, procedures and the control board. Study by qualified human factors specialists should be carried out to outline ways to improve procedures for future plants and practical means for improving existing procedures with a minimum of interference with operators or plant operations.

(3) The academic (entry-leve1) requirements for operator training and the academic content of training programs should be reviewed by qualified persons. It is the opinion of MSU/CNS staff that such a study would reveal that a significant upgrading of requirements and course content is necessary. 
5. PROPOSED PROCEDURES FOR SELECTING EQUIPMENT MALFUNCTIONS FOR SIMULATION

The malfunctions that can be simulated by 14 training facilities are listed in Appendices $A$ and $B$. Although some differences in the malfunctions listed for the various facilities can be attributed to design variances between the plants and/or simulators, it became evident during this survey that a more significant variation exists in the exercises actually performed in operator training programs by similar facilities. This variation is considered to be a result of not having a consistent process by which malfunctions to be simulated can be selected and emphasized.

In responding to questions raised by TMI-2 concerning operator training and specific criteria for selecting simulator training exercises, the office of Nuclear Reactor Regulation recommended that more explicit requirements regarding training exercises be included in simulator requalification programs (SECY-79-330E, July 30, 1979). Shortly before, of course, our own preliminary report on this project had cited the need for a consistent methodology for determining which malfunctions should be simulated, and, as a result, the NRC Division of Reactor Safety Research had expanded our project work statement to include the development of such a methodology.

From the outset it was recognized that the identification of equipment malfunctions for simulation cannot be a completely generic consideration. For a given simulator, the specific history of the reference plant, as well as the differences in design between the reference plant and any other plant for which the simulator will be used, must be considered in selecting the exercises. On the other hand, generic criteria can be defined by which any specific malfunction can be screened and evaluated, and the results can then be used as a measure of the importance of that malfunction for simulation.

In developing the criteria, it became obvious that the currently accepted practice of simulating only safety-related malfunctions was not sufficient. Although safety issues are of primary importance, a malfunction may not be related to safety, at least not directly, and yet be extremely important, as, for example, one that results in an extended plant outage. Thus, the first step in the methodology development was to determine what plant conditions operators should be trained to prevent and the relative importance of each of those conditions to the overall plant operation. This, in turn, would set the criteria by which each malfunction could be evaluated. The resulting general criteria are described in detail in Section 5.1 below.

In order to illustrate and test the procedures, the proposed criteria were applied to a relatively large number of malfunctions, in particular to malfunctions that have been reported from operating expericnce, malfunctions that have been derived from analyses of generic PWR and BWR systems, and safety-related malfunctions that have been identified in the reference plant FSARs. Finaliy, the criteria were applied to malfunctions that might lead to the abnormal events specified for simulation in ANSI/ANS-3.5 (1979). In 
all cases, only those malfunctions that could occur at PWR and BWR plants in the United States were considered, and no distinction was made between equipment malfunctions that resulted from personnel error and those that resulted from material defects, faulty design, etc.

\subsection{Development of General Screening Criteria}

In considering the impact of equipment malfunctions on plant operations, it was concluded that the importance of a malfunction could be determined by examining it in the following four areas:

A. The importance of the malfunction to the safety of the plant and the public - that is whether or not the malfunction itself comprises 'a safety-related event.*

B. The frequency with which the malfunction occurs.

C. The extent to which the malfunction is a precursor to a safety-related event.*

D. The importance of the malfunction to a forced outage of the power plant.

These four areas were in turn subdivided, with "importance factors" assigned to each subdivision. The sum of the importance factors then becomes the index by which the malfunction is rated, as is explained in the following paragraphs.

\subsubsection{Malfunctions That Comprise Safety-Related Events}

Malfunctions that comprise safety-related events were subdivided into four categories by using a methodology similar to that of American National Standard N18.2 ("Nuclear Safety Criteria for the Design of Stationary Pressurized Water Plants"). Classification of specific equipment malfunctions into these categories must be based upon the subjective judgement of experienced power piant personnel as to the impact of the llalfunction on the health of the public and the operation of the plant. The categories are defined as follows:

Class 1. Following the occurrence of the malfunction, the operator is able to continue operating the reactor and plant within its technical specifications with no more than one operator action required at any one time.

\footnotetext{
*An event is considered to be a plant condition that results from one or more equipment malfunctions occurring in sequence or simultaneously. As such, events are not analyzed. Oiily the equipment malfunctions which comprise the events are analyzed.
} 
Class 2. Following the occurrence of the malfunction, the operator is required to shut down the plant, but the shutdown and subsequent cooldown may be accomplished in an orderly fashion. Any release of radioactive materials in effluents to unrestricted areas will be in conformance with paragraph 20.1 of 10 CFR 20.

Class 3. Following the occurrence of the malfunction, the reactor trips and a radioactivity release in excess of limits established in 10 CFR 20 may occur, but the release shall not be sufficient to restrict public use of areas beyond the exclusion radius.

Class 4. Following the occurrence of the malfunction, the reactor trips and a radioactivity release in excess of the limits established in 10 CFR 20 occurs, but the release shall not exceed 10 CFR 100 criteria.

\subsubsection{Malfunctions That Occur Frequentiy}

The frequency of occurrence of an event must be considered as an important factor in the selection of equipment malfunctions for simulation. In safety analysis, it is recognized that as a result of good design, events with greater consequences tend to occur less frequently and, in fact, accidents often are classed according to their expected frequency of occurrence. Events having a high frequency need to be considered for their impact on availability even if their direct impact on safety is not great. In the ranking system devised here, the frequency of occurrence is listed independentiy of the safety or availability consequences and thus can be superimposed on either or both to determine the importance of an event. An assignment of importance, however, should consider the frequency of occurrence within plants that are "similar" to the unit being considered in order to avoid effects of major design differences. That level of detail was not possible in this project.

\subsubsection{Malfunctions That Are Precursors to Safety-Related Events}

In some cases, equipment malfunctions may not be directly safety-related but may precipitate or enhance safety-related malfunctions uniess appropriate corrective action is taken. Similarly, one safety-related malfunction may lead to another independent malfunction. The following definition identifies a precursor as used in the proposed ranking criteria:

A precursor is an equipment malfunction that may result in a second equipment malfunction that is safety related; the precursor itself may or may not be safety related. 
Example 1: An example of a precursor in a PWR plant is the failure or drift of the Volume Control Tank (VCT) level instrument. In normal use, the level in the VCT is allowed to decrease as water is intermittently pumped by the charging pump into the Chemical Volume and Control System (CVCS) for normal charging and reactor coolant pump seal supply. When the water level in the VCT drops below a preset point, suction is normally shifted to the Refueling Water Storage Tank (RWST). Failure of the level instrument will therefore result in the eventual loss of coolant water to the charging pump in service and subsequently to damage to that pump. Continued plant operation with loss of one charging pump is normally allowed under Technical Specifications. However, the operator must verify availability of the second pump and activate it before continuing operation of the plant. Thus, the loss of one charging purmp becumes a safety-related ovont as defined. in 5.1 .1 and the loss of VCT level instmontation would be a precursor.

Example 2: An example of a precursor in a BWR plant is the failure of the keep-full system. In normal use, the system maintains the highpressure coolant injection pipe full of water. Failure of the keep-full system will not, by itself, result in any damage. If, however, highpressure coolant injection (HPCI) occurs, either inadvertently or for a specific reason, the instant pressumiation of the empty piping by the HPCI pump will result in a hydraulic shock to the piping system and possibly to its rupture. Thus, failure of the keep-full system is a precursor that could lead to a safety-related malfunction.

\subsubsection{Malfunctions That Result in Plant Outage}

Certain equipment malfunctions result in significant plant outages due to the amount of time required for repair or replacement, time required for component or system testing after repair, time required for decontamination and cleanup, or any combination of these factors. Other types of malfunctions may be relatively minor in terms of the time required for correction prior to resuming plant operation. Since plant outage is an important consideration in deterinining power plant economy and reliability, an additional point value is added to the importance factor of applicable malfunctions lo account for this parameter. An arbitrary outage period of two weeks, or longer, was selected as the definition of significant plant outage.

\subsubsection{Ranking of Malfunctions in Terms of Their Importance}

In order to rank equipment malfunctions in terms of their relative importance for simulation, the following numerical ranking system was devised:

A. Safety-Related Malfunctions

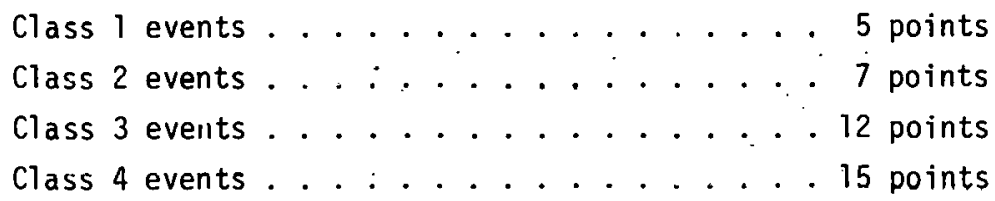


B. Frequently Occurring Malfunctions

$$
\begin{array}{r}
\text { Nonzero }-1.49 . . \text {. events/reactor year. . . . } 1 \text { point } \\
1.5-2.49 . . \text {. events/reactor year. . . . } 2 \text { points } \\
2.5-3.49 . . \text {. events/reactor year. . . . } 3 \text { points } \\
3.5-4.49 . . \text {. events/reactor year. . . . } 4 \text { points }
\end{array}
$$

C. Precursors................ 5 points

D. Malfunctions Resulting in Significant Plant Outage . 3 points

A perspective of how events might be ranked using the system outlined above may be obtained by using these criteria to rank the generic classifications of events specified in American National Standard N18.2. Table 5.1 shows, as would be expected, that the importance of the four conditions included in the standard increases progressively.

Table 5.1. Ranking of Events Included in ANS N18.2 by Proposed Methodology

\begin{tabular}{lcccccr}
\hline & \multicolumn{6}{c}{ Assigned Point Values } \\
\cline { 2 - 6 } Event & Safety & Frequency & Precursor & Outage & Total. \\
\hline Condition I & 5 & $0-4$ & 0 or 5 & 0 & $5-14$ \\
Condition II & 7 & 1 & 0 or 5 & 0 or 3 & $8-16$ \\
Condition III & 12 & $\cdot$ & Oor $b$ & 3 & $16-21$ \\
Condition IV & 15 & 0 & 0 or 5 & 3 & $18-23$ \\
\hline
\end{tabular}

The lower and upper limits of point values assigned by the ranking system correspond to the following:

(a) Lower: Malfunctions that are not safety related (0), are not precursors to safety-related malfunctions $(0)$, do not result in significant plant outage (0), but do occur (1-4). Total point range, 1-4 points.

(b) Upper: Malfunctions that are safety related (15), can also be precursors (5), do result in significant plant outage (3), and may or may not occur frequently (0-4). Point range, 23-27 points. 


\subsection{Application of Criteria}

The criteria defined in Section 5.1 were applied to over 400 equipment malfunctions, not only as a trial use and evaluation of the criteria themselves, but also to determine whether those malfunctions currently being simulated and those malfunctions (events) specified for simulation in the plant FSARs were indeed the most important.

\subsubsection{Sources of Data}

Operational Analyses of Generic Plant Systems. The primary basis for selecting malfunctions for review was an analysis of generic systems for typical PWRs and BWRs. The analyses were performed by the project team, which, as mentioned earlier, consisted of experienced reactor operators.

Survey of Operating Experience. The principal source of data on operating experience was a total of 20,000 LERs provided by the ORNL Nuclear Safety Information Center. Within the time constraints of the project period, however, only about 3,000 LERs could be analyzed. For consistency, all the LERs analyzed were selected from those recorded during a six-month period in 1978.* The results of this analysis are presented in detail in Appendices $E$ and $F$ and are summarized in Tables 5.2 and 5.3. Table 5.2 shows that the PWR systems in which malfunctions most frequently occur are the containment system, reactor coolant system, rod control system, radiation monitoring system, emergency diesel generators, emergency core cooling, and the main steam and turbine system. Table 5.3 shows that the systems in which malfunctions occur most frequently in BWR plants are essentially the same as those in PWR plants. ${ }^{\dagger}$

*NOTE: Initially the LERs were analyzed with computer methods, but it was decided that the only effective method for obtaining the necessary information was for an individual experienced in the operation and/or maintenance of a nuclear power plant to screen each LER. This technique was costly in terms of professional manpower, but a more accurate assessment of what malfunctions were actually present in each LER was obtained. At the same time, certain facts became apparent which should be mentioned. Although the LERs represent a valuable source of information and data, a great deal of improvement could be made in their information content. Also, a more precise and effective mearis of recording the data on the LERs could be. defined. Comments for improving the LERs have already been made in NUREG-0578, and we endorse those recommendations. Of particular importance would be to record in an easy-to-access format specific data giving the cause and effect of each event and listing the components involved. Such an assembly of facts could best be made by the personnel who inspect the actual event and should be prepared on site.

${ }^{\dagger}$ As noted earlier, in determining the equipment malfunctions to be simulated on any given simulator, the malfunctions evaluated should be limited to those from plants having systems generic to the systems of the plant for that simulator. 
Table 5.2. PWR Malfunctions, June-December, 1978

\begin{tabular}{lc}
\hline System & $\begin{array}{c}\text { Number of } \\
\text { Malfunctions }\end{array}$ \\
\hline Containment & 61 \\
Electrical Distribution & 19 \\
Chemical and Volume Control & 16 \\
Component Cool ing Water & 4 \\
Auxiliary Feed Water & 13 \\
Plant Chemistry & 6 \\
Circulating Water System & 19 \\
Steam Generator Blowdown & 5 \\
Emergency Diesel Generator & 35 \\
Condensate & 12 \\
Waste Disposal & 9 \\
Mode Status Requirements & 1 \\
Radiation Monitoring & 26 \\
Rod Control & 32 \\
Reactor Protection & 5 \\
Feedwater & 6 \\
Fuel Handling & 4 \\
Emergency Plan & 3 \\
Plant Ventilation & 19 \\
Service Water & 11 \\
Nuclear Instrumentation & 19 \\
Reactor Coolant & 58 \\
Residual Heat Removal & 7 \\
Fire & 18 \\
Main Steam and Turbine & 31 \\
Emergency Core Cooling & 51 \\
\hline
\end{tabular}

Table 5.3. BWR Malfunctions, January-June, 1978

\begin{tabular}{lc}
\hline \multicolumn{1}{c}{ System } & $\begin{array}{c}\text { Number of } \\
\text { Malfunctions }\end{array}$ \\
\hline Condensate and Feed Water & 4 \\
Conta inment & 92 \\
Control Building Ventilation & 4 \\
Diesel Generator. & 22 \\
ECCS - Core Spray & 8 \\
ECCS - HPCI & 30 \\
ECCS - Isolation Condenser & 4 \\
ECCS - LPIC & 7 \\
ECCS - Reactor Core I solation & 19 \\
ECCS - Residual Heat Removal & 12 \\
Electrical & 17 \\
Fire Protection & 19 \\
Main Steam and Turbine & 35 \\
Nuclear Instrumentation & 19 \\
Off Gas & 28 \\
Radiation Monitoring & 5 \\
Reactor Controls & 19 \\
Reactor Coolant & 50 \\
Service Water & 3 \\
Standby Liquid Control & 8 \\
Waste Disposal & 7 \\
\hline
\end{tabular}


Nuclear Regulatory Commission Guide 1.70. Information on malfunctions currently required for inclusion in the safety analyses of plant FSARs was obtained from the NRC Guide 1.70 .

Survey of Simulators. Information on malfunctions currentiy simulated were obtained from the surveys recorded in Appendices $A$ and B. In general, these malfunctions have also been deduced from engineering analyses of the plant systems, with emphasis on safety considerations.

\subsubsection{Screening of Data}

The results of applying the proposed ranking criteria to specific malfunctions are presented in Appendices $G$ and $H$ for PWRs and BWRs, respectively. Malfunctions that are listed were carefully selected from those currently being simulated at training facilities (Appendices A and B), LER survey results, NRC Regulatory Guide 1.70, and from personal operating experiences of the MSU/CNS staff. In each case, the format of presentation is as follows:

(a) Malfunctions are organized by system and numbered sequentially in order of consideration.

(b) The frequency of occurrence given in the third column represents the number of such events per reactor year of operation for all BWRs or PWRs operating during the six-month period surveyed during 1978. Zeros indicate that the associated malfunction did not appear in the LER data that were evaluated.

(c) The information listed in the fourth column on the malfunctions currently simulated is given in the form of $x / y$, where $x$ is the number of simulators surveyed that simulate that particular malfunction (i.e., see Appendices $A$ and $B$ ) and $y$ is the total number of simulators included in the survey at the time the analysis was completed for that malfunction.

(d) Column 5 indicates whether the malfunction represents an event that must be analyzed in safety analysis reports.

(e) Finally, justification for simulation of the malfunclion is given in terms of point values assigned to the four general criteria described in Section 5.1:

\section{Column A: Safety related malfunction \\ Column B: Frequency of occurrence \\ Column C: Precursor \\ Column D: Plant outage}


(f) The total of the numerical ratings given to the malfunction is recorded as the importance factor. Importance factors can range in value from 1 to 27 .

A number of conclusions may be drawn from this preliminary application of the proposed criteria to equipment malfunctions. Immediately obvious is the fact that a number of malfunctions that were assigned importance factor values are not currentiy being simulated by the facilities surveyed. This is shown in Tables 5.4 and 5.5 for PWRs and BWRs, respectively. If the results of this trial application are validated, then it would appear that many options exist for improving both current simulators and simulator training programs.

Table 5.4. Analysis of PWR Malfunctions (Refer to Appendix G)

\begin{tabular}{|c|c|c|c|c|c|c|}
\hline \multirow[b]{2}{*}{ System } & \multicolumn{6}{|c|}{$\begin{array}{l}\text { Number of Malfunctions in System } \\
\text { With Importance Factors of }\end{array}$} \\
\hline & $0-4$ & $5-8$ & $9-12$ & $13-16$ & $17-20$ & $27-24$ * \\
\hline Reactor Coolant & 2 & 0 & 1 & 16 & 1 & 12 \\
\hline Component Cooling Water & 1 & 0 & 3 & 5 & 5 & 2 \\
\hline Circulating Water & 0 & 1 & 1 & 7 & 0 & 0 \\
\hline Service Water & 0 & 1 & 2 & 2 & 0 & 2 \\
\hline Chemical and Volume Control & 0 & 0 & 3 & 6 & 0 & 4 \\
\hline Rod Control & 0 & 5 & 3 & 8 & 4 & 7 \\
\hline Electrical Distribution & 0 & 1 & 6 & 0 & 2 & 4 \\
\hline Emergency Diesel Generator & 0 & 0 & 2 & 5 & 3 & 9 \\
\hline Main Steam and Turbine & 2 & 0 & 0 & 8 & 3 & 2 \\
\hline Condensate & 0 & 1 & 2 & 5 & 0 & 1 \\
\hline Feedwater & 0. & 2 & 1 & 14 & 0 & 0 \\
\hline Auxiliary Feedwater & 0 & 0 & 2 & 5 & 1 & 2 \\
\hline Nuclear Instrumentation & 0 & 1 & 0 & 14 & 0 & 0 \\
\hline Residual Heat Removal & 0 & 2 & 2 & 3 & 1 & 3 \\
\hline Plant Ventilation & 0 & 0 & 1 & 6 & 0 & 3 \\
\hline Radiation Monitoring & 0 & 1 & 0 & 14 & 0 & 1 \\
\hline Reactor Protection & 0 & 0 & 0 & 0 & 2 & 2 \\
\hline Conta inment & 0 & 1 & 1 & 5 & 0 & 9 \\
\hline Emergency Core Cooling & 0 & 0 & 0 & 9 & 3 & 14 \\
\hline Emergency Plan. & 0 & 1 & 0 & 4 & 1 & 0 \\
\hline Mode Status Requirements & 0 & 0 & 0 & 0 & 3 & 3 \\
\hline Fire. & 2 & 1 & 1 & 4 & 7 & 4 \\
\hline Total for All Systems & 7 & 18 & 31 & 140 & 36 & 84 \\
\hline $\begin{array}{l}\text { Number of Malfunctions Simulated } \\
\text { by } 50 \% \text { or More of Simulators }\end{array}$ & 0 & 7 & 7 & 37 & 4 & 15 \\
\hline
\end{tabular}

*None of the malfunctions had an importance factor greater than 24 . 
Table 5.5. Analysis of BWR Malfunctions (Refer. to Appendix $H$ )

\begin{tabular}{|c|c|c|c|c|}
\hline & \multicolumn{4}{|c|}{$\begin{array}{l}\text { Number of Malfunctions in System } \\
\text { With Importance Factors of }\end{array}$} \\
\hline & $0-4$ & $5-8$ & $9-11$ & $12-23 *$ \\
\hline Reactor Coolant & 1 & 0 & 3 & 6 \\
\hline Standby Liquid Control & 0 & 1 & 2 & 1 \\
\hline Reactor Controls & 0 & 1 & $\uparrow$ & 4 \\
\hline Electrical & 0 & 1 & 0 & 2 \\
\hline Diesel Generator. & 1 & 4 & 0 & 0 \\
\hline Main Steam \& Turbine & 0 & 1 & 2 & 2 \\
\hline Condensate and Feedwater & 1 & 0 & 1 & 1 \\
\hline Nuclear Instrumentation & 6 & 1 & 3 & 0 \\
\hline Containment. & 1 & 4 & 2 & 3 \\
\hline Off Gas/Standby Gas Tr. & 0 & 1 & 0 & 3 \\
\hline ECCS - Core Spray & 0 & 0 & 2 & 1 \\
\hline ECCS - HPCI & 1 & 2 & 3 & 2 \\
\hline ECCS - LPCI & 0 & 0 & 2 & 0 \\
\hline ECCS - I solation Condenser & 0 & 1 & 1 & 0 \\
\hline ECCS - RCIC & 0 & 1 & 4 & 0 \\
\hline ECCS - RHR & 0 & 0 & 1 & 2 \\
\hline Fire Protection & 0 & 0 & 2. & 0 \\
\hline Total for All Systems & $11^{\circ}$ & 18 & 29 & 27 \\
\hline $\begin{array}{l}\text { Number of Malfunctions Simulated } \\
\text { by } 50 \% \text { or More of Simulators }\end{array}$ & 0 & 2 & 8 & 2 \\
\hline
\end{tabular}

*None of the malfunctions had an importance factor greater than 23.

\subsubsection{Comparisons with ANSI/ANS-3.5}

As pointed out in Section 3, Amerïcan National Standard ANSI-3.5 requires that 21 specific events be simulatable on nuclear power plant simulators. As an additional evaluation of the criteria developed in this chapter, malfunctions that would lead to these events and/or abnormal conditions were also evaluated. The results, presented in Table 5.6 , show that $89.4 \%$ of the 57 events screened have ranking scores equal to or greater than 10 even though values for frequency of occurrence were not assigned. 
Table 5.6. Evaluation of Events Required for Simulation in ANSI-3.5

Event and Malfunction
Importance Factors*

A C $\quad$ D Total

1. Loss of coolant (LOCA)

Smali break within capacity of high head injection pumps

Smal1 to medium size break in which pressurizer level is lost

Medium size break with initiation of containment spray, etc.

Medium to large size break with core area bubble and loss of natural circulation

Large size break with injection of all ECCS equipment and core

partially uncovered

Extra large break in reactor vessel refilled by ECCS

2. Loss of instrument air

$\begin{array}{rrrr}7 & & 3 & 10 \\ 12 & & 3 & 15 \\ 15 & & 3 & 18 \\ 15 & 5 & 3 & 23 \\ 15 & & 3 & 18 \\ 15 & 5 & 3 & 23 \\ 12 . & 5 & 3 & 20\end{array}$

3. Loss of electrical power

Loss of generator output

Loss of normal offsite power

Loss of alternate offsite power

Loss of one emergency diesel.

Loss of all emergency diesels

Loss of one-half required busses

Loss of all ac power, diesels inoperative

4. Loss of reactor coolant flow, pump. flow and natural circulation

5. Loss of condenser vacuum

6. Loss of service water

Loss of nonsafety system service water, possibly resulting in excessive initial containment pressure for low-pressure containments

Loss of safety system (ESF) service water, containment peak pressure will be excessive and several major components will sustain damage

$\begin{array}{llll}12 & 5 & 3 & 20\end{array}$

$\begin{array}{llll}5 & 5 & 3 & 23\end{array}$

7. Loss of shutdown cooling

Loss of RHR (residual heat removal or decay heat removal) system Loss of steam generator secondary heat removal capability

$\begin{array}{llll}12 & 5 & 3 & 20\end{array}$

$\begin{array}{llll}15 & 5 & 3 & 23\end{array}$

8. Loss of component cooling

Loss of containment equipment component cooling

Loss of auxiliary equipment component cooling

$\begin{array}{rrrr}12 & 5 & 3 & 20 \\ 7 & 5 & 3 & 15\end{array}$

9. Loss of feedwater

Loss of main feedwater

Loss of auxiliary feedwater

$\begin{array}{rrrr}7 & & 3 & 10 \\ 15 & 5 & 3 & 23\end{array}$

10. Loss of neutron flux indication

Loss of shutdown nuclear flux instruments

Loss of all neutron flux indication

$\begin{array}{rrr}5 & 3 & 8 \\ 7 & 3 & 10\end{array}$

11. Mispositioned control rod or rods

Core-limiting hot channel factors (peaking factor) limits may be exceeded

Rods insertion limits exceeded violation of 1 imits

Startup not allowed: violation of limit for criticality

$\begin{array}{rrrr}15 & 5 & 3 & 23 \\ 15 & 5 & 3 & 23 \\ 7 & 5 & 3 & 15\end{array}$

12. Inability to drive one or more control rods

Stuck rod or rods ( $r$ ) stuck out of the core

Malfunctioning control rod drives $\begin{array}{llll}15 & 5 & 3 & 23\end{array}$ 
Table 5.6 (continued)

Event and Malfunction

Importance Factors*

A C D Total

13. Conditions requiring use of backup reactor shutdown systems

Passive systems failure--accumulators, core flood tanks, core

fill tanks, core injection tanks

Passive systems failure--ice condenser; containment design pressure exceeded

Active systems failure--core spray, high lead safety injection, intermediate lead safety injection, low lead safety injection

Active systems failure--containment spray (suppression) containment design pressure exceeded

$\begin{array}{llll}15 & 5 & 3 & 23 \\ 15 & 5 & 3 & 23 \\ 15 & 5 & 3 & 23 \\ 15 & 5 & 3 & 23\end{array}$

14. Fuel cladding failure or high activity in reactor coolant or off gas $7 \quad \begin{array}{llll}7 & 3 & 15\end{array}$

15. Turbine trip

Turbine trip

Failure of turbine to trip, excessive cooldown, safety injection

$\begin{array}{rrrr}7 & & 7 \\ 12 & 5 & 3 & 20\end{array}$

16. Failure of automatic reactivity control systems

Control rods positive reactivity addition control failure

Control rods negative reactivity addition control failure

Inadvertent boration

Inadvertent dilution

17. Steam generator tube leak

$\begin{array}{llll}7 & 5 & 3 & 15 \\ 7 & 5 & 3 & 15 \\ 7 & 5 & & 12 \\ 7 & 5 & & 12\end{array}$

18. Steam leaks

Inside containment--small

Inside containment--large; ice condenser operation, spray

actuation level

Outside containment--small

Outside containment--large

Steam line break without isolation--rupture, excessive cooldown

19. Failure of pressure control systems--primary system

Solid plant--pressure increase exceeds limit

Sol id plant--power-operated rel ief valve opened

Pressurizer spray valve continuously open; loop and pressurizer temperatures equalize

Pressurizer power-operated relief valve or safety valve open

continuously

Pressure increase exceeds safety valve limit setting

$\begin{array}{rrrr}7 & 5 & 3 & 15 \\ 12 & 5 & 3 & 20 \\ 7 & 5 & 3 & 15 \\ 12 & 5 & 3 & 20 \\ 15 & 5 & 3 & 23\end{array}$

20. Generator trips

Generator trips

Generator failure to trip

$\begin{array}{rrrr}7 & 5 & 3 & 15 \\ 7 & 5 & 3 & 15 \\ 12 & 5 & 3 & 20 \\ 15 & 5 & 3 & 23 \\ 12 & 5 & 3 & 20\end{array}$

21. Reactor trips (scrams)

Reactor trip (scram)

Failure of reactor to trip (scram)

$\begin{array}{lllr}5 & & 5 \\ 7 & 5 & 3 & 15\end{array}$

$\begin{array}{rrrr}5 & & 5 \\ 15 & 5 & 3 & 23\end{array}$

* A, safety-related malfunction; $C$, precursor of safety-related malfunction; $D$, malfunction results in plant outage; $B$, frequency of occurrence, is not included. 


\subsection{Conclusions and Recommendations}

This study has shown that a discrepancy exists between those malfunctions currently simulated and the malfunctions selected as important by the proposed criteria. It also shows that criteria can be effectively applied to screen malfunctions.

It is recommended that formal development of criteria be undertaken. Steps necessary to implement this recommendation would include: (1) a review of weighting factors for each aspect category and the categories themselves to identify possible improvements, and (2) the systematic application of these criteria by a team of "experts" to malfunctions of a selected reactor. The result of this development would establish the utility of criteria and provide one element of assurance for the nuclear industry. 
Appendix A

SYSTEMS AND MALFUNCTIONS SIMULATED FOR PWR PLANTS

This appendix uses a matrix system to compare the malfunctions that can be simulated for nine different PWR plants. The data are organized in terms of 17 different plant systems as follows:

1. Reactor Coulant

2. Component Cooling Water

3. Reactor Building Cooling

4. Chemical and Volume Control

5. Reactor Control

6. Electrical

7. Diesel Generator

8. Main Steam and Turbine

9. Condenser/Condensate

10. Feedwater

11 . Nuclear Instrumentation

12. Residual Heat Removal

13. Boron Recovery System

14. Waste Disposal

15. Radiation Monitoring

16. Containment

17. Emergency Core Coolant

Blanks within the matrix indicate that that particular malfunction is not simulated for the specified plant. (Exception: The three completely blank columns indicate that no data were made available for these plants.) 


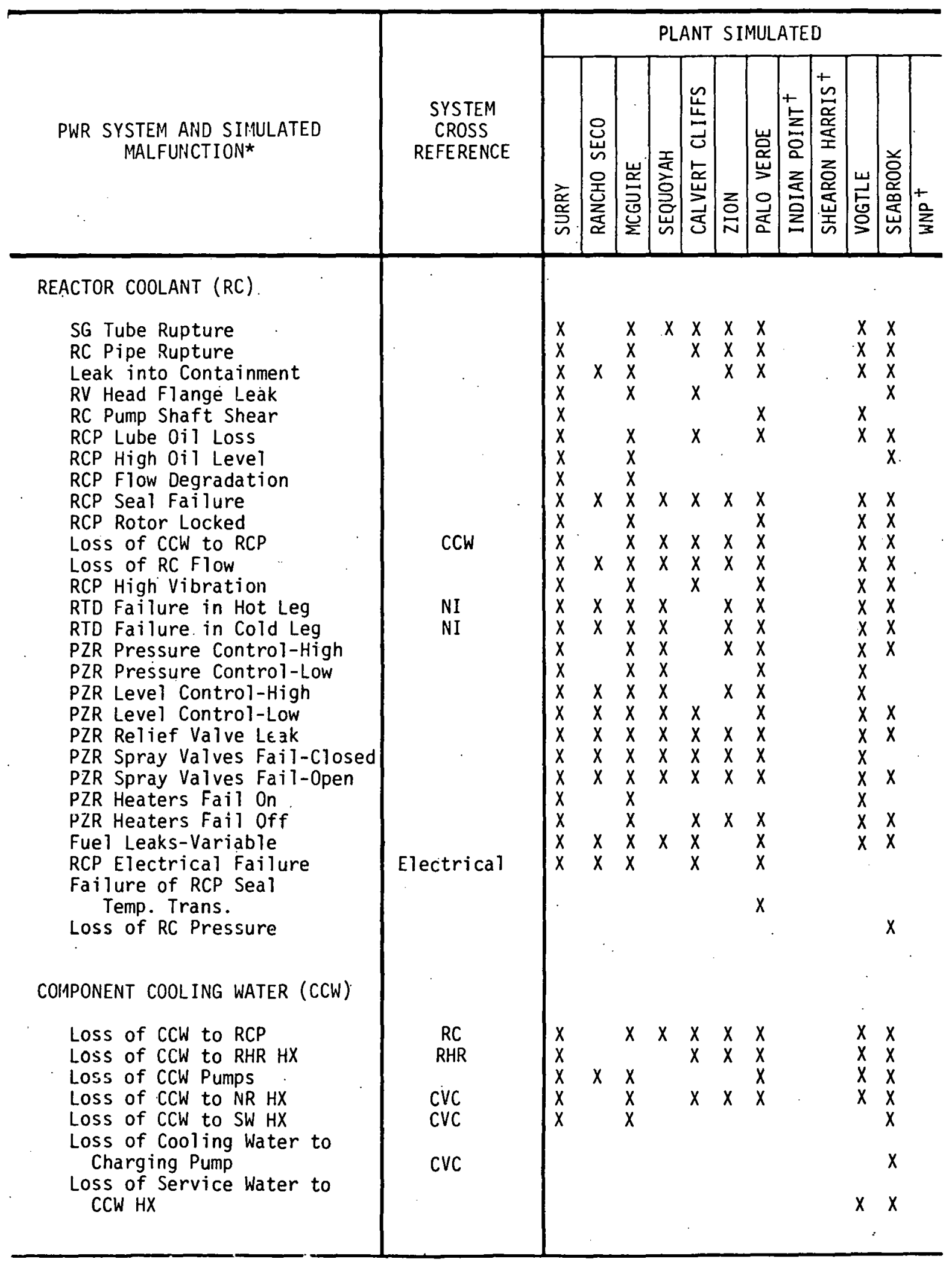

* See Appendix I for definitions of acronyms.

tData not available. 


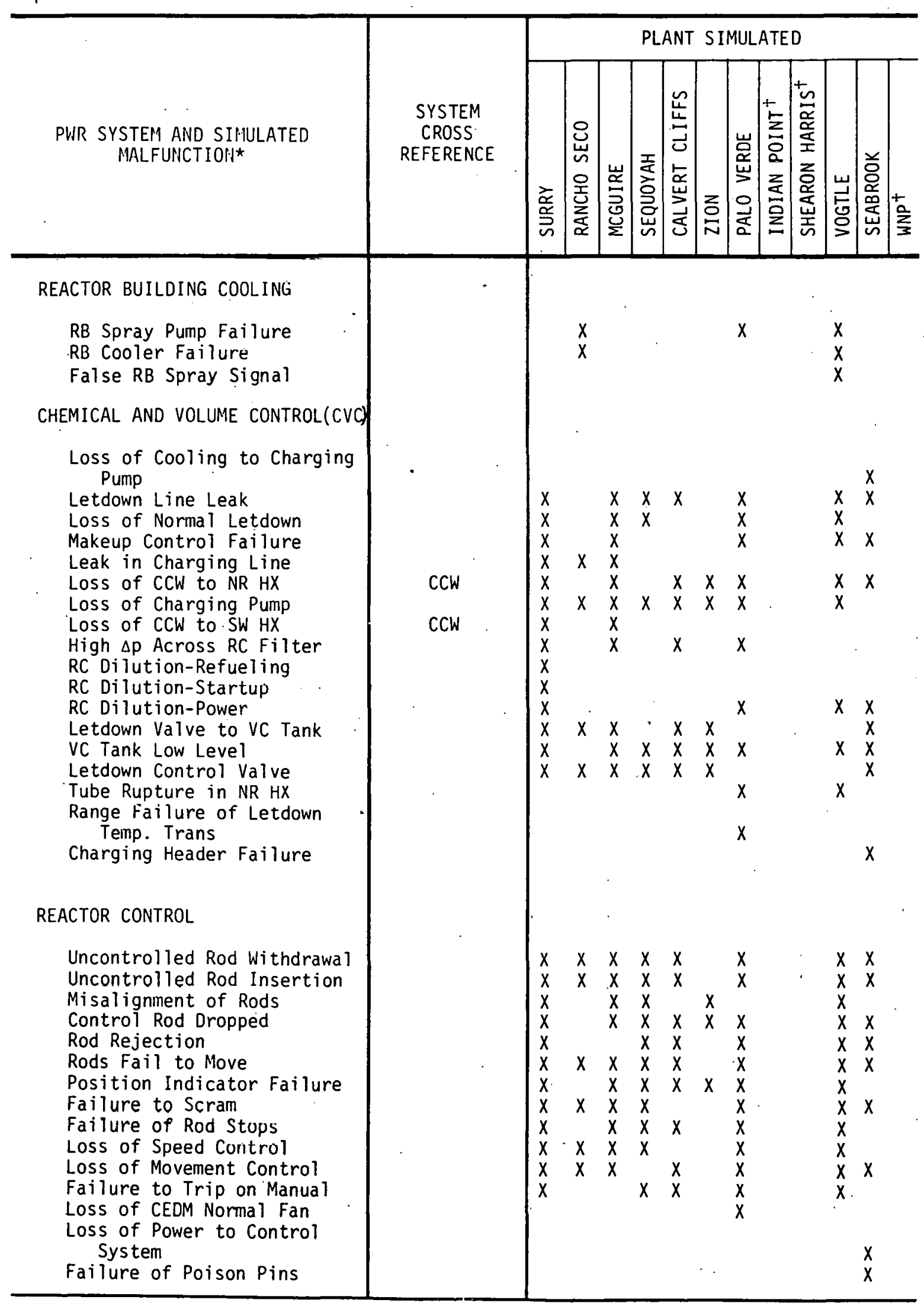




\begin{tabular}{|c|c|c|c|c|c|c|c|c|c|c|c|c|c|}
\hline \multirow[b]{2}{*}{$\begin{array}{l}\text { PWR SYSTEM AND SIIUULATED } \\
\text { MALFUINCT ION* }\end{array}$} & \multirow[b]{2}{*}{$\begin{array}{l}\text { SYSTEM } \\
\text { CROSS } \\
\text { REFERENCE }\end{array}$} & \multicolumn{12}{|c|}{ PLANT SIMULATED } \\
\hline & & 㕍 & 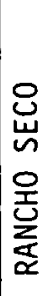 & 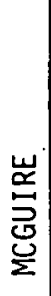 & 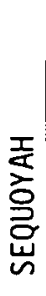 & 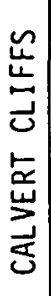 & 悥 & 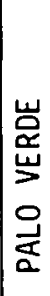 & 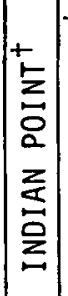 & 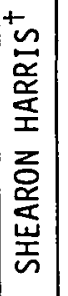 & 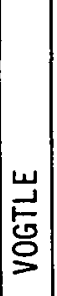 & & $+\frac{+}{2}$ \\
\hline ELECTRICAL & & & & & & & & & & & & & \\
\hline $\begin{array}{l}\text { Loss of All Offsite Power } \\
\text { Loss of Station Transformers } \\
\text { Loss of Emergency Bus } \\
\text { Loss of } 125 \mathrm{~V} \text { DC Bus } \\
\text { Main Generator Trip } \\
\text { Voltage Regulator Failure } \\
\text { RCP Electrical Failure } \\
\text { Loss of Load Center } \\
\text { Main Generator Oil System } \\
\text { Failure } \\
\text { Loss of Inverter } \\
\text { Loss of High Voltage Bus } \\
\text { Loss of Main Generator } \\
\text { Exciter } \\
\text { Loss of All AC Power }\end{array}$ & $R C$ & $\begin{array}{l}x \\
x \\
x \\
x \\
x \\
x \\
x\end{array}$ & $\begin{array}{l}x \\
x \\
x\end{array}$ & $\begin{array}{l}X \\
X \\
X \\
X \\
X \\
X \\
X \\
X\end{array}$ & $\begin{array}{l}X \\
X\end{array}$ & $\begin{array}{l}x \\
x \\
x \\
x\end{array}$ & $\begin{array}{l}x \\
x \\
x \\
x\end{array}$ & $\begin{array}{l}x \\
x \\
x \\
x \\
x \\
x \\
x \\
x\end{array}$ & & & $\begin{array}{l}X \\
X \\
X \\
X \\
X \\
X\end{array}$ & $\begin{array}{l}x \\
x\end{array}$ & \\
\hline $\begin{array}{l}\text { DIESEL GENERATOR } \\
\text { LOSS of Diesel Generator } \\
\text { Loss of Bearing Cooling }\end{array}$ & & $\begin{array}{l}x \\
x\end{array}$ & $x$ & & $x$ & $x$ & & $x$ & & & $x$ & $x$ & \\
\hline $\begin{array}{l}\text { MAIN STEAM AND TURBINE } \\
\text { Turbine Trip } \\
\text { Turbine Lube 0il Loss } \\
\text { Pressure Transmitter Failure } \\
\text { Failure of Turblne Trip } \\
\text { Failure of EHC Systen } \\
\text { Turbine Governor Valve } \\
\text { Turbine Stop Valve } \\
\text { Turbine High Vibration } \\
\text { Turbine Lube Oil Pressure } \\
\text { Turbine Driven Lube Oil Pump } \\
\text { Loss of EH Fluid Pump } \\
\text { Turbine Lube Oil Temperature } \\
\text { Turbine Auto Run Back } \\
\text { Turbine Overspeed } \\
\text { M.S. Trip Valve Fails Shut } \\
\text { M.S. Line Rupture Inside } \\
\text { Containment } \\
\text { M.S. Line Rupture After MSIV } \\
\text { S.G. Level Control-High } \\
\text { S.G. Level Control-Low } \\
\text { Failure of Auto Steam Dump } \\
\text { Steam Header Press Control }\end{array}$ & . & $\begin{array}{l}x \\
x \\
x \\
x \\
x \\
x \\
x \\
x \\
x \\
x \\
x \\
x \\
x \\
x \\
x \\
x\end{array}$ & $\begin{array}{l}x \\
x\end{array}$ & $\begin{array}{l}x \\
x \\
x \\
x \\
x \\
x \\
x \\
x \\
x \\
x \\
x\end{array}$ & $\begin{array}{l}x \\
x \\
x \\
x \\
x\end{array}$ & $\begin{array}{l}x \\
x \\
x \\
x\end{array}$ & $\begin{array}{l}x \\
x \\
x \\
x \\
x\end{array}$ & $\begin{array}{l}x \\
X \\
x \\
X \\
x \\
X\end{array}$ & & & $\begin{array}{l}x \\
x \\
x \\
x \\
x\end{array}$ & $\begin{array}{l}x \\
x \\
x \\
x \\
x\end{array}$ & \\
\hline
\end{tabular}




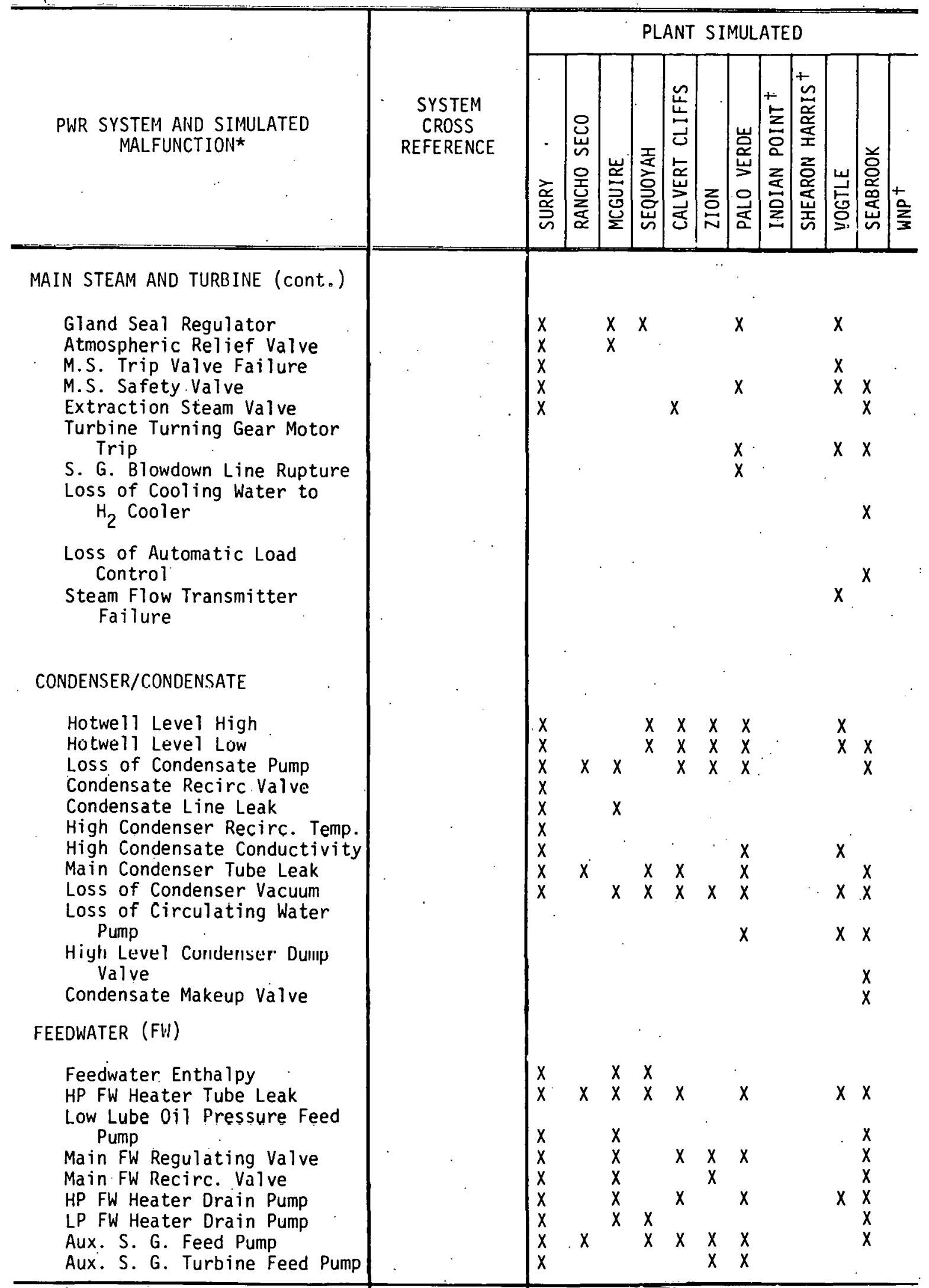




\begin{tabular}{|c|c|c|c|c|c|c|c|c|c|c|c|c|c|}
\hline \multirow[b]{2}{*}{$\begin{array}{l}\text { PWR SYSTEM AND SIMULATED } \\
\text { MALFUNCTION* }\end{array}$} & \multirow[b]{2}{*}{$\begin{array}{c}\text { SYSTEM } \\
\text { CROSS } \\
\text { REFERENCE }\end{array}$} & \multicolumn{12}{|c|}{ PLANT SIMUULATED } \\
\hline & & $\begin{array}{l}\text { 产 } \\
\text { 亭 } \\
\text { 心 }\end{array}$ & 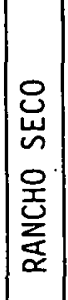 & 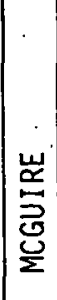 & 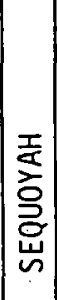 & 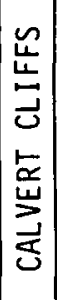 & $\underset{\sim}{2}$ & 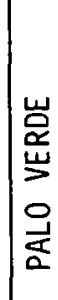 & 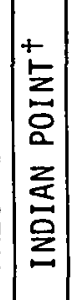 & 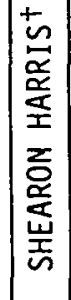 & 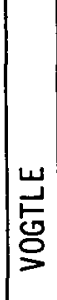 & 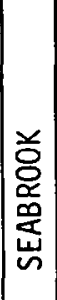 & + \\
\hline $\begin{array}{l}\text { FEEDWATER (Cont.) } \\
\text { FW High Conductivity } \\
\text { FW Heater Failure } \\
\text { Low Canal Level } \\
\text { Feed Flow Transmitter Fail. } \\
\text { FW Line Rupture Inside } \\
\text { Containment } \\
\text { FW Heater Level Switch } \\
\text { Failure } \\
\text { Heater Drain Tank Fails Open } \\
\text { LP FW Heater Bypass Valve } \\
\text { HP FW Heater Level Control } \\
\text { Valve } \\
\text { FW Line Rupture Outside } \\
\text { Containment } \\
\text { FW Pump Trip } \\
\text { Fouling of SG Flash Tank HX } \\
\text { Total Loss of FW }\end{array}$ & . & $\begin{array}{l}x \\
x \\
x\end{array}$ & $x$ & & & $x$ & & $\begin{array}{l}x \\
x \\
x \\
x\end{array}$ & & & $\begin{array}{l}x \\
x \\
x\end{array}$ & $\begin{array}{l}x \\
x\end{array}$ & \\
\hline NUCLEAR INSTRUMENTATION (NI) & & & & & & & & & & & & & \\
\hline $\begin{array}{l}\text { SRM Failure-High } \\
\text { SRM Failure-Low } \\
\text { PRM Failure-High } \\
\text { PRM Failure-Low } \\
\text { IRM Failure to Allow Manual } \\
\text { SRM Sluggish Indication } \\
\text { IRM Overcompensated } \\
\text { IRM Failure-High } \\
\text { IRM Failure-Low } \\
\text { Loss of Power to PRM } \\
\text { Axial Flux Tilt } \\
\text { Radial Flux Tile } \\
\text { RTD Failure in Hot Leg } \\
\text { RTD Failure in Cold Leg } \\
\text { Axial Zenon Oscillation } \\
\text { Core Monitoring Computer } \\
\text { Failure } \\
\text { Loss of Power to SRM } \\
\text { PRM Output Oscillates }\end{array}$ & $\begin{array}{l}\mathrm{RC} \\
\mathrm{RC}\end{array}$ & $\begin{array}{l}x \\
x \\
x \\
x \\
x \\
x \\
x \\
x \\
x \\
x \\
x \\
x \\
x \\
x\end{array}$ & $\begin{array}{l}x \\
x \\
x \\
x \\
x \\
x \\
x \\
x \\
x\end{array}$ & $\begin{array}{l}x \\
x \\
x \\
x \\
x \\
x \\
x \\
x \\
x \\
x \\
x \\
x \\
x \\
x\end{array}$ & $\begin{array}{l}x \\
x \\
x \\
x\end{array}$ & $\begin{array}{l}x \\
x \\
x \\
x\end{array}$ & $\begin{array}{l}x \\
x \\
x \\
x \\
x \\
x \\
x \\
x\end{array}$ & $x$ & & & $\begin{array}{l}x \\
X \\
x \\
X \\
X\end{array}$ & $\begin{array}{l}x \\
x\end{array}$ & \\
\hline RESIDUAL HEAT REMOVAL (RHR) & & & & & & & & & & & & & \\
\hline $\begin{array}{l}\text { LoSs of RHR Pump } \\
\text { RHR System Temperature } \\
\text { RHR System Flow } \\
\text { Loss of CCW to RHR HX }\end{array}$ & CCW & $\begin{array}{l}x \\
x \\
x \\
x\end{array}$ & $x$ & & $\begin{array}{l}x \\
x \\
x\end{array}$ & $\begin{array}{l}x \\
x\end{array}$ & $\begin{array}{l}x \\
x \\
x\end{array}$ & $x$ & & & $x$ & & \\
\hline
\end{tabular}




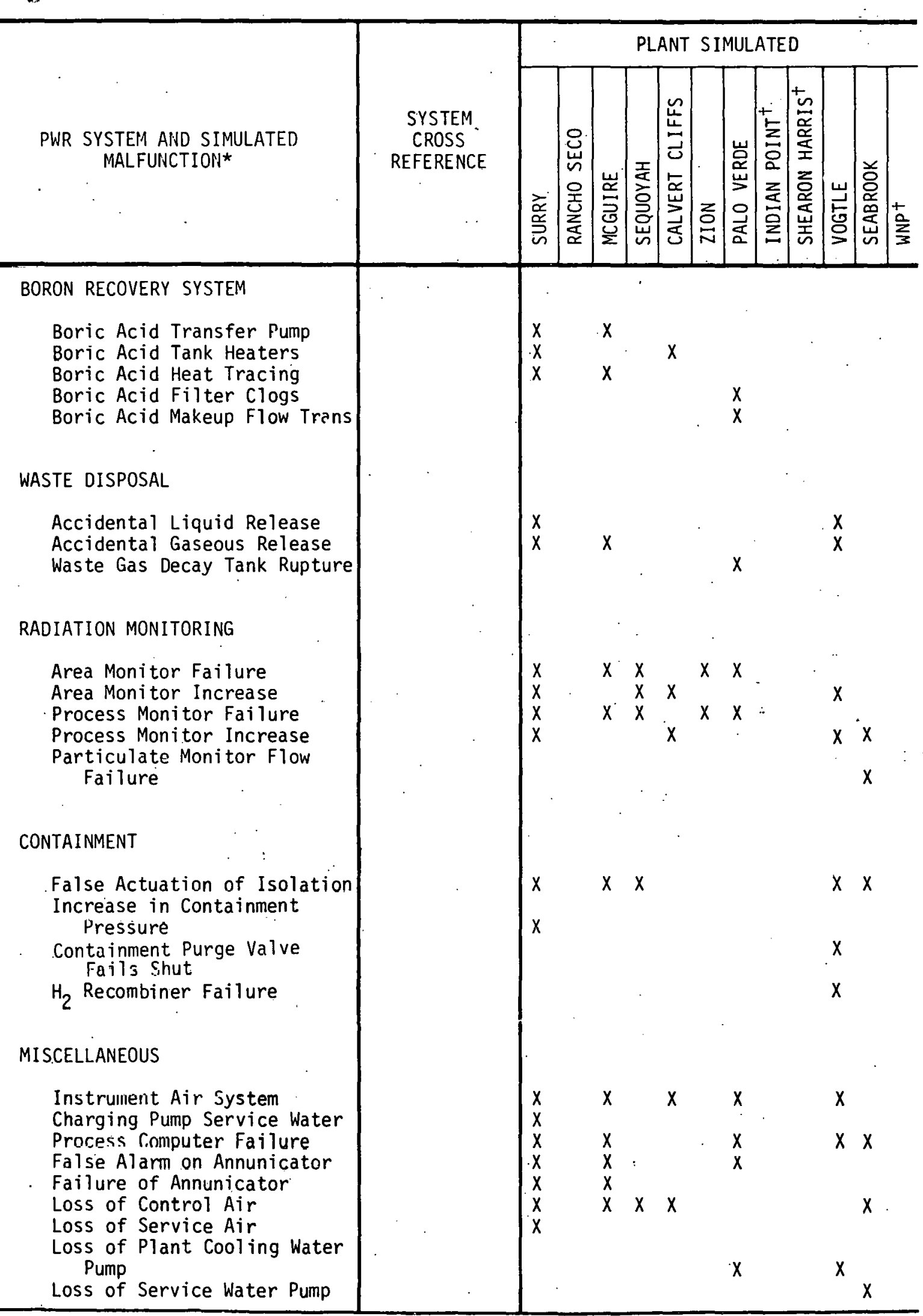




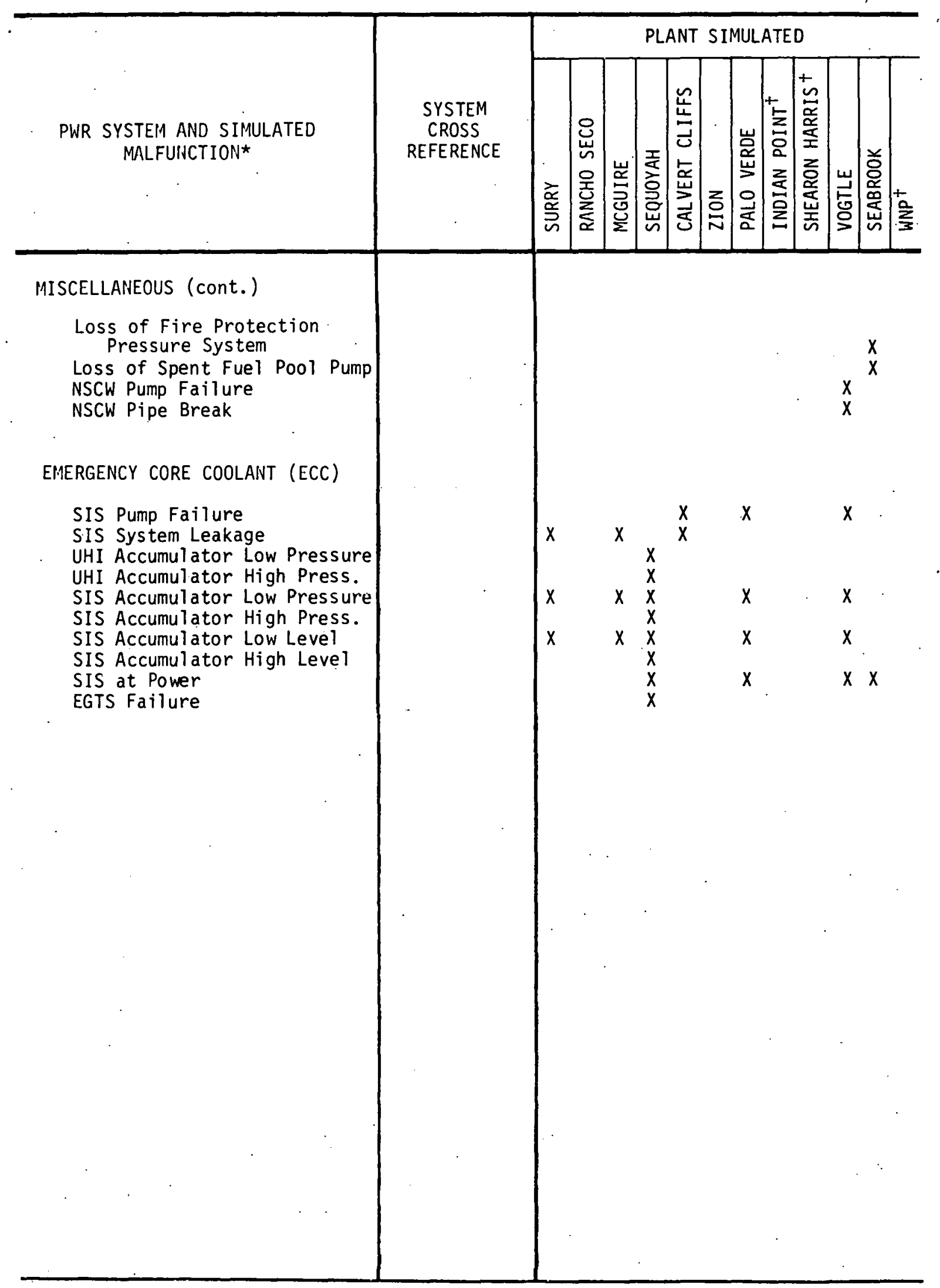




\section{Appendix B}

\section{SYSTEMS AND MALFUNCTIONS SIMULATED FOR BWR PLANTS}

This appendix uses a matrix system to compare the malfunctions that can be simulated for five different BWR plants. The data are organized in terms of 18 different plant systems as follows:

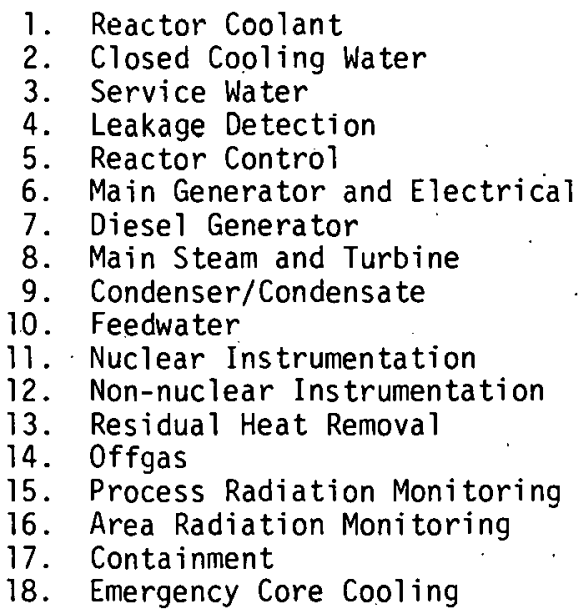

Blanks within the matrix indicate. that that particular malfunction is not simulated for the specified plant. (Exception: The two completely blank columns indicate that no data were made available for these plants.) 


\begin{tabular}{|c|c|c|c|c|c|c|c|c|}
\hline \multirow{2}{*}{$\begin{array}{l}\text { BWR SYSTEM AND SIMULATED } \\
\text { MALFUNCTION* }\end{array}$} & \multirow[b]{2}{*}{$\begin{array}{c}\text { SYSTEM } \\
\text { CROSS } \\
\text { REFERENCE }\end{array}$} & \multicolumn{7}{|c|}{ PLANT SIMULATED } \\
\hline & & 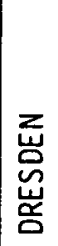 & 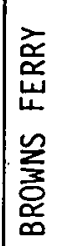 & 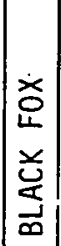 & 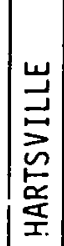 & $\mid$ & 总 & 离 \\
\hline $\begin{array}{l}\text { REACTOR COOLANT (RC) } \\
\text { Fuel Cladding Failure } \\
\text { Recirc Pump Failure } \\
\text { Recirc Pump Suction Valve } \\
\text { Recirc Pump Control Valve } \\
\text { Flow Control Actuator } \\
\text { Total FW Flow } \\
\text { Main Flow Control Valve } \\
\text { Recirc Pump Line H/L Flow } \\
\text { Recirc Pump Seal Leak } \\
\text { R. P. Seal Temp. High } \\
\text { RWCU Influent Conduct. } \\
\text { RWCU Effluent Conduct. } \\
\text { Pressure Relief Valve } \\
\text { PRV Fails Open } \\
\text { High PRV Line Temperature } \\
\text { PRV Does Not Open Manual } \\
\text { Recirc Pump Trouble } \\
\text { Recirc M/G Set Failure } \\
\text { RWCU System Trip } \\
\text { Recirc Pump Field Breaker } \\
\text { Trip } \\
\text { Jet Pump Failure. } \\
\text { RWCU Drain Flow Regulator } \\
\text { Failure } \\
\text { RWCU Demin. Resin Depletion }\end{array}$ & $\begin{array}{l}\text { Feedwater } \\
\text { Feedwater }\end{array}$ & $\begin{array}{l}x \\
x\end{array}$ & $\begin{array}{l}x \\
x \\
x \\
x\end{array}$ & $\begin{array}{l}x \\
x \\
x\end{array}$ & $\begin{array}{l}x \\
x \\
x\end{array}$ & & $\begin{array}{l}x \\
x \\
x \\
x \\
x \\
x \\
x\end{array}$ & \\
\hline $\begin{array}{l}\text { CLOSED COOLING WATER } \\
\text { LOSS of Main Circulator } \\
\text { Air Binding in Main Condenser } \\
\text { CCW Flow LoSS } \\
\text { CCW Flow to RWCU HX } \\
\text { CCW Flow to Drywell }\end{array}$ & . & & $x$ & $x$ & $x$ & & $x$ & \\
\hline $\begin{array}{l}\text { SERVICE WATER } \\
\text { NSSS SW Header } \\
\text { BOP SW Header } \\
\text { Drywell Chilled Water Temp. } \\
\text { C. B. Chilled Wàter Temp. } \\
\text { Fuel Pool Cooling Temp. } \\
\text { ESW Pump Trip }\end{array}$ & & & & & & & $x$ & \\
\hline
\end{tabular}

* See Appendix I for definitions of acronyms.

tData not available. 


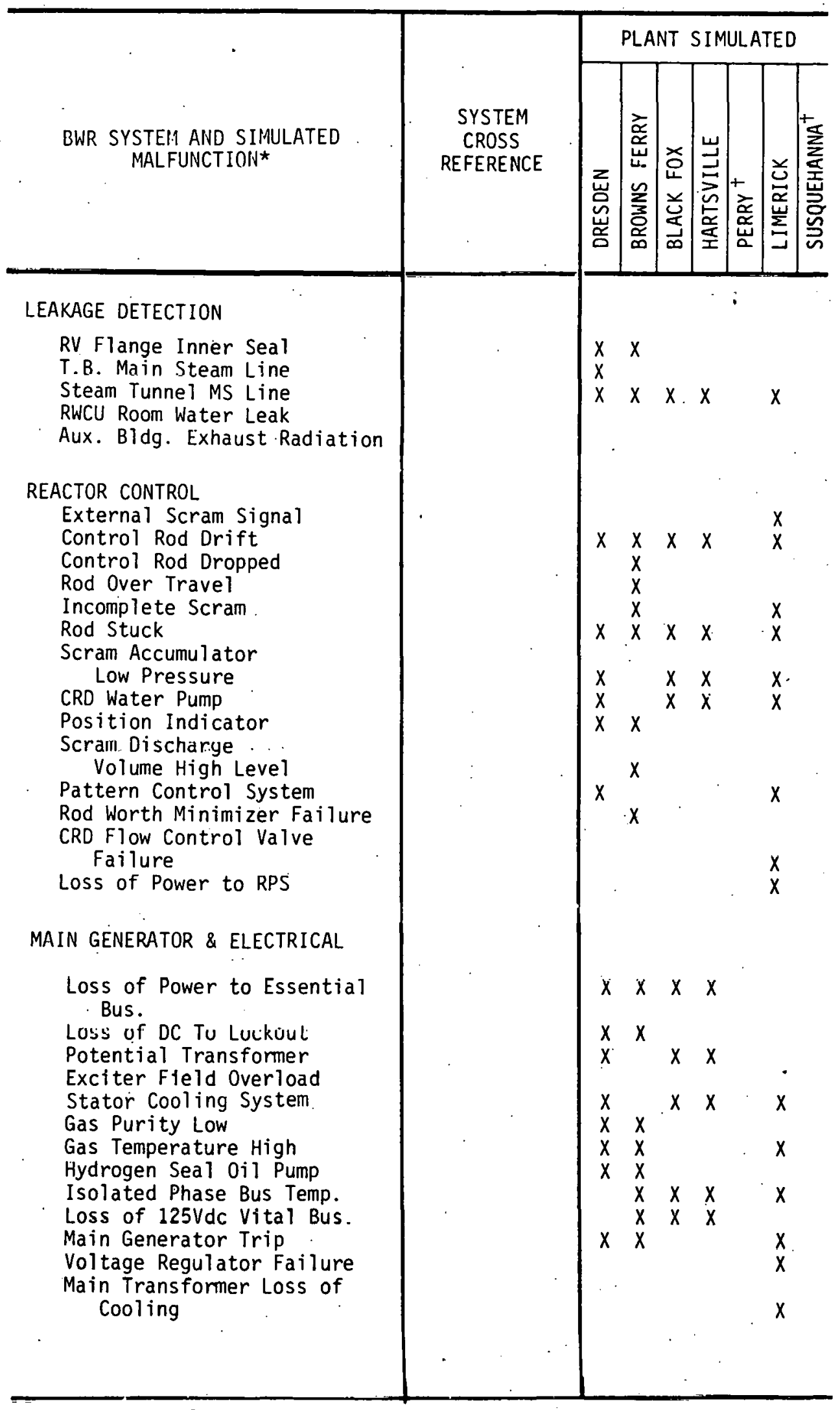




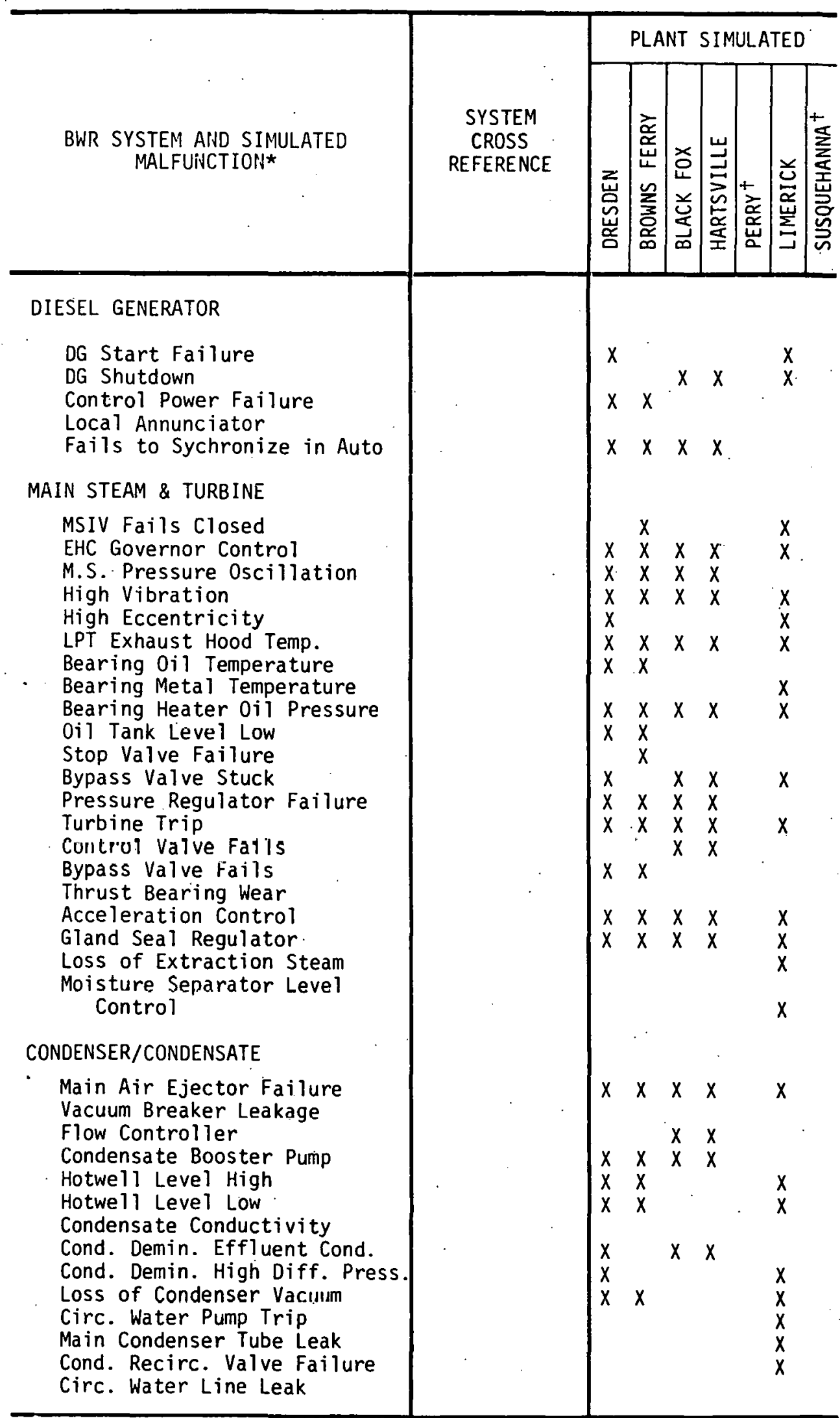




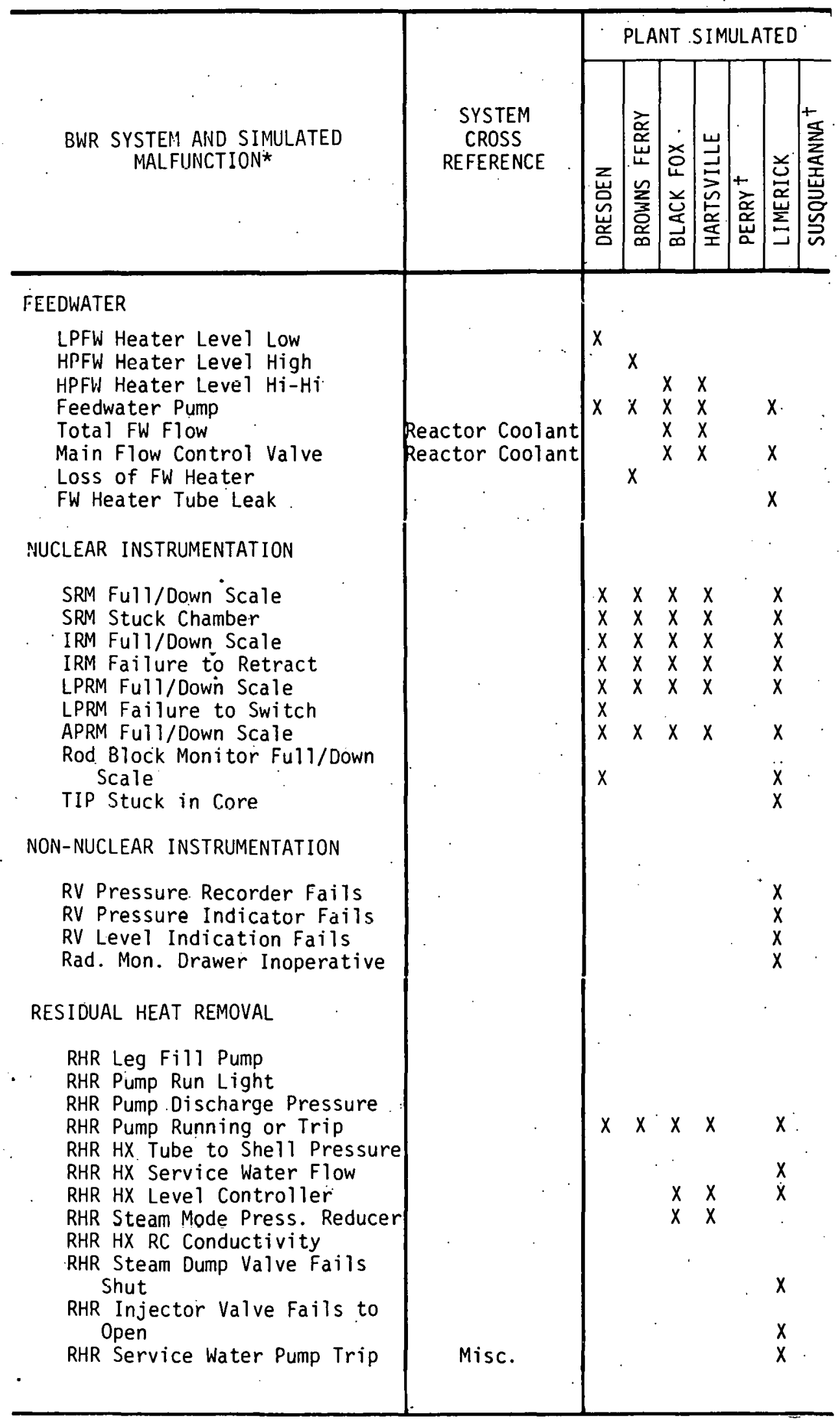




\begin{tabular}{|c|c|c|c|c|c|c|c|c|}
\hline \multirow[b]{2}{*}{$\begin{array}{l}\text { BWR SYSTEM AND SIMULATED } \\
\text { NALFUNCTION* }\end{array}$} & \multirow[b]{2}{*}{$\begin{array}{c}\text { SYSTEM } \\
\text { CROSS } \\
\text { REFERENCE }\end{array}$} & \multicolumn{7}{|c|}{ PLANT SIMULATED } \\
\hline & & 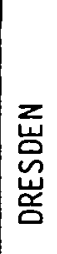 & 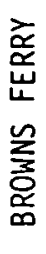 & 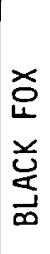 & 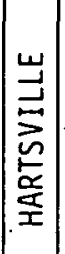 & 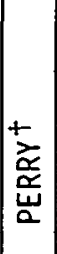 & 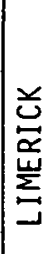 & 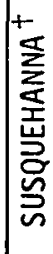 \\
\hline $\begin{array}{l}\text { OFFGAS } \\
\text { Glycol Solution Temp. } \\
\text { Drier Discharge Humidity } \\
\text { Steam Flow Low } \\
\text { Air Ejector. Discharge } \\
\text { Explosion } \\
\text { Recombiner Malfunction }\end{array}$ & & & & & & & $\begin{array}{l}X \\
X\end{array}$ & \\
\hline $\begin{array}{l}\text { PROCESS RADIATION MONITORING } \\
\text { Main Steam Line Hi-Hi } \\
\text { M.S. Line Down Scale } \\
\text { M.S. Line High } \\
\text { Off-Gas Pretreatment } \mathrm{Hi} \\
\text { Off-Gas Posttreatment Hi-Hi } \\
\text { Off-Gas Vent Pipe Hi } \\
\text { Liquid Effluent Hi } \\
\text { CCW Liquid Hi } \\
\text { Service Water Hi } \\
\text { Carbon Bed Vault Hi } \\
\text { Cont. Vent. Exhaust Hi } \\
\text { Cont. Vent Discharge Hi } \\
\text { RHR Service Water Hi } \\
\text {. Failure of PMS Computer }\end{array}$ & $\cdot$ & $\begin{array}{l}x \\
x \\
x\end{array}$ & $\begin{array}{l}x \\
x \\
x \\
X\end{array}$ & $\begin{array}{l}x \\
x \\
x\end{array}$ & $\begin{array}{l}x \\
x \\
x\end{array}$ & & $\begin{array}{l}x \\
x\end{array}$ & \\
\hline $\begin{array}{l}\text { AREA RADIATION MONITORING } \\
\text { Reactor Building } \\
\text { Turbine Building } \\
\text { Radwaste Building } \\
\text { Auxiliary Building } \\
\text { Fuel Building } \\
\text { Monitor-Down Scale }\end{array}$ & & $\begin{array}{l}x \\
x\end{array}$ & $\begin{array}{l}x \\
x\end{array}$ & & & & & \\
\hline $\begin{array}{l}\text { CONTAINMENT } \\
\text { Pressure Control Flow Low } \\
\text { Annulus Exhaust Flow Low } \\
\text { Fuel Bldg. Pressure Control } \\
\text { Steam Line Break } \\
\text { Water Line Break } \\
\text { High Drywell Pressure }\end{array}$ & . & $x$ & $x$ & $\begin{array}{l}x \\
x\end{array}$ & $\begin{array}{l}x \\
x\end{array}$ & & $\begin{array}{l}x \\
x\end{array}$ & \\
\hline
\end{tabular}




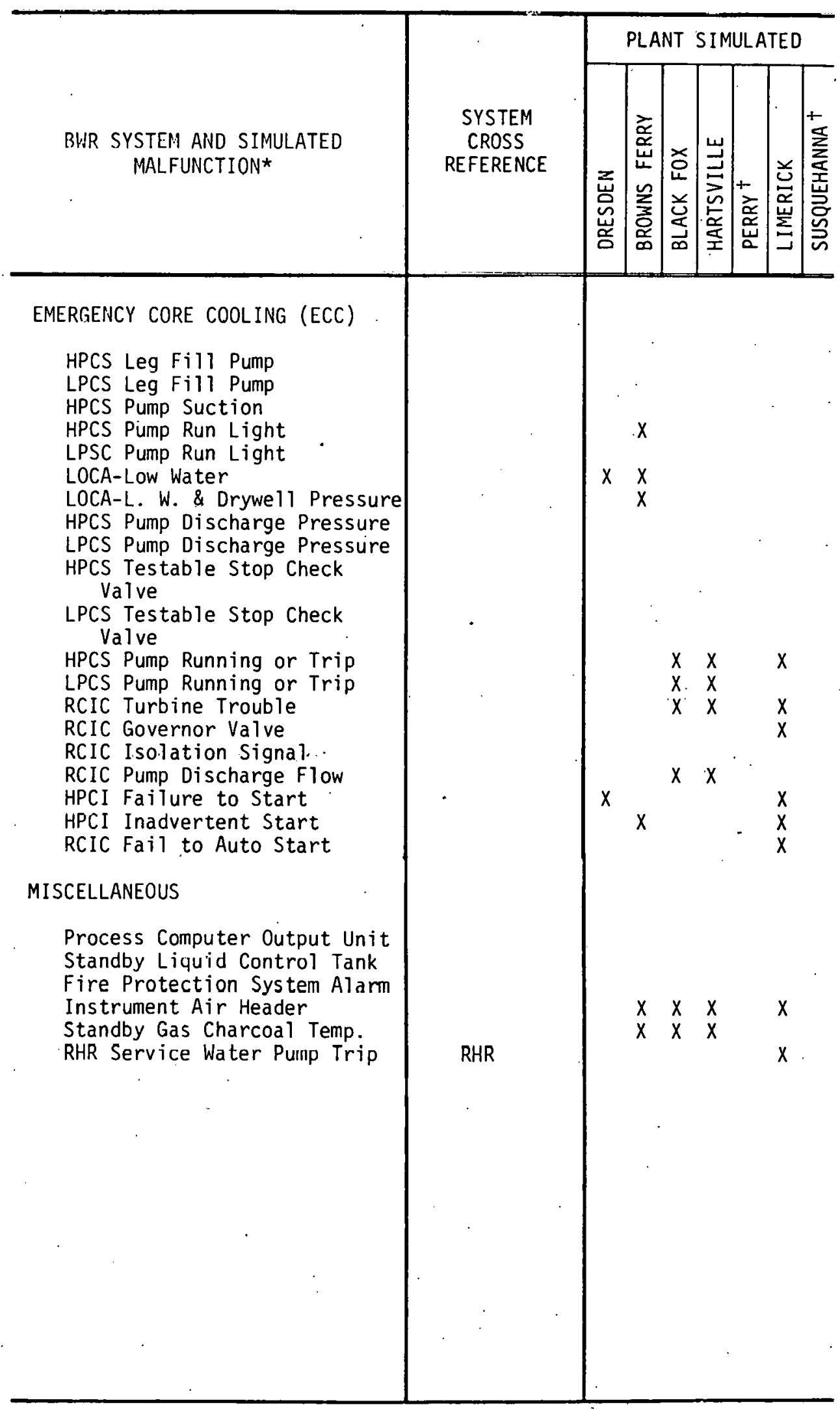




\section{Appendix C}

OUTLINE OF TVA COLD LICENSE TRAINING PROGRAM FOR PWR OPERATORS

An overview of Cold License Simulator Training Programs is presented in Section 4.1.1 of this report. A detailed outline of one of the programs, the 12-week TVA Cold License Simulator Training Course, is presented in this appendix. 


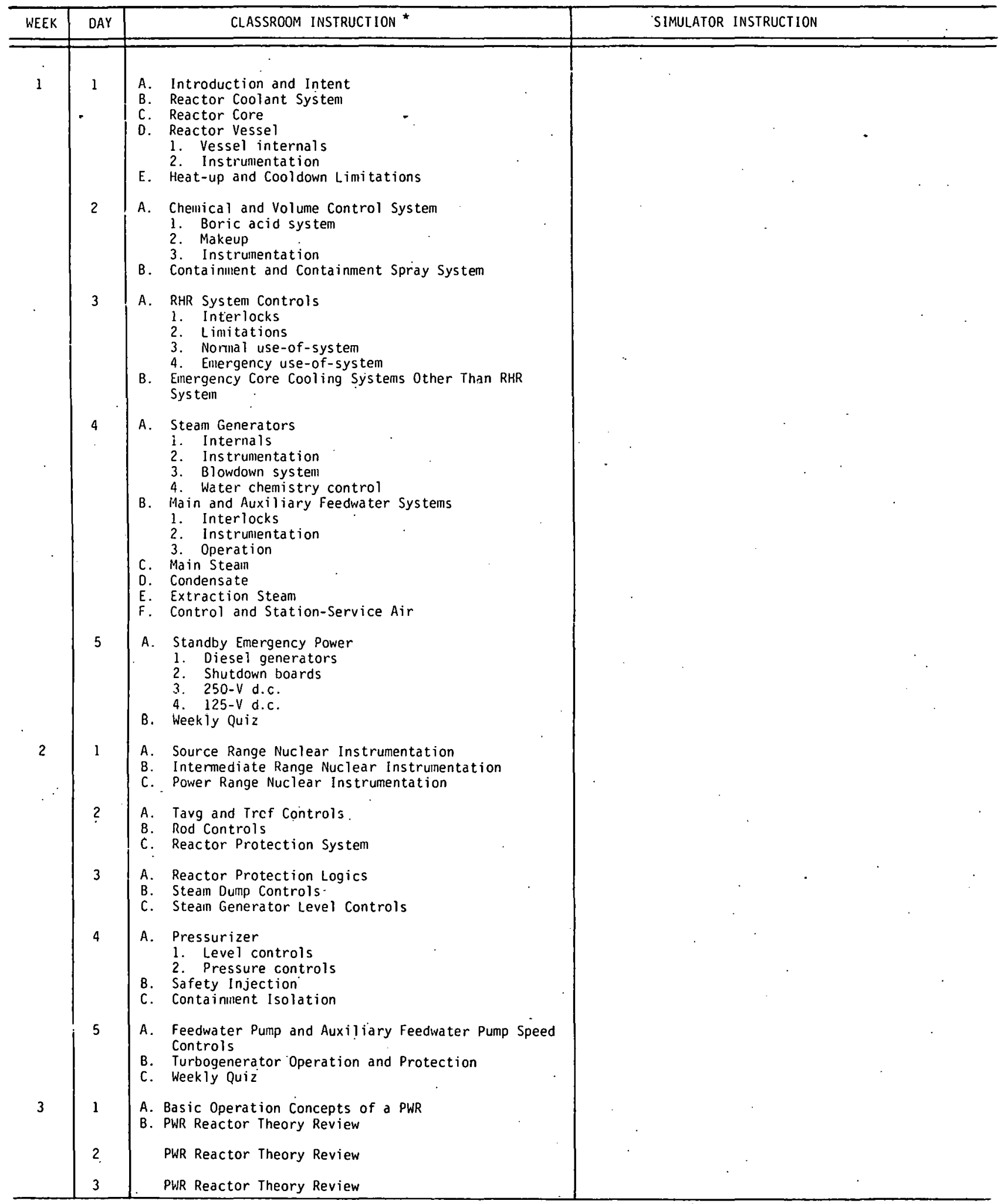

*See Appendix I for definitions of acronyms. 


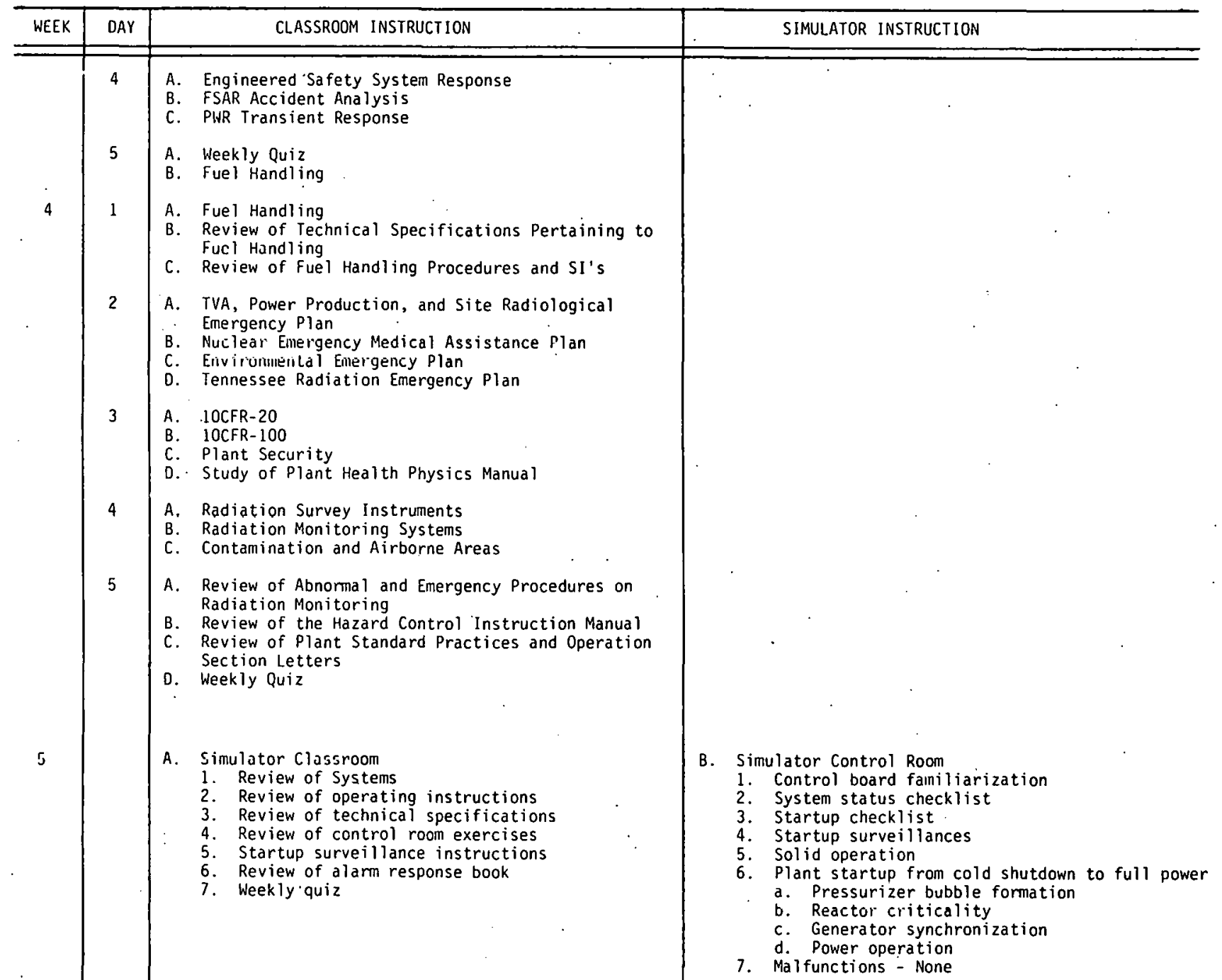

A. Simulator Classroom

1. Review of systemis

2. Review of operating instructions

3. Review of technical specifications

4. Review or abnorillal operating instructions

5. Review of emergency operating instructions

6. Review of control room exercises

7. Weekly quiz

A. Simulator Classroom

1. Emergeney and abnormal operating instructions

2. Review of systems

3. Review of operating and surveillance instructions

4. Review of technical specifications

5. Review of control room exercises

6. PWR transient response

7. Shutdown margin calculation

8. Estimated critical condition calculation

9. Mid-course written test

B. Simulator Control Room
1. Power operation from minimum to $100 \%$ power
2. Reactor trip control
3. Shutdown to hot shutdown condition
4. Shutdown Surveillance Instructions
5. Shutdown to cold shutdown condition
6. Plant Cooldown
7. Placing the pressurizer in a solid condition
8. RHR operation
9. Malfunctions
a. Minor equipment failures
b. Turbine trip
c. Generator trip

B. Simulator Control Room

1. Power maneuvering

2. Reactor scram recovery including a shutdown margin calculation and estimated critical condition calculated

3. Three-loop operation

4. Malfunctions

a. System malfunctions

b. Instrumentation malfunctions

c. Feedwater and condensate failures

d. Chemical volume Control System failures

e. Reactor trip malfunctions

5. Mid-course oral examination 


\begin{tabular}{|c|c|c|c|}
\hline WEEK & DAY & CLASSROOM INSTRUCTION & SIMULATOR INSTRUCTION \\
\hline 8 & & $\begin{array}{l}\text { A. Simulator Classroom } \\
\text { 1: Emergency and abnormal instructions } \\
\text { 2. Operating and surveillance instructions } \\
\text { 3. Study of nuclear instrumentation and their } \\
\text { failures } \\
\text { 4. Pressurizer and controls and their failures } \\
\text { 5. Reactor Coolant System and Reactor Coolant } \\
\text { 6ystem Failures } \\
\text { 7. Review of control room exercises } \\
\text { 7. Weekly quiz }\end{array}$ & $\begin{array}{l}\text { B. Simulator Control Room } \\
\text { 1. Startups with malfunctions } \\
\text { 2. System malfunctions } \\
\text { 3. Power operation with malfunctions } \\
\text { 4. Low power operation for manual manipulation of } \\
\text { 5. Malfunctions } \\
\text { a. Nuclear instrumentation failures } \\
\text { b. Loss of feedwater } \\
\text { c. Control rod drive failures } \\
\text { d. Pressurizer relief and safety valve failur } \\
\text { e. Loss of reactor coolant } \\
\text { f. Reactor Coolant Pump seal failures } \\
\text { g. Steam generator level control malfunctions }\end{array}$ \\
\hline 9 & & $\begin{array}{l}\text { A. Simulator } \mathrm{Classroom} \\
\text { 1. Review of operating instructions } \\
\text { 2. Review of surveillance instructions } \\
\text { 3. Review of emergency operating instructions } \\
\text { 4. Review of technical specifications on } \\
\text { 5. Elargency Core Cooling System } \\
\text { 6. Diesel generical systems - Blackout procedures } \\
\text { 7. Review of control room exercises } \\
\text { 8. Weekly quiz }\end{array}$ & $\begin{array}{l}\text { 8. Simulator Control Room } \\
\text { 1. Power operation with mal functions } \\
\text { 2. Surveillances on all Emergency Core Cooling } \\
\text { 3. Survem } \\
\text { 4. Transflance on diesel generators } \\
\text { 5. Malfunctions of plant electrical supplies } \\
\text { a. Secondary plant mal functions no. } 3 \text { and } \\
\text { b. Ex. } 7 \text { High Del ta Pressure trip } \\
\text { c. Turbine runback failure } \\
\text { d. Condenser tube leak } \\
\text { e. Hotwell level mal functions } \\
\text { f. Feedwater heater tube leak } \\
\text { g. Electrical mal functions } \\
\text { h. Generator and turbine trips }\end{array}$ \\
\hline 10 & & $\begin{array}{l}\text { A. Simulator Classroom } \\
\text { 1. Study of ins trumentation failure analys is } \\
\text { 2. Review of nuclear ins trumentation } \\
\text { 3. Emergency and abnormal operating instructions } \\
\text { 4. Review of control room exercises } \\
\text { 5. Weekly quiz }\end{array}$ & $\begin{array}{l}\text { B. Simulator Control Room } \\
\text { 1. Startups and power operation wi th } \\
\text { instrumentation mal functions } \\
\text { 2. Shutdown to cold shutdown condition RHR } \\
\text { operation } \\
\text { 3. Mal functions } \\
\text { a. Reartirir fonl ant. Syst.pm Failures } \\
\text { b. Resistant Temperature Detector failures } \\
\text { c. Pressurizer pressure and level control } \\
\text { d. Control rod mal functions on startup and } \\
\text { e. power operation }\end{array}$ \\
\hline 11 & & $\begin{array}{l}\text { A. Simulator Classroom } \\
\text { 1. Review of energency and abnormal instructions } \\
\text { 2. Review of technical specifications } \\
\text { 3. Review of PhR theury } \\
\text { 4. Review of safety analysis transients } \\
\text { 5. Review of health physics and radiation control } \\
\text { 6. Weekly quiz } \\
\end{array}$ & $\begin{array}{l}\text { B. Simulator Control Room } \\
\text { 1. Major accidents } \\
\text { 2. Radiation malfunctions } \\
\text { 3. Xenon transients and xenon effects on reactor } \\
\text { 4. Malfup } \\
\text { a. Loss of coolant accident steam line startu } \\
\text { b. Steam generator tube rupture } \\
\text { c. Chemical Volume Control System letdown lea } \\
\text { d. Station blackout } \\
\text { e. Reactor Coolant Pump failures } \\
\text { f. Rod control malfunctions }\end{array}$ \\
\hline 12 & & $\begin{array}{l}\text { A. Simulator Classroom } \\
\text { 1. Overall review } \\
\text { 2. Reactor operator written certification } \\
\text { 3. Senination } \\
\text { examination }\end{array}$ & $\begin{array}{l}\text { B. Simulator Control Room } \\
1 . \text { Oral and simulator certification examinations }\end{array}$ \\
\hline
\end{tabular}




\section{Appendix D}

JOB DIMENSIONS OF NUCLEAR REACTOR OPERATORS

The need for a thorough task analysis as a basic element in a systems approach to training is discussed in Section 4.3 of this report. Such an analysis for nuclear training programs must include the job dimensions of the reactor operator. Narrative examples of 17 job dimensicns, extracted from a task analysis previously developed by MSU/CNS and used as a basis for reactor operator selection prograns, are presented in this appendix. 


\section{AREA 1 - Tool Handling}

The operator uses precision tools or instruments little if any during a normal working day. He does make use of nonprecision tools and instruments, such as wrenches and valve helpers, to assist in opening and closing tightly bound valves. Other tools and handling devices he uses are cranes, hoists, come-alongs and overhead pulleys to lift heavy tools. Elevators are used to go from floor to floor in the plant. He makes use of loading dollys to move items such as boric acid barrels from one place to another. In the equipment that the operator uses, very little assembling or disassembling is required of him. He is often required to interpret graphs where they need some type of ruler or measuring device to determine length and correlate that to a reading. Also, hand-held temperature-measuring equipment is used to some extent.

\section{AREA 2 - Input from Instrumentation}

Because radiation by its own nature has to be observed remotely, it is vitally important to constantly monitor visual displays, dials, gauges, and signal lights. One of the major sources of information to the operator that enables him to perform his duties is input from visual displays. He must constantly survey, interpret and monitor dials, instruments and gauges in the control room and throughout the plant. The operator does a tremendous amount of monitoring of machines or equipment that are used to operate the plant. He does most of his operating by remotely operated equipment where he is operating switches, variable controls, etc. He also uses fixed setting controls in his operations. There are many types of valves that have detents that are operated either in one position or many positions. An operator is expected to operate these on an intermittent basis. The operator uses variable setting controls also. He must maintain remntely operated valves that he can station at any position he wants to such as an air signal or an electrical signal. He makes use of keyboard devices such as calculators, and at the more modern plants, computers are available where the operator is expected to be able to use to insert and withdraw necessary information.

Another major source of information for the operator is from verbal sources. This is particularly important at the end of each shift. As an operator leaves his shift he must report the current condition of the plant and any conditions which the operator coming on duty should be aware of. Somc reliance is made on written log books; however, most of the operating information is relayed verbally. Recognition, vigilance and monitoring are critical to the operator's job. He is expected to be able to recognize normal conditions -- the normal position of dials and gauges, etc. on the control panels at a glance. The operator's job is hours and days of stable conditions interspersed with moments of great stress and activity. An operator must constantly be on the alert for infrequent events. The normal condition would be everything stable. There are certain 
components in a plant that are continually changing and have to be monitored closely at very specific time periods. Examples of these activities are steam generator levels during startup, boric acid processing systems and waste processing systems.

\section{AREA 3 - Contacts with People}

The semiprofessional nature of the job along with the responsibility requires certain personal contact. This contact may range from executives to manual and service workers. In the control room the reactor operator has a senior reactor operator who is constantly supervising him. He also has frequent contact with other plant operators whom he has to direct by giving instructions on what jobs to perform and when to perform them. He has little contact with anyone of an executive or plant superintendent status on a continuing basis. Intermittently, the operator will have direct contact with various department heads during the performance of his job; however, this is not a normal situation. In the field of professionals, operators have contact with engineering personnel on a limited basis. Semiprofessional personnel with whom the operator has contact include instrument technicians, which would generally be on a daily basis. He has intermittent contact with clerical workers usually once or twice a month. An operator would have contact perhaps once a day with lower skilled maintenance and utility personnel, such as those who clean the offices.

This type of job demands almost no contact with persons unrelated to the field of nuclear operations. Groups such as students, sales persons, public customers or special interest groups have very little contact with the nuclear reactor operator. He is rarely called upon to discuss his job with personnel outside the plant.

\section{AREA 4 - Physical Hazards}

The idea of permanent physical disability or impairment due to the nature of his job is minimal. The major first-aid cases with which an operator contends on a usual basis would be burns from steam pipes. Falls while crawling on pipes in attempts to operate valves would be a hazard to a lesser extent. Temporary disability also would occur usually from a fall resulting in a broken bone or something of this nature. Operators are constantiy working in the vicinity of rotating equipment with the possible loss of a limb but this is an extremely unlikely situation. This job does have the possibility of overexposure to radiation causing radiation sickness, but it is usually not a great concern because of safeguards built into the system.

\section{AREA 5 - Perception and Mental Processing}

Rarely does the operator have to make estimations on the speed of moving objects or parts of objects. Any information of this sort is given to the operator on a gauge or some type of instrumentation. An operator must, however, estimate the speed of processes. 
He needs to estimate the length of time to complete specific functions such as adding chemicals to the reactor cooling system or the length of time it would take to line up the valves of the system. This would be considered a major concern of the operator. Some judgment by the operator must be made in the condition and quality of equipment that is perhaps malfunctioning or may be expected to malfunction.

There is a large amount of inspection in the operator's job. An operator will have a specific procedure whereby he inspects to make certain all the conditions meet the requirements or the surveillance procedure. This task is required on a daily basis.

\section{AREA 6 - Conformity to Regulation}

An operator's mode of dress would be "blue collar" apparel, such as is worn in factories and on construction work. The operator almost exclusively works on a rotating shift basis. The shifts generally are a week in duration with one, two, three or four days off after each shift. In the period of a month an operator typically will have worked a complete rotation of shifts.

Certification is an absolute in the job of nuclear reactor operator. The nuclear Regulatory Commission reactor operator's license is required before a person can perform the functions of an operator. These licensing requirements are set forth in the United States Nuclear Regulatory Commission Rules and Regulations Title 10; Chapter 1, Code of Federal Regulations, Part 55.

\section{AREA 7 - Job Responsibilities}

The operator who is in charge of the reactor panel has the legal responsibllity for the reactor. The worth of the plant may be estimated at approximately one billion dollars. The operator is charged with the responsibility to operate the plant safely, which is a tremendous responsibility so far as material assets are concerned. Because the operator has control of the plant, this must be considered a very critical position. An inadequate job performance on his part can cause serious material damage and monetary cost in plant operation. An additional general responsibility an operator would have includes, to a minor extent, directing the work of other operators in lower positions at the plant, such as auxiliary operators.

\section{AREA 8 -Potential for Frustration}

The operator's job has an average amount of frustrating situations. His job demands information and cooperation from other departments in the plant. The operator is in charge of operating a system; however, he must get clearance for the system from other departments before the operation can begin and this would be the general cause of frustration for the operator. 
There are few strained personal contacts in the operator's job. This would be due. mainly because he has fewer persons with whom he must come in contact; therefore, the situation for strained relations would have fewer opportunities to occur. The greatest personal sacrifice an operator is expected to make is the shift work necessary to provide around the clock electrical power. Interpersonal conflict situations are relatively low in the operator's job. One source of conflict which may arise is when an engineer or technician in the plant may want to do a specific job but the operator must say no because it would be unsafe for the plant at that particular time.

\section{AREA 9 - Job Demands}

The ability to follow procedures and meet urgent time deadlines with a certain amount of precision requires a great deal of attention to details. An operator must follow set procedures in almost every phase of his job that is closely related to operating the reactor. He has procedures which cover operating phases, startups, shutdowns, etc.

The time pressure of a situation is extremely high at certain periods of time for an operator. During startups and shutdowns of a power plant, timing is critical and there is much pressure to make certain everything necessary is done at the proper time. Examples include the criticalness of steam generator levels of the startup and trying to maintain the proper level of the steam generators because the improper level could cause a reactor trip.

The operator needs to be precise in making his log entries, describing. what he has done with the reactor during his shift period in fairly precise terms. He must also be very precișe in giving directions to co-workers as to what he wants done beçause it is such a complex operation. The operator must pay constant attention to detail. He must be certain each facet of his job is performed correctly and completely before he begins another facet because of the tremendous energies involved.

\section{ARCA 10 - Information from Printed sources}

To adequately complete his job, the operator must supplement his information from various instruments as well as from written and quantative materials such as graphs and tables of numbers and pictorial materials. There is constant use of written material in the operator's job because he must refer to operations manuals, technical specification documents, procedures; etc. He must make use of quantitative materials such as graphs and and reference materials at his disposal. There are many instances where the operator must refer to graphs or tables that describe set points for different equipment. He will often use pictorial materials such as blueprints that show diagrams of the different systems, piping layouts in order to trace the location or arrangement of different valves and components of the system so he can determine how to operate that system. Another use of pictorial materials, particularly in the modern plants, would be cathode ray tube type displays for many of the operating parameters. 
AREA 11_-Oral Communication

Because the operator is a generalist by design and nature, very often the specialists of the plant -- the technicians and engineers -- will request information on how a procedure or an operation with which they are concerned will affect the overall plant and the operator is responsible for advising the specialists as to the soundness of the procedure.

\section{AREA 12 - Supervision and Coordination of Personnel}

There is minimal observation of other people other than in a normal supervisory capacity in the operator's job. The reactor operator has the responsibility of supervising some nonsupervisory personnel, specifically, the auxiliary operator, as they work in the plant. This could include one to three persons. The senior reactor operator is responsible for supervising the entire shift, which could include from six to eight people. The reactor operator has little if any direction of supervisory personnel. The shift engineer must be a senior reactor operator and he would supervise the unit foreman who is the first 1 ine supervisor and probably also a senior reactor operator. He would in turn supervise the reactor operator on the panel. The senior reactor operatur has some supervision in this case, but it would be on the order of one to two persons. The total number of persons the reactor operator is responsible for is approximately one to three and the senior reactor operator is responsible for approximately ten persons.

\section{AREA 13 - Próblem Solving}

The operator has to use a great deal of organized reasoning in order to operate the plant. He has to take in a mass of data and reach conclusions as to how the reactor is going to respond to specific combinations of circumstances and he has to be able to recognize those situations and predict what the response will be. The operator who is actually on the control panel does a minimal amount of planning or scheduling within his job. He is assigned a job and then he has to plan how that job has to be carried out to reach the deadline established by his supervisors. The senior reactor operator does quite a bit more planning and scheduling because he has to coordinate the operations of the entire plant.

The operator must combine large amounts of information because he has a large number of instruments to monitor. Each instrument.gives the operator a specific bit of information that he has to combine and synthesize into a working hypothesis as to how the plant is going to respond. In operating the plant a situation may arise where a malfunction occurs that is not associated with the particular area in which the malfunction manifests itself. The operator must analyze all available information and data in order to determine exactly what the problem is and how to correct i.t. The operator is constantly compiling data by taking logs and recording instrument readings of the plant operation for legal records. 
AREA 14 - Nonvisual Sensory Input

Working in an environment which ranges from office to factory, the operator must make moderate use of his sensory perceptions. In order to determine if equipment in the plant is operating properly, the operator must use senses other than visual. He uses touch to determine whether a bearing is operating hot or not and to determine if vibration exceeds normal, expected levels. He does not need to have an olfactory sense as a prerequisite for his job but he uses this sense to detect changes in plant conditions, such as a fire by detecting smoke. The operator is constantly attuned to a normal sound pattern in his environment and when it changes he should be able to detect that change and be alerted to investigate that some plant condition has changed. A turbine will change pitch when a load is added or removed from the turbine and the operator is sensitive to this pitch as well as the general sound patterns. He must be constantly on guard as he walks through the plant for any changes in his sensory environment. The operating environment of a nuclear power plant control room is relatively quiet; however; the plant itself has areas which range from very noisy to moderately noisy. There is considerable exposure to noise intensity but only in a few areas is the intensity extremely high.

An operator is required to crawl into all sorts of different areas of the plant in order to operate valves that may be in very unreachable areas, and a good sense of balance: is needed by the operator because he may be fifty feet in the air on a ladder in order to operate a hard-to-reach vaive.

\section{AREA 15 - Peripheral Observation}

The operator uses various types of measuring devices relatively frequently. in performing certain aspects of his job. He frequently uses rulers to work with nomographs or he will use contact thermometers to determine the temperature of bearings. ine operator also uses mechanical devices on a moderate basis. He is concerned with the instruments on the control panels. He observes level floats, level instruments that float and through mechanical leakage give the operator a level reading. He also uses ball-lype rlowmeters which indicate the flnw of a liquid or qas. Other instruments would be slide rules or calculators.

\section{AREA 16 - Physical Coordination}

The amount of body coordination, including hand/arm steadiness, eye/hand coordination, and limb movement necessary to perform the job of nuclear reactor operator is moderate. Hand/arm steadiness is necessary, in the operator's job but at a rather low level: He will operate some continuous controls by turning knobs and dials very carefully. The operator needs a moderate amount of eye/hand coordination. He watches instruments and controls tuning and settings on the controller without looking at the controller itself. He will be looking at other instruments so he has to. be able to recognize a change with 
his eyes and respond to that by manipulating the controls with his hands. There is very. little call for limb movement without visual control in the operator's job. In fact, an operator should never reach for a control without looking because there are so many controls he could easily make an adjustment on the wrong one.

\section{AREA 17 - Job Environment}

The physical environment of an operator is varied, ranging from the controlled environment of the control room to the general environment of the plant. Since a large part of the operator's time is spent in the control room of the plant, surrounded by delicate instruments, a great deal of his physical environment must, of necessity, be controlled. There is very little fluctuation in the temperature of the control room. There must be no air contamination to cause the instruments to wear and vibrations must be nonexistent to ensure the accuracy of the instruments and dials. The only periods of time for fluctuations in the operator's environment are the times he must be in the plant. There are areas in a power plant where the temperature would reach $120^{\circ}$ to $130^{\circ}$ because of the high temperature steam being used. The operator would be required to enter these areas on an infrequent basis. Operators must also check the position of valves or the condition of tanks located outside the plant. In the colder climates the operator would be exposed to low temperatures while completing these tasks.

An operator is subjected to the possibility of encountering radioactive contamination in the air but it is very unlikely this would happen. There would be very little other smoke or toxic fumes which would be encountered in operating a nuclear plant. Valves may be located in inaccessible areas in a plant that are rather poorly illuminated. An operator will normally carry a flashlight with him at all times since he may have to work in those areas. Because these valves may be located in inaccessible parts of the plant, a small amount of the operator's time is spent in awkward or confining work spaces. 


\section{Appendix $E$}

\section{LIST OF MALFUNCTIONS EXPERIENCED AT PWR POWER PLANTS}

Data on specific malfunctions that have occurred at nuclear power plants are recorded on Licensee Event Reports (LERs) that are subsequentiy filed with the ORNL Nuclear Safety Information Center. For this study the Center made over 20,000. LERs. available, but only about 3000 could be analyzed. For consistency, the data used were obtained from occurrences during a six-month period. The resulting list of malfunctions that were experienced at PWR plants during June through December, 1978, is presented in this appendix. 


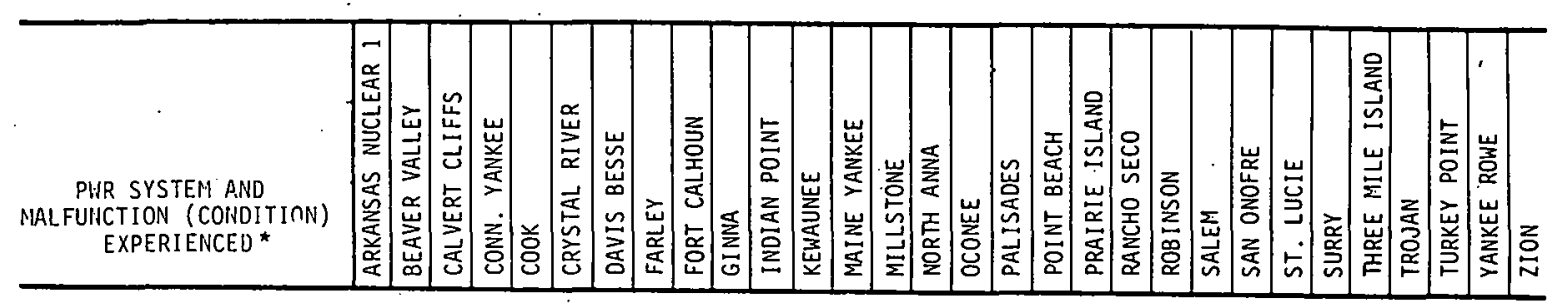

REACTOR COOLANT

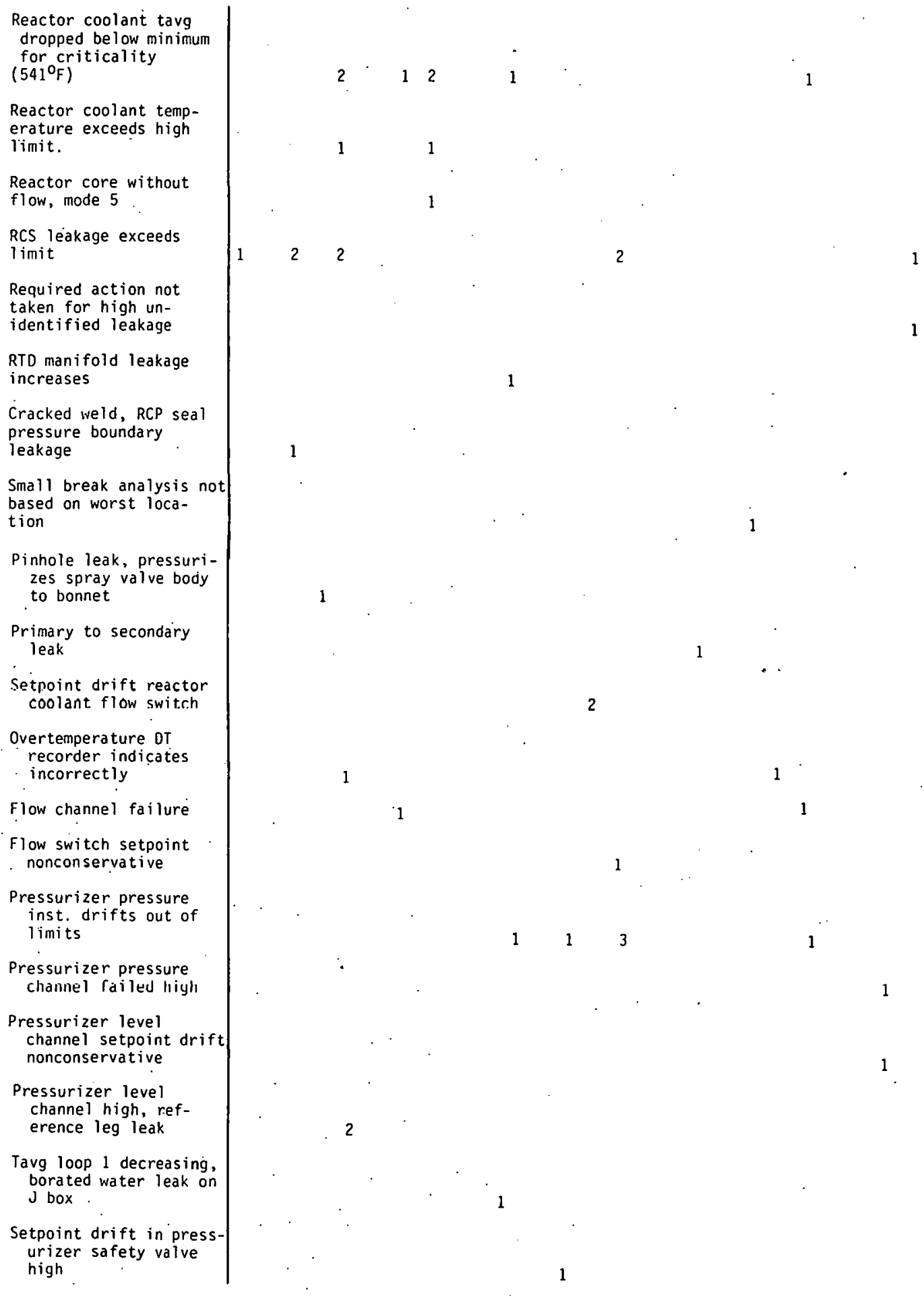

*See Appendix I for definitions of acronyms. 


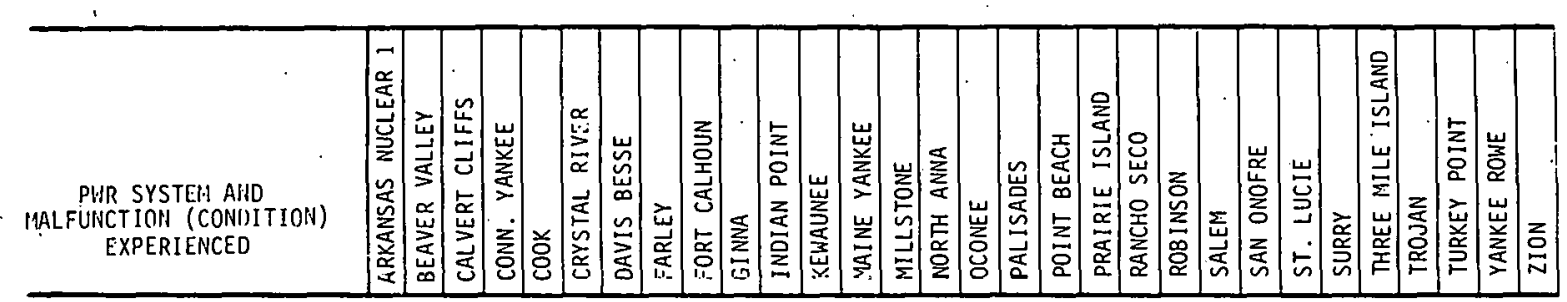

REACTOR COOLANT (cont.)

Pressurizer safety vaive
temporarily gaged
RCP seal failure not
determined
Loop stop valve relief
line flow interlock
setpoint low
Loop isolation valves
not electrically dis-
connected as required
Peak RCS pressure, FW
line break, might
slightly exceed max-
imum allowable
CV for new pressurizer.
relief valves less
than specified, re-
duced relieving cap-
acity
Reactor vessel weld
material deficiency
RCS pressure decrease,
partially open spray
valve
RCP surveillance not
completed, cumputer
trend block not re-
instated
RCS pressure low
limit exceeded
CoMPONENT cooling waTER
Heat exchanger leak to
onvironment
Pump surveillance not
nerfnrmed
Valving abnormalities
performed
Pump bearing failure,
seizures

CIRCULATING WATER - SYSTEM

Water inlet temperature exceeds iomit

Water outlet value fáilure

Chlorine residual exceeded limit 


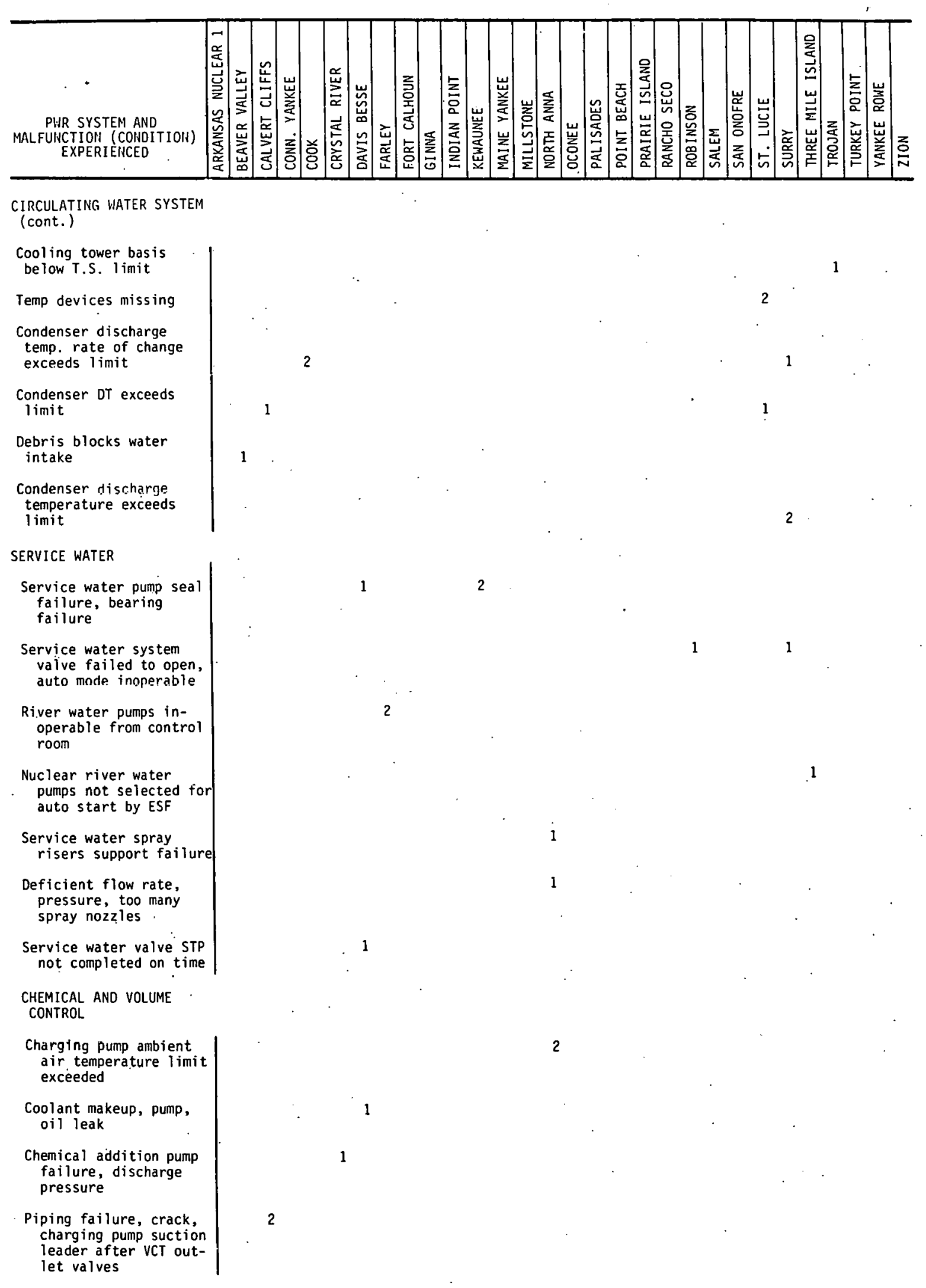




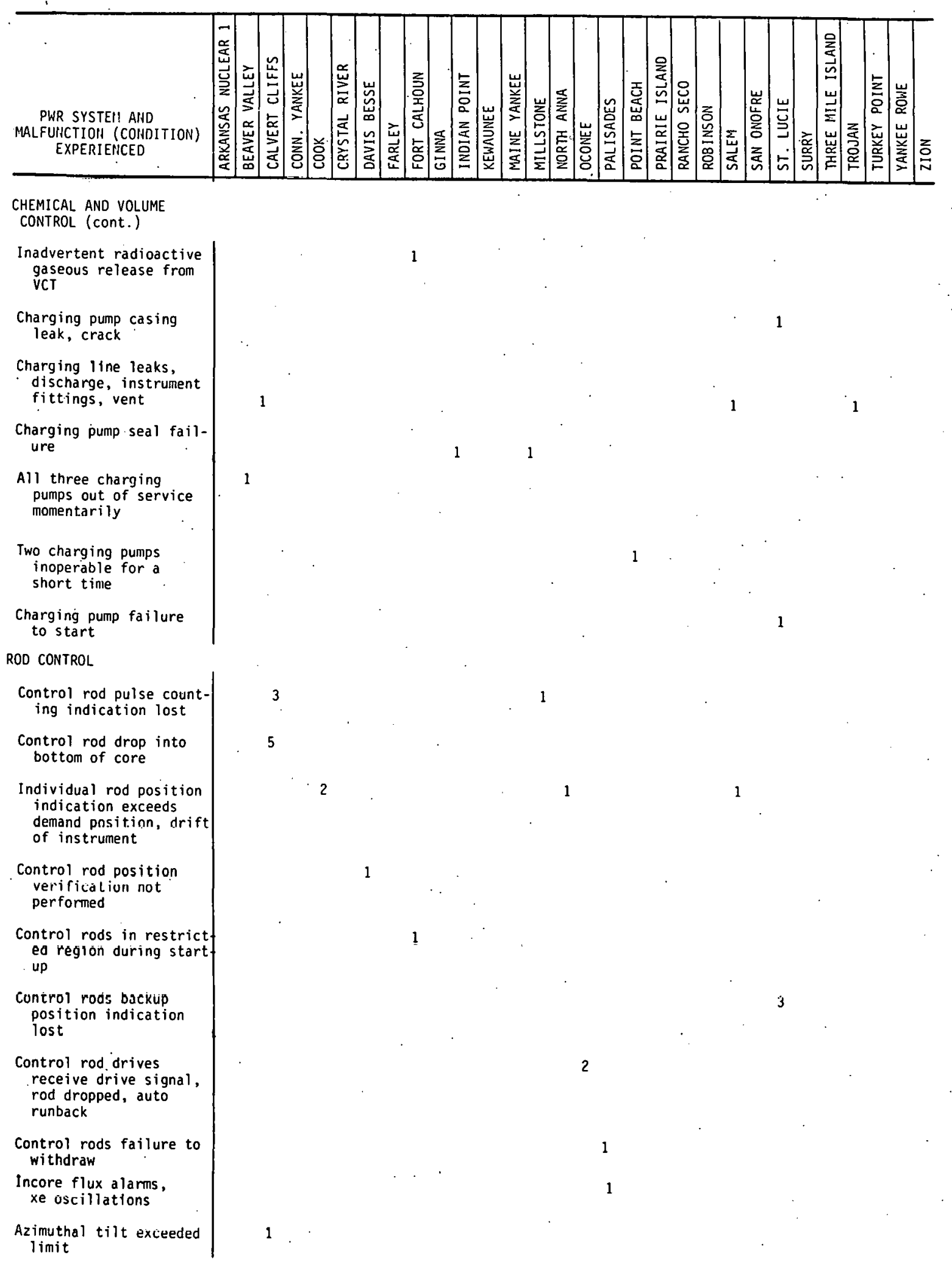




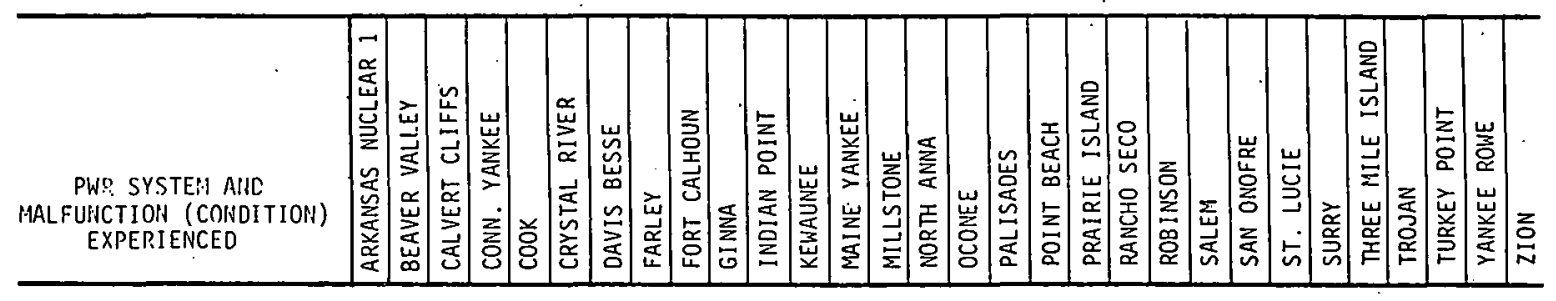

ROD CONTROL (cont.)

Quadrant power tilt exceeded limits

Axial flux difference

outside of target.

band, exceeded limit

Asymmetric power alarm

Radial flux tilt

exceeded limit

FUEL HANOLING
Aux. bldg. equipment
access door open
during fuel handling
Crane hook failure while
moving test weight in
spent fuel pool
Spent fuel pit cooling
pump mechanical
failure.
Incorrect fuel assembly
loaded into core
Unplanned reactivity
insertion, auxiliary
switches on handling
equipment, control rod.
withdrawal

ELECTRICAL DISTRIBUTION

RCP undervoltage relay damage

Battery charges output bkr. trips

Battery cell termina? failure, test

Battery surveillance not performed on time.

Battery failure to meet design criteria, electrolyte

Loss of two off'site power sources, lightning

Loss of startup transformers, $2 / 4$ 120VAC vital buses, DG load on busES, sequences failure to start charging pump, RNR pump not started, SI
1

1

2
1

1 
PIIR SYSTEM AND MALFUHCTION (CCNDITION) EXPERIEIICEO

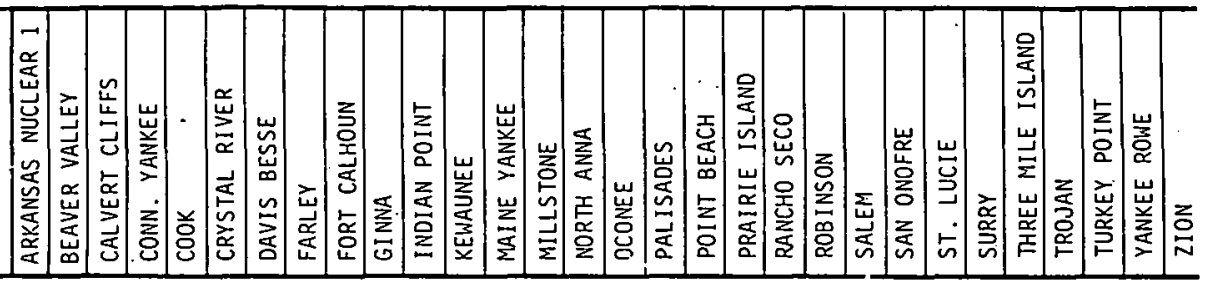

ELECTRICAL OISTRIBUTION (cont.)

Main transformer single phase failure, all RCP trip UF, is DG

failure, manualiy flashed

Startup transformer breaker trip

Auto transformer trip, timed overcurrent two units

Loss of onsite $A C$, auto transformer lockuul, inverters failure

Vital buses inverter failure, automatic decay heat removal isolation

Momentary loss of $480 \mathrm{VAC}$ MCC, ESF auxiliaries

1

Inverter failure, loss of vital bus, SI, open $A C$ breaker test

Undervoltage relay, $6.3 \mathrm{KV}$ bus actuation out of limits, nonconservative

$13 \mathrm{KV}$.breaker trip, scram, feed pump trip

Instrument inverter failure

Battery racks improperi.y installed

STTEAM GENERATOR BLOWOOWN

Stean generator blowdown rate exceeded

S. G. blowdown isolation valves time not checked, surviellance

MERGENCY DIESEL

GENERATOR

Output breaker automatic closure failure

Output breaker manual closure failure

Output breaker trip

when closed 


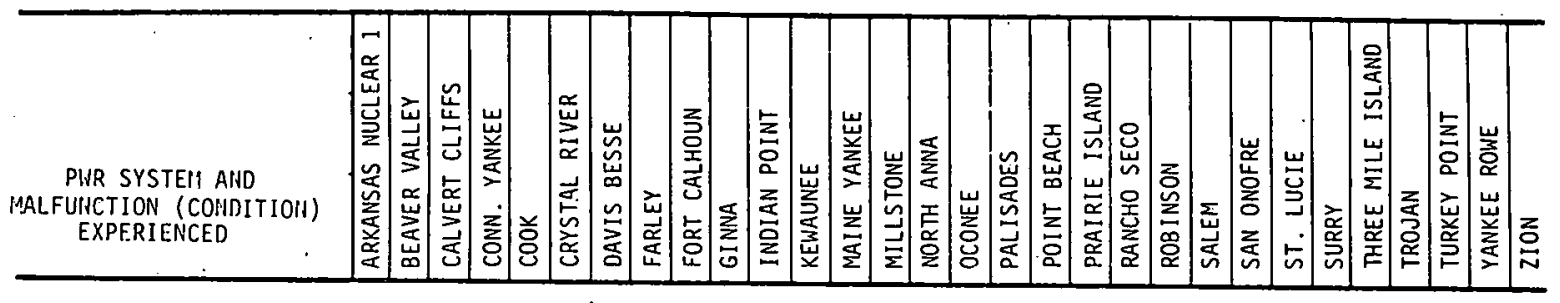

EMERGENCY DIESEL

GENERATOR (cont.)

Diesel generator inoperable, tagging and not testing

Both diesel generators inoperable simultaneously

Failure to start, lack of fuel to injectors

Failure to start, control room inability

Faiture to start, fuel linkage bound

Failure to start, air pilot failure

Inoperable for maintainance, improper approval, not tested

Inoperable, inverter fai Ture

Loading sequence failure

Failure to start, manual, auto

Speed and voltage regulation failure

Diesel generator trip. coolant temperature high

Overspeed trip

Possibie speed adjustment urublem

Load decrease

Load limit loading fajlure

Delayed loading, excitation fuses blown

Air start valve stuck open

Starting air pressure low

1

Diesel lube oil cooler service water leak

Jacket water coolant leak, test fitting failure

Diesel fuel leak, injector 


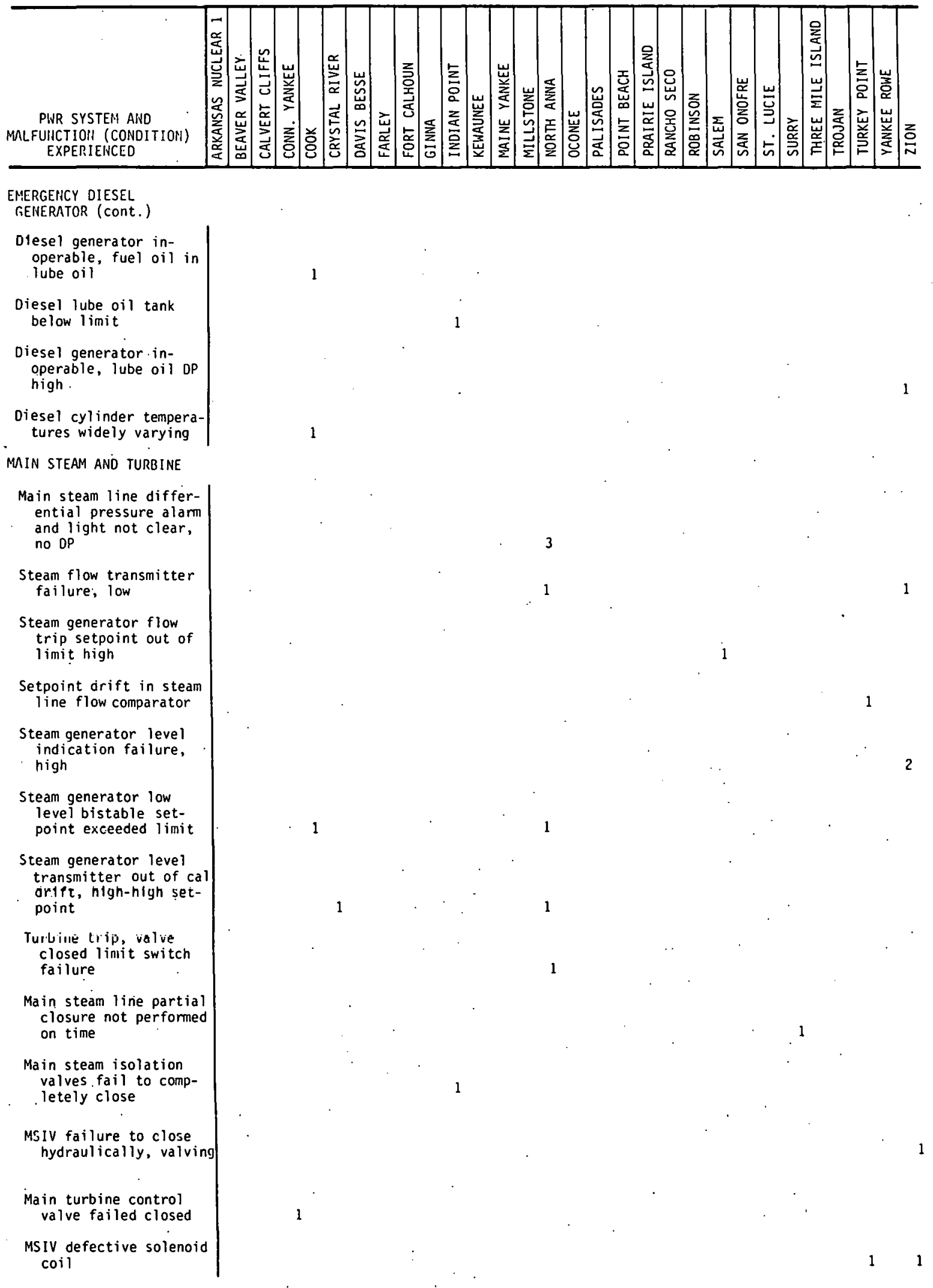




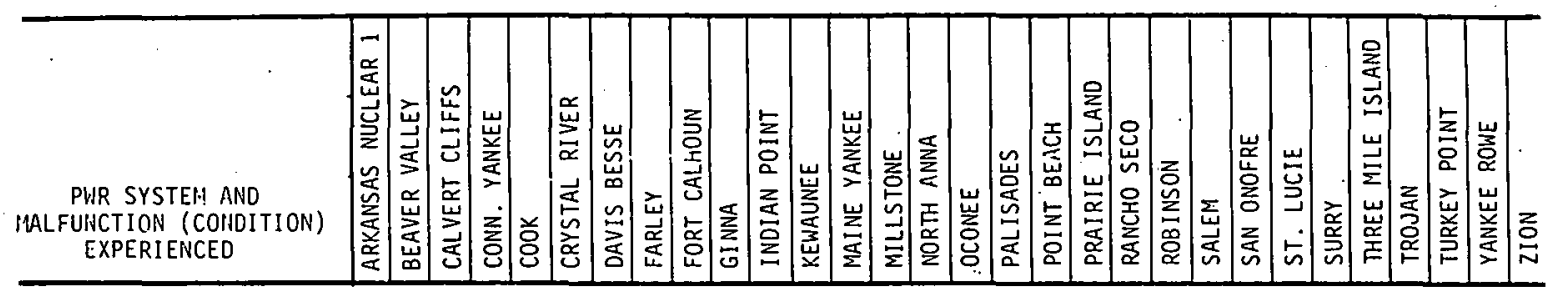

MAIII STEAli MID TURGIHE (cont.)

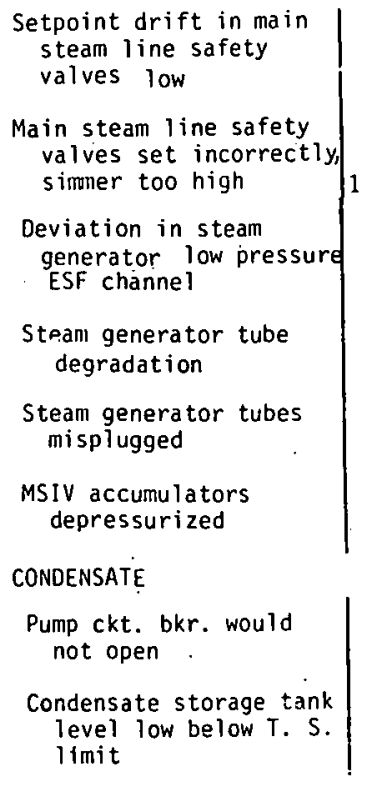

\section{FEEDWATER}

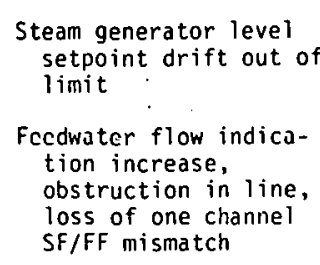

Feedwater flow switch setpoint high above i imit

Feedwater stop valve breakers open, not reclosed after test

Feedwater flow fails low

Main feedwater isolation valves not time tested

AUXILIARY FEED WATER

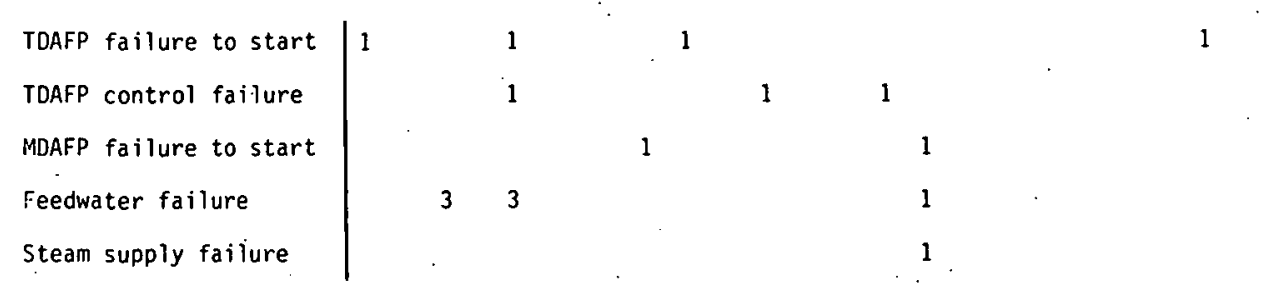




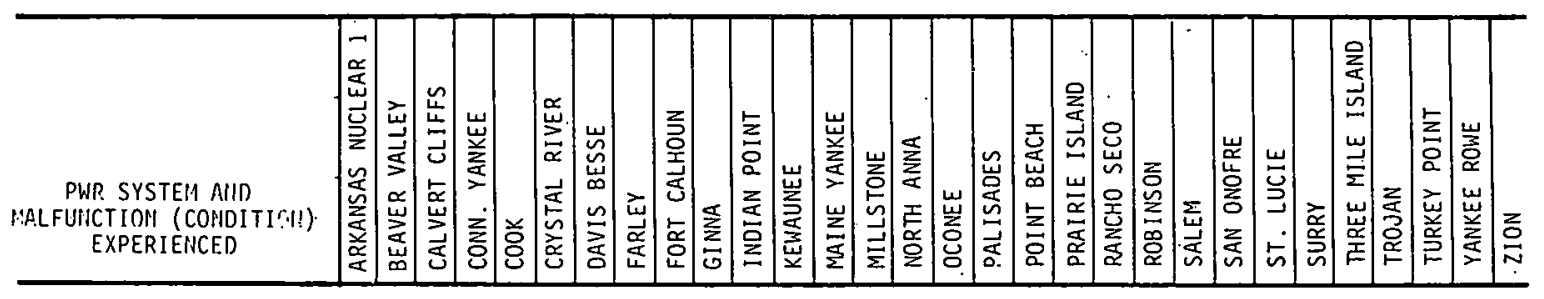

NUCLEAR INSTRUMENTATION

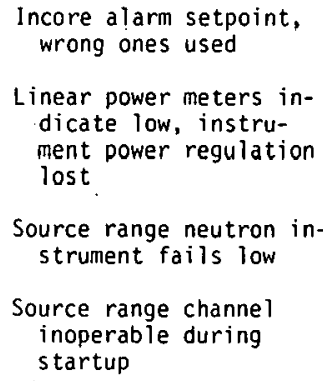

Linear power meters indicate low, instrument power regulation lost

Source range neutron instrument fails low

Source range channel inoperable during startup

11

Both source range channels lost simul taneously

Axial power distribution out of limits

APDMS nonconservative data, rounding of $f$ data, $F$ as a function. of cose height

Setpoint drift in APDMS actuation point

One of timed APOMS surviellanceses missed

Indicated quadrant power tilt exceeds 1.02

Power range detects placed in tripped

Power range channel removed from service

RESIDUAL HEAT REMOVAL
RHR pump excessive sea? leakage

Both RHR pumps inoperable, air bound, primary drained

Decay heat flow lost for shnrt. time

Decay heat cooler outlet valve inoperable

RHR pipe leak, between cont. iso valves and pump

RHR pump suction valve time exceeded limit

1

2

2 
PWP SYSTEM ANO MALFUIICTION (CONDITION) EXPERIENCED

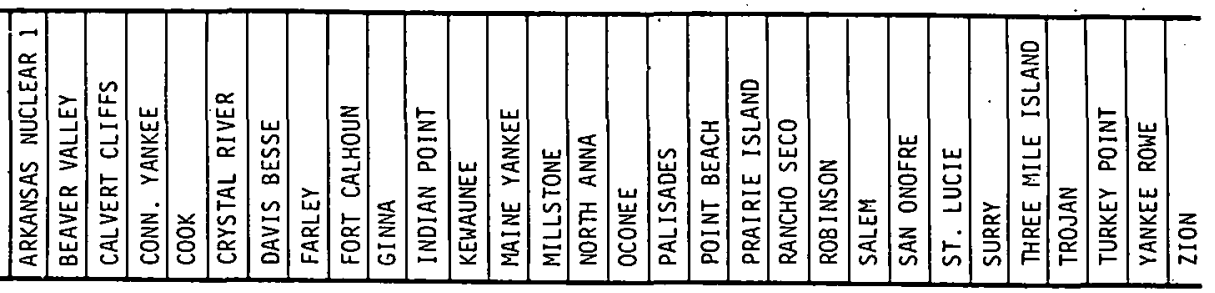

PLANT CHEMISTRY

S. G. Chlorides out of limits

RCS Chloride out of limits

Iodine indication of failed fuel clad

PLANT VENTILATION

Control room ventila-
tion damper failure tion damper failure
test, ESF signal

Control room air conditions compressor or components failure

Iodine filter bank operation coil failure to change position

Methyl iodide removal efficiency low on charcoal filter train

Excess filter penetra$t i o n$ of penetration room filter, limit, gas treatment

RCFC accident inlet dampor failuro

RCFC auto start low speed failure

Fan coil unit discharge to dome damper failure

Flapper valve out of floor drain, possible shield bidg. integrity Jrawdown requirement

Shield bldg. ventilation failure to draw measurable vacuum in annulus, STP

Aux. blid, ventilation reversed

Hydrogen skimmer fan failure to start in. required time, drift

Hydrogen purge system trip during run

Containment fan coil unit motor cooler leak

Containment air recirc. fan surveillance not completed on time 


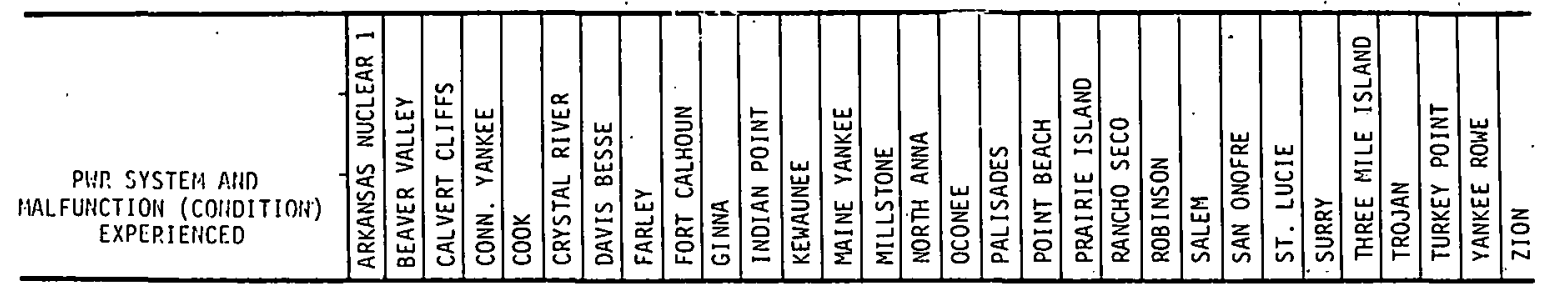

WASTE DISPOSAL

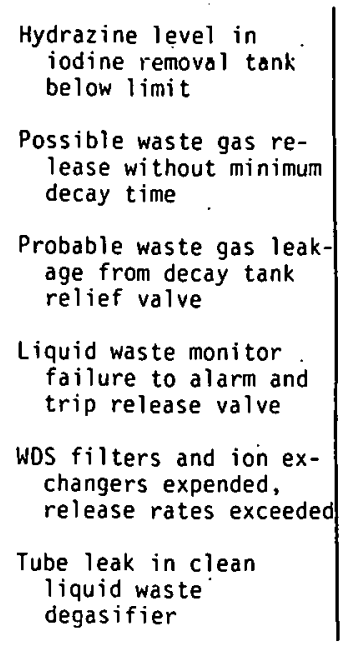

CONTAINMENT

Cable splices
Containment casing cool-
ing exceeds linlit
Containment casing cool-
ing inoperable
Containment casing cool-
ing surveillance
Isolation failure,
valves sticking, in-
operable
Isolation failure,
valves leaking
Isolation failure,
surviellance
Isolation failure,
Phase A
Seismic recorder,
detector inoperable
Containmenl leak tests
Containment, reactur
building pressure
Air lock surveillance
Air lock leakage excess-
ive




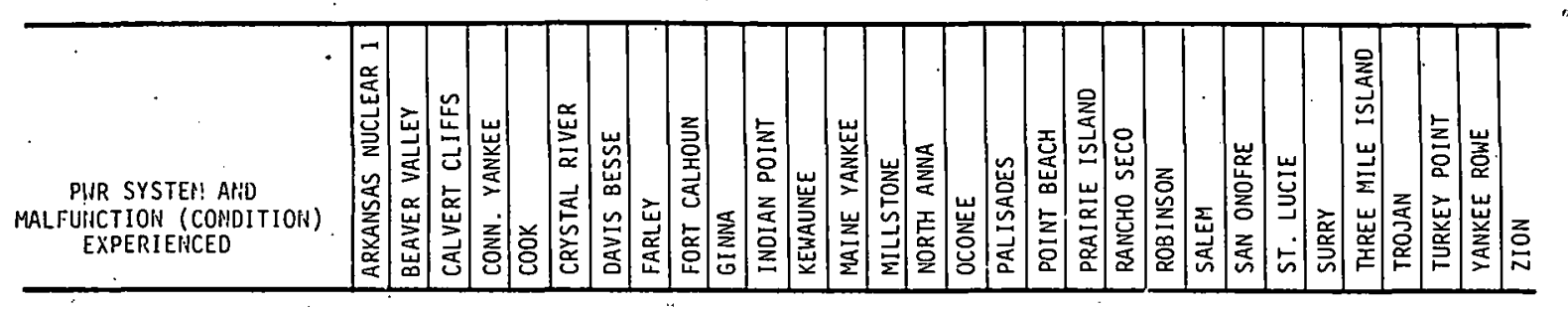

CONTAINAENT (cont.)

\section{Air lock inoperable, or broken interlock \\ Vacuum relief inopera- able, leak \\ Ice condenser inlet doors, not opening \\ Containment pressure exceeds limit \\ Containment spare penetrations, FSAR barrier \\ Containment leakage monitoring inoperable. pumps inoperable \\ Isolation, steam and feedwater rupture system trip \\ Containment sump isola- tion valves leakage}

\section{RADIATION MONITORING}

Two containment channels fail, high ambient temperature, post accident monitors inoperable

Containment vesse] post accident rad. monitor failure

Containment particulate and gaseous monitors f1lters and charcoal

filters clogged, drive mech. jammed

Fuel bldg. area radiation monitor failure

Containment purged with high rad. signal to iso. values bypassed

Conta inment. a tmosphere grab samples not

taken, pipe tunnel.

vent stack exhaust

monitor out of service

Containment particulate

monitor reads off

scale, failed low scintillator

Containment air sampling valve shut
3

1

1
1
4

1 
PUR SYSTEH AIIO MALFUIICTION (COIDITION) EXPERIEIHCED

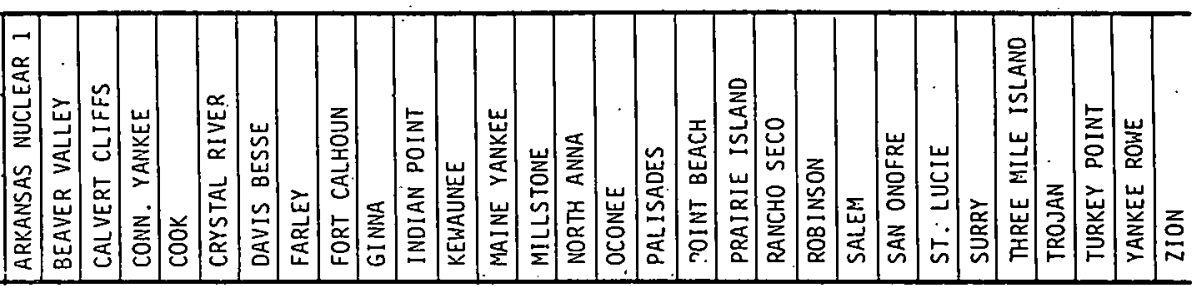

RADIATION MONITORING

(cont.)

Vapor containcr air particulate monitor failure, pump inoperable

High range rad. monitor failure

Primary vent stack monitor failure

Pipe tunnel passive gas monitor inoperable

SG rad. liquid monitor inoperable

CCW rad. monitor not responding to check source

REACTOR PROTECTION

Reactor protection trip unit failed in tripped condition

Reactor trip breaker failure to open immediately

Setpolnts noncunservative, pressurizer pressure, SG pressure

Setpoint drift, steam feedwater flow inst muttiplier divider card.

False temperature signal scnzed by protection channel

EMERGENCY CORE COOLING

Boron injection tank
concenlration below concein

Boron injection tank, boric acid storage tank concentration too high

Boron injection tank recirc. valve failure

Boric acid supply from lánks tú boric acid punips isolated

Boron injection flowpath throttle valves out of position 


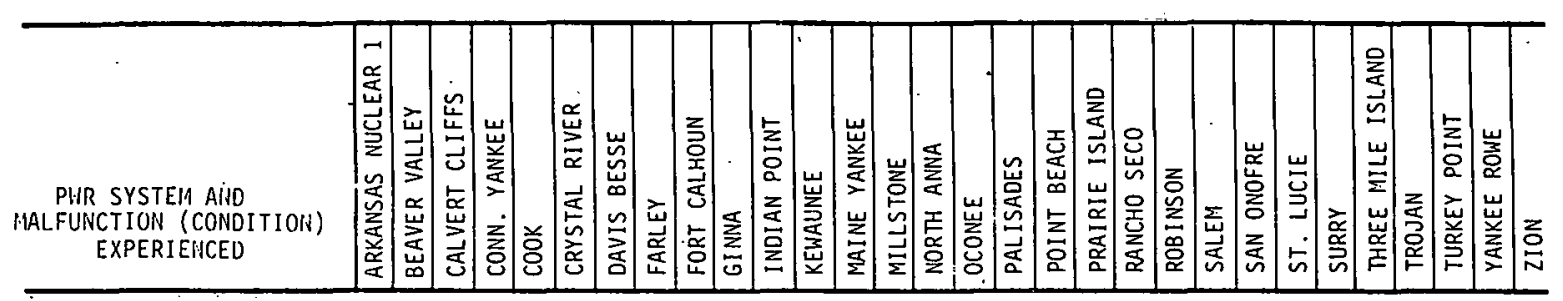

\section{EMERGENCY CORE COOLING} (cont.)

Boron injection tank operability survejl. lance not perfomiled

Heat tracing ckt. for BIT low

1

Redundant heat tracing failure, blender and emergency borate

Boric acid to blender blocked

Redundant BIT bypass heat tracing ckts faults

Containment recirc sump to CTS pump loss of suction

Both containment spray pumps out of service

Containment sump valve failure to open

Containment spray headers orifices not installed

Containment spray pump failure to start

Containment spray pump auto start failure

Diesel containment spray pump made inoperable. redundant train not t.ested

RWST level alarm drift

RWST level below limit

Ice condenser inlet doors monitoring inujeràble

RWST boron concentration low

Feedwater SI pumps valve to RWST opened

Suction valves from RWST failed to open

Hydro pump to accumula- tors pressure failure RWST bypass ESF failure 


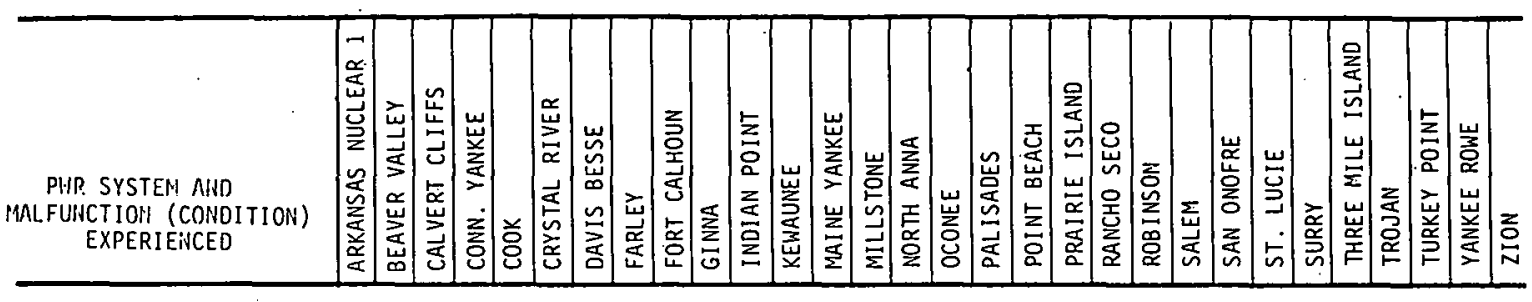

EMERGENCY CORE COOLING

(cont.)

Recirc. mode value lowhead SI to RCS failure to open

ESF sequence timer failure

Safety injection actuation relay setpoint drift

LOCA blowdown analys is error

Lubricant un valve seál co:t*zinment spray

Two charging pumps out of service

Low head SI header manual valve will not close

Core flood tank volume below limit

Cure fluod tank vent failure

Core flond tarik level setpoint drift

1

SI check valve leakage

High pressure injection pump mounting bolts lúsé

Safety injection and rapid depressurization of KLS by opened nower relief, depenerg ized vital bus

Safety injections pressure channel failure to trip

SI tank level exceeds high limit

SI tank filled to above the high limit

SI tanks boron concentration too low, below limit

Accumulator level indication low

1

Spray additive sodium hydroxide level exceeds low linit 


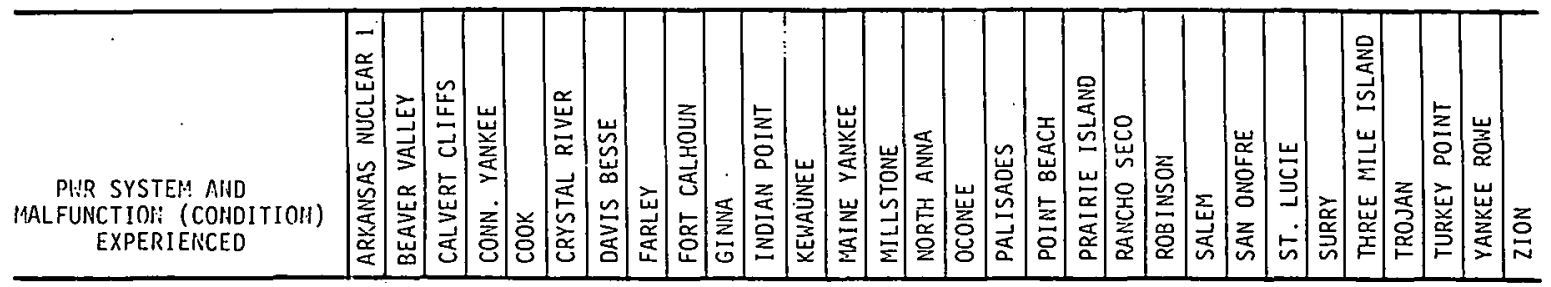

MODE STATUS REQUIREMENTS.

Mode change, 4 to 3 ,
without completion
of required tests
Miscellaneous valve
quarterly tests not
performed as required
Valves leakage exceeded
limit
Loop seal rad. monitor
low, high voltage
drift
drift

Nuclear power and river $\Delta \mathrm{T}$ surveillance not performed

Temporary change sheet not approved as required

MuP lube oil pump backup pump failure to start

EMERGENCY PLAN

Wind stability determination not made, temperature $\Delta T$ sensor failure

Peak shock annunciator alarm, recording scribes operable

Seismic monitoring calibration exceeds time limit

FIRE

Diesel fire pump failure

Motor driven fire pump inopcrablc

Diesel fire pump failure to start

Diesel fire pump starting pressure switch setpoint below limit

1.

Fire pumps in manua? operation, inoperable in auto, low control air to deluge valves

Fire suppression system inoperable, outside fire hydrant modification

Fire barrier seals lacking

1

1

1 


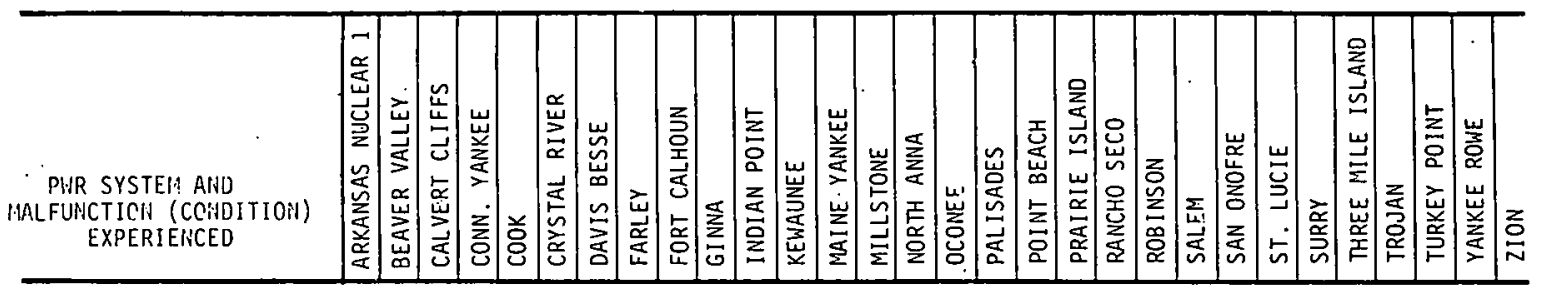

FIRE (cont.)
Fire watch not continumed established

fire protection valve buried

Combustible duct seal compound

Halon bottles below

minimum allowed weight

Break in fire main, isolation

Hose cabinet not relocated when hydrant moved
1
1

1 


\section{Appendix F}

\section{LIST OF MALFUNCTIONS EXPERIENCED AT BWR POWER PLANTS}

Data on specific malfunctions that have occurred at nuclear power plants are recorded on Licensee Event Reports (LERs) that are subsequently filed with the ORNL Nuclear Safety Information Center. For this study the Center made over 20,000 LERs available, but only about 3000 could be analyzed. For consistency, the data used were obtained from occurrences during a six-month period. The resulting list of malfunctions that were experienced at BWR power plants during January through June, 1978, is presented in this appendix. 


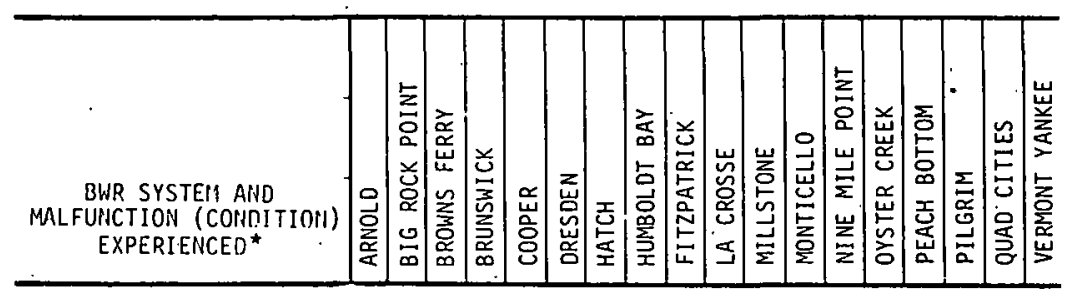

REACTOR COOLANT

Recirc. pump TRP (Actual)

1

Recirc pump instrumentation out of spec

1

RWCU system failurecomponent mech/inst

RWCU system failure piping failing rup-

Core flow units

(instrumentation) out of calibration

Heat-up/cool-down rates exceeded

Pressure relief valve

failed-valve set point 1

Pressure relief valve fails open-actual

Pressure relief valve fails due to metal fatigue

1

1

Reactor pressure instru mentation inoperable

Reactor water level instrument failure

Coolant leaks due to piping failure

Jet pump failureinstrumentation

SERVICE WATER

Service water failure

11

2

Discharge temperature excessive

STANDOY LIOUIO CONTROL

System inoperative-

valve alignment

System inoperativevalve failure

SLC pump pressure relief lifted-set point drift

*See Appendix I for definitions of acronyms. 


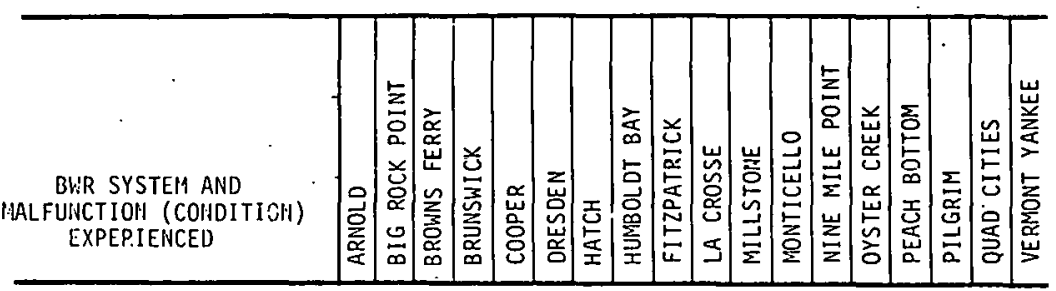

STANDBY LIQUID CONTROL

(ront.)

Leak rate limit exceed

Failure to test SLC

puinps

REACTOR CONTROL

Control rod drive
piping cracked
Control rod drive
accumulator inop.
Control rod inoperative
Scram discharge volume
isolated.
Rod sequence control
systenl test not done
Rod worth minimizer
continuously bypassed
Critical power ratio
exceeded
Reload anaiysis null-
conservative

Fuel pin cladding degraded

1

1.

4

1

1

ELECTRICAI.

Station batteries out of service

Insufficient voltage for postulated accidents

Loss of off site power

Transformer degradation

Electrical connections fail

Surveillance not completed on time

Breaker failure (breakers of $4 \mathrm{kv}$ or less)
$2 \quad 1$

2

2

1

2

1

1
1

1

1 


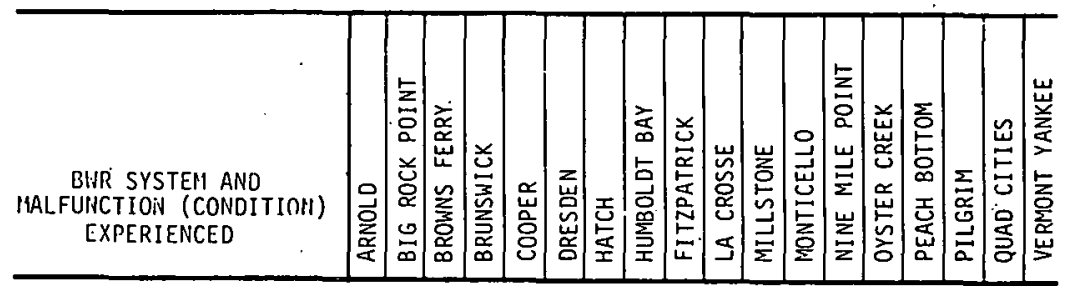

DIESEL GENERATOR

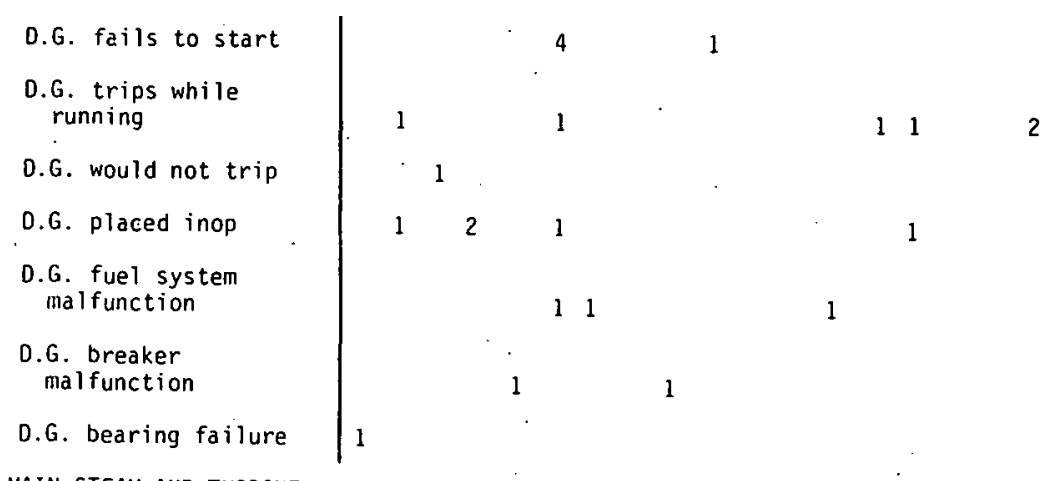

MAIN STEAM AND TURBINE

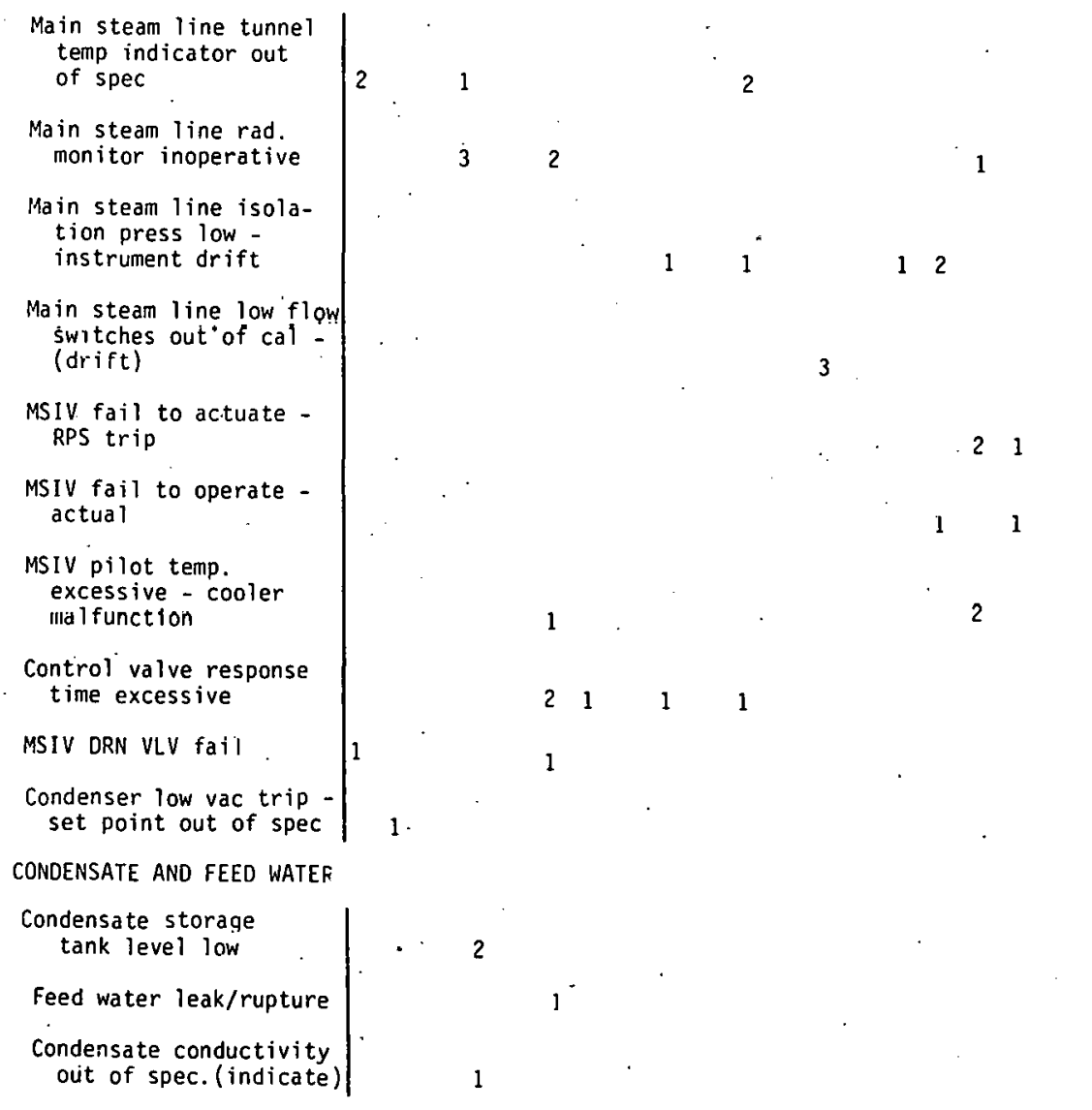




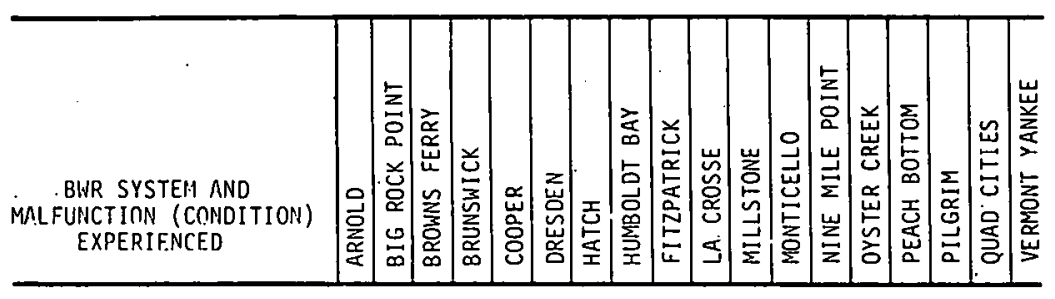

NUCLEAR INSTRUMENTATION

IRM set point out of
calibration (drift)
Excessively high period
APRM out of calibration
IRM failed during
start-up
SRM failure
Rod block monitor
failure (drift)
LPRM instrumentation
failure (drift) -
APLHGR exceeded
APRM instrument failure
(drift)
APRM instrument failure
TIP system failure -
mechanical failure
TIP system failure -
ilistiuntit failule
(drift)

WASTE DISPOSAL

Radioactive spill

Radwaste discharye válvè fails to trip

Non-conforming bolts on shipping cask

3

1

2

1

2

1

1

1

1

$1 \mathrm{i}$

\section{1}

1

1

RADIATION MONITORING

Reactor building vent
mnnit.or innperative

Area radiation monitors failed

CONTAINMENT

Cad.tank level out of
spec

Toris level out of spec (indicated)

Torus level out of spec (actual) 


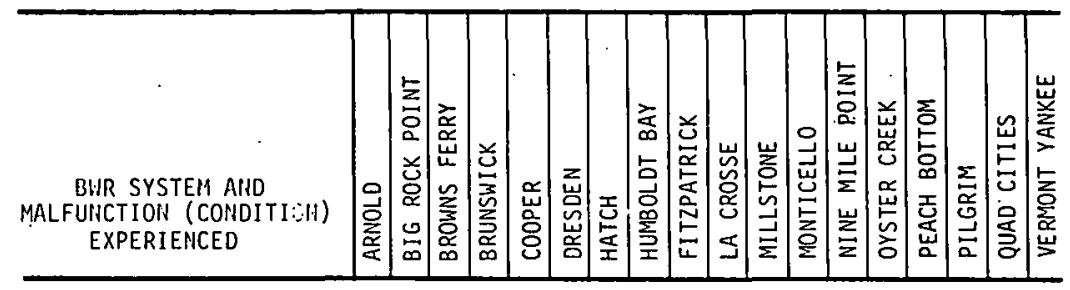

CONTAINMENT (cont.)

Torus to dry well vacuum BKRS malfunction

$$
.2
$$

11

1

Torus to R. B. vac BKRS malfunction

Containment integrity violated/broken

Containment oxygen/. hydrogen out of spec (indicated)

Results of leak rate testing out of spec

Dry well pressure out of spec (indicated)

Containment atmosphere rad.llonitors fail/inop

Primary containment isolation valves fail/inoperative

2

Water leakage in drywell out of spec (actual/indicated)

Containment isolation valves/components inadequate for postuiated accidents

Set points out of limits on containutent . (non-conservative)

Surveillance not com. pleted when required

CONTROL BUILOING

VENT ILATION

Control building emergency ventilation fails to start

Control building

standby filter unit failure

3.

2

OFF-GAS

Duarterly limits exceeded -gaseous release

Stack monitor inop $\mid \begin{array}{lllll}1 & 2 & 1 & 1\end{array}$ 1

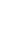




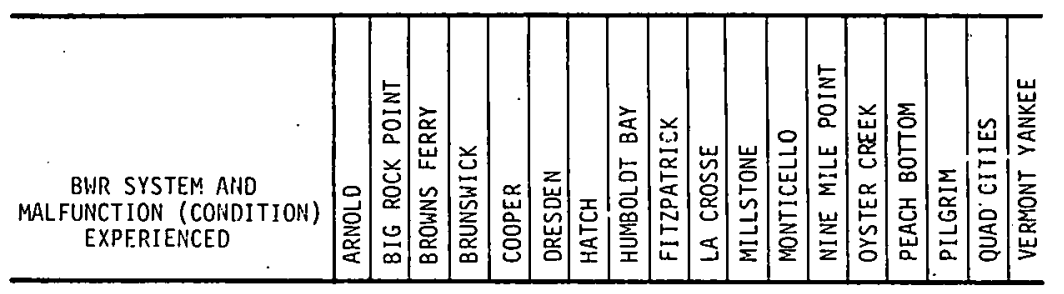

OFF-GAS (cont.)

SBGT system failure
SBGT not tested within
specified time frame
Off gas hold-up system
due to piping failure
SJAE failure to isolate
SJAE monitor failure
Off gas line leaks/
ruptures

EMERGENCY CORE CCOLANT -CORE SPRAY

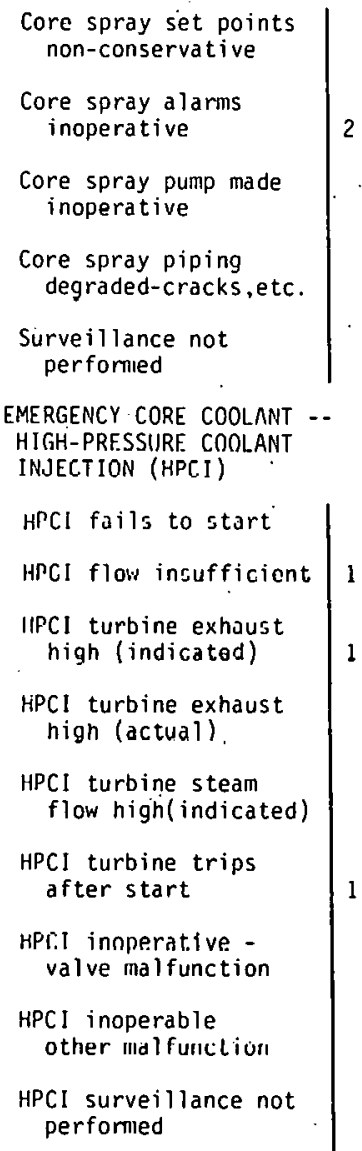

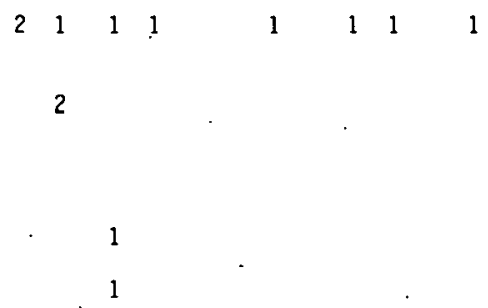

1 


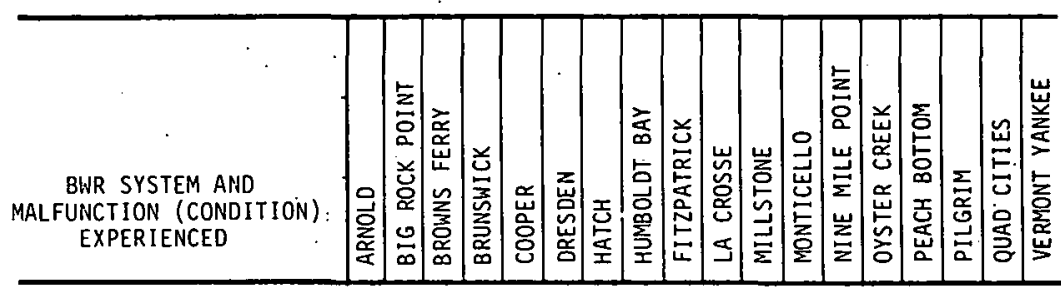

F.MERGENCY CORE COOLAIT --

HISH-PRESSUPE CONLANT

IN.IECTION (HPCI) (cont.)

HPCI area temp high .actual

HPCI area temp instrument malfunction

EMERGEHCY CORE COOLANT --

LOW-PRESSURE CCOLANT

IN.IECTION (LPCI)

LPCI inoperativevalve malfunction

LPCI pump start logic inoperative

LPCI inoperativeinstrumentation failure

EMERGENCY COPE COOLANT -ISOLATIOI COHDENSER

Isolation condenser
inoperative-valve mal function

I solation condenser level' low

Isolation condenser

level high.

EMERGENCY CORE COOLANT --

REACTOR CORE ISOLATIOH:

COOLING ' RCIC)

Turbine speed crratic

Turbine trip

stem line area temp high

RCIC inoperative (valve failure)

Turbine exhaust instrument failure

Turbine trip instrumentation inoperative

RCIC leaks

Auto initiation logic failure

RCIC steam line high flow (indicated)

2111

2

1

2

11

1

1 


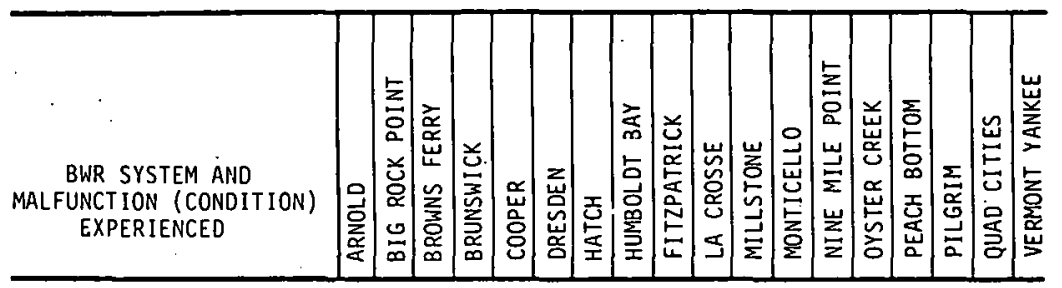

EIIERGENCY CORE COOLANT --

P.ESIDUAL IIEAT REHOVAL/

SHUTDOINI COOLING

RHR instrumentation failure

RHR system inoperativevalve nalfunction

RHR piping cracked

RHR system inoperativeother

RHR service water pump failure

FIRE PROTECTION

Fire doors/dampers improperly installed

Fire detector failure

Fire pump slow response. equipment

\section{$\begin{array}{lll}2 & 1 & 1\end{array}$} 2

System inoperative pump failure

Heat detector panel inoperative-electrical

Fire inspection not performed

Inadvertent $\mathrm{CO}_{2}$ system artuation ins trument

2

33

Fire pump inoperativebattery failure

Fire pump inoperativema intenance

I

1

\section{3}

2 
Appendix G

\section{CLASSIFICATION OF PWR MALFUNCTIONS BY PROPOSED SCREENING METHOD}

In Chapter 5 of this report procedures are offered.for selecting the most important equipment malfunctions for simulation during operator training programs. To illustrate the procedures, we have applied them to a group of typical malfunctions gathered from LERs and other sources. In each case. the malfunction is ranked in the following four areas:

A. Whether it constitutes a safety-related event.

B. How frequentiy it occurs.

C. Whether it is a safety-related precursor.

D. Whether it results in significant plant outage.

A numerical evaluation is given to each of these categories, and their sum is identified as the "importance factor" for the malfunction. The maximum importance factor possible is 27 .

This appendix presents the results of applying the proposed procedures to PWR malfunctions. The frequency of occurrence given in the third column represents the number of such events per reactor year of operation for all PWRs based on a six-month operating period in 1978; the information listed in the fourth column (as $x / y$ ) indicates the number of simulators surveyed that simulate. that particular malfunction $(x)$ and the total number of simulators included in the survey at the time the analysis was completed for that malfunction $(y)$; and the fifth column indicates whether the malfunction represents an event that must be analyzed in salety analysis reports. (For additional information, see Chapter 5:) 


\begin{tabular}{|c|c|c|c|c|c|c|c|c|c|}
\hline \multirow{2}{*}{ NO. } & \multirow{2}{*}{ PWR SYSTEM, MALFUNCTION (EVENT) * } & \multirow{2}{*}{$\begin{array}{c}\text { FREQUENCY } \\
\text { OF } \\
\text { OCCURRENCE }\end{array}$} & \multirow{2}{*}{$\begin{array}{l}\text { CURRENTLY } \\
\text { SIMULATED }\end{array}$} & \multirow{2}{*}{$\begin{array}{l}\text { ANALYSIS } \\
\text { REQUIRED }\end{array}$} & \multicolumn{4}{|c|}{ JUSTIFICATION } & \multirow{2}{*}{$\begin{array}{l}\text { IMPOR- } \\
\text { TANCE } \\
\text { FACTOR }\end{array}$} \\
\hline & & & & & A & B & C & 0 & \\
\hline
\end{tabular}

REACTOR COOLANT (A11 HodeS)

1. Average temperature $\left(T_{\text {avg }}\right)$ below minimun acceptable for criticality avg

Channel $T_{\text {avg }}$ failure high

Channel $T_{\text {avg }}$ failure low

Average temperature ( $T_{\text {avg }}$ ) high limit exceeded,

large deviation at full power

5 Overtemperature $\Delta T$ indication in error

$6 \quad$ Reactor $\Delta T$ limit exceeded, $\Delta T$ trip setpcint calculation in error

7 Degraded system natural circulation

8 Total failure of system natural circulation

9 Reactor core thermocouple failure, individual

10 Reactor thermocouple instrument failure

11 Loss of pressurizer level

12 Pressurizer level channel failure, high

13 Pressurizer level channel failure, low

14 Pressurizer pressure channel failure, high

\begin{tabular}{c|c}
0.26 & $0 / 7$ \\
0 & $6 / 7$ \\
0.04 & $6 / 7$ \\
& \\
0.26 & $0 / 7$ \\
0.09 & $6 / 7$ \\
0 & $0 / 7$ \\
0 & $0 / 7$ \\
0 & $0 / 7$ \\
0 & $0 / 7$ \\
0 & $0 / 7$ \\
0 & $0 / 7$ \\
0.17 & $6 / 7$ \\
0 & $6 / 7$ \\
0.3 & $5 / 7$ \\
&
\end{tabular}

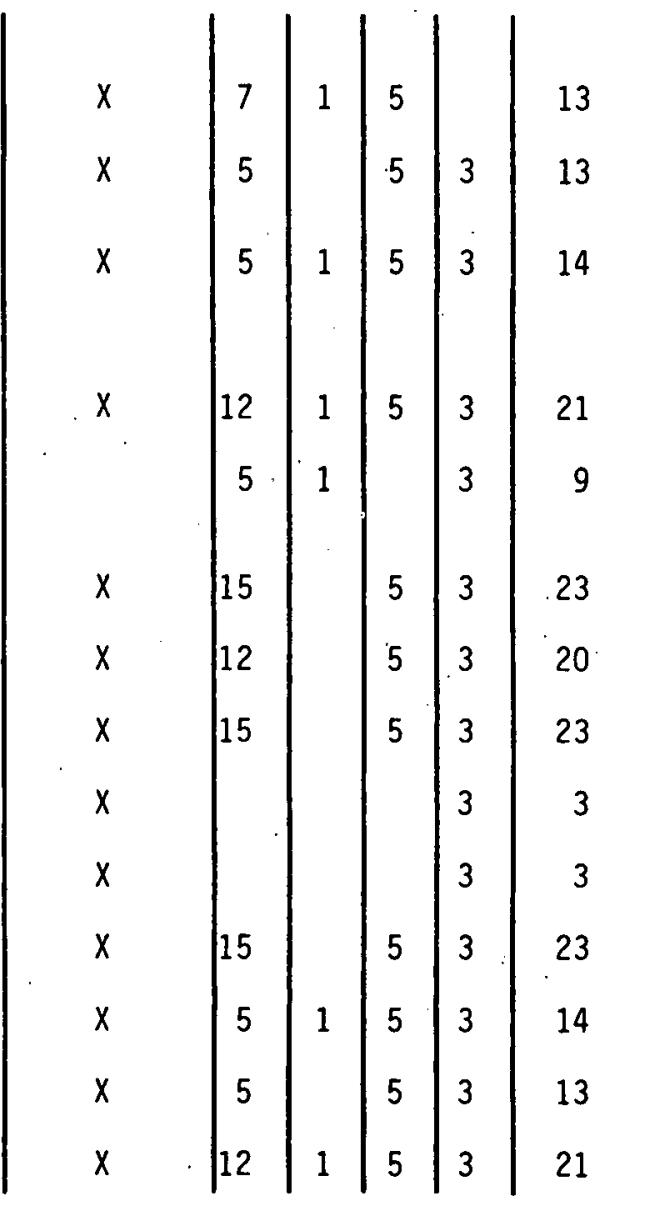

*See Appendix I for definitions of acronyms. 


\begin{tabular}{|c|c|}
\hline 15 & Pressurizer pressure channè failure, low \\
\hline 16 & Pressurizer heaters failure, SCR failure \\
\hline 17 & Pressurizer level high limit exceeded \\
\hline 18 & Pressurizer pressure high limit exceeded \\
\hline 19 & Pressurizer power relief vaives capacity reduced \\
\hline 20 & $\begin{array}{l}\text { Pressurizer safety valve serpoint below low } \\
\text { limit }\end{array}$ \\
\hline 21 & $\begin{array}{l}\text { Pressurizer safety valve se -point above high } \\
\text { limit }\end{array}$ \\
\hline 22 & All pressurizer safety valves inoperable \\
\hline 23 & Pressurizer pressure lcw linit exceeded \\
\hline 24 & System unidentified leakage exceeds limit \\
\hline 25 & System identified leakáge exceeds limit \\
\hline 26 & Pressurizer safety valve failed open, blowdown \\
\hline 27 & Fuel element failure, radionuclide release \\
\hline 28 & $\begin{array}{l}\text { Loss of all reactor coolant flow, mode } 5 \text {, } \\
\text { shutdown }\end{array}$ \\
\hline 29 & Loss of all reactor coolant flow, mode 3 , hot \\
\hline 30 & Loss of all reactor coolant flow, mode 2 , startup \\
\hline 31 & Steam generator tube leak failure \\
\hline 32 & Steam generator tubes gross failure \\
\hline 33 & Small break analysis not based on worst case \\
\hline 34 & Degraded system normal full flow \\
\hline
\end{tabular}

\begin{tabular}{|c|c|c|c|c|c|c|}
\hline 0.3 & $4 / 7$ & $x$ & 1 & & 5 & 3 \\
\hline 0 & $5 / 7$ & $x$ & & & 5 & 3 \\
\hline 0 & $0 / 7$ & $i$ & & & 5 & 3 \\
\hline 0 & $0 / 7$ & $x$ & & & 5 & 3 \\
\hline 0.09 & $0 / 7$ & $x$ & & & 5 & 3 \\
\hline 0 & $0 / 7$ & $x$ & & & 5 & 3 \\
\hline 0.04 & $0 / 7$ & $x$ & & & 5 & 3 \\
\hline 0.04 & $0 / 7$ & $x$ & & & 5 & 3 \\
\hline 0.04 & $7 / 7$ & $x$ & & & 5 & 3 \\
\hline 0.39 & $5 / 7$ & $x$ & & & 5 & 3 \\
\hline 0.39 & $5 / 7$ & $x$ & & & 5 & 3 \\
\hline 0 & $0 / 7$ & $x$ & 1 & & 5 & 3 \\
\hline 0.13 & $6 / 7$ & $x$ & 1 & & 5 & 3 \\
\hline 0.04 & $7 / 7$ & $x$ & & & 5 & 3 \\
\hline 0 & $7 / 7$ & $x$ & & & 5 & 3 \\
\hline 0 & $7 / 7$ & $x$ & & & 5 & 3 \\
\hline 0 & $0 / 7$ & $x$ & & & 5 & 3 \\
\hline 0 & $0 / 7$ & $x$ & 1 & & 5 & 3 \\
\hline 0.04 & $0 / 7$ & $x$ & & & 5 & 3. \\
\hline 0 & $2 / 7$ & $x$ & 1 & & 5 & 3 \\
\hline
\end{tabular}




\begin{tabular}{|c|c|c|c|c|c|c|c|c|c|}
\hline \multirow{2}{*}{ NO. } & \multirow{2}{*}{ PWR SYSTEM, MALFUINCTION (EVENT) } & \multirow{2}{*}{$\begin{array}{c}\text { FREQUENCY } \\
\text { OF } \\
\text { OCCURRENCE }\end{array}$} & \multirow{2}{*}{$\begin{array}{l}\text { SIIPRENTLY } \\
\text { SIMULATED }\end{array}$} & \multirow{2}{*}{$\begin{array}{l}\cdot \\
\text { ANALYSIS } \\
\text { REQUIRED }\end{array}$} & \multicolumn{4}{|c|}{ JUSTIFICATION } & \multirow{2}{*}{$\begin{array}{l}\text { IMPOR- } \\
\text { TANCE } \\
\text { FACTOR }\end{array}$} \\
\hline & & & & & $A$ & $B$ & C & 0 & \\
\hline
\end{tabular}

COMPONENT COOLING WATER (A11 Modes)

1 Component coot.ing water heat exchanger leak to service water, environment

2

Loss of in-service CCW heat exchanger cooling

A. Reactor startup, subcritical

B. Full power operation, maximum heat

3

Loss of all CCW heat exchanger cooling

A. Reactor startup, subcritical

B. Full power operation, maximum heat generation

CCW piping breaks in containment, in auxiliary building

Loss of CCW to containment components

6

Loss of $\mathrm{CCW}$ to reactor coolant pump(s)

Loss of CCW to RHR heat exchanger

$\mathrm{CCW}$ system high activity

9

Loss of all CCW pumps

Loss of CCW surge (expansion) tank level (empty).

CCW pumps surveillance not performed

CCW pump bearing failure or seizure

13 RHR heat exchanger leak to $\mathrm{CCW}$ system

14 CCW surge (expansion) tank isolated from system

\begin{tabular}{|c|c|c|c|c|c|c|}
\hline 0.04 & $0 / 7$ & & 5 & 1 & & 3 \\
\hline $\begin{array}{l}0 \\
0\end{array}$ & $\begin{array}{l}0 / 7 \\
0 / 7\end{array}$ & $\begin{array}{l}x \\
x\end{array}$ & $\begin{array}{l}5 \\
5\end{array}$ & $\begin{array}{l}1 \\
1\end{array}$ & & $\begin{array}{l}3 \\
3\end{array}$ \\
\hline 0 & $0 / 7$ & $x$ & 12 & & 5 & 3 \\
\hline 0 & $0 / 7$ & $x$ & 15 & & 5 & 3 \\
\hline 0 & $0 / 7$ & $x$ & 7 & & 5 & 3 \\
\hline 0 & $0 / 7$ & $x$ & 12 & & 5 & 3 \\
\hline 0 & $6 / 7$ & $x$ & 12 & & 5 & 3 \\
\hline$j$ & $4 / 7$ & $x$ & 12 & & 5 & 3 \\
\hline$\hat{v}$ & $0 / 7$ & $x$ & 12 & & & 3 \\
\hline 0 & $3 / 7$ & $x$ & 15 & & 5 & 3 \\
\hline 0 & $0 / 7$ & $x$ & 12 & & 5 & 3 \\
\hline 0.04 & $0 / 7$ & & & 1 & & \\
\hline 0.04 & $3 / 7$ & $x$ & 7 & 1 & 5 & 3 \\
\hline 0 & $0 / 7$ & $x$ & 7 & & 5 & 3 \\
\hline 0 & $0 / 7$ & $x$ & 7 & & 5 & 3 \\
\hline
\end{tabular}


CIRCULATING WATER (Modes 1-3)

1 Cooling water inlet temperature in excess of limit

Cooling water temperature measurement devices missing

3 Loss of main condenser cooling supply

4 Condenser $\Delta T$ rate of change :s excess of limit

5 Partial blockage of intake cooling water

6 Cooling jower basin level below limit

7 Failure of traveling screens, trash removal

8 Deicing gates (valve) inoperabie

9 Circulating water pump failure

SERVICE WATER (A11 Modes)

1 Service water, pump failure, non safety system service water

Loss of service water, non safety system service water

Service water pump failure, safety system service water

Loss of service water, safety system service water

Service water selected remote valves failure

Service water unisolable leak in containment

Loss of main turbine seavice water

\begin{tabular}{|c|c|c|c|c|c|c|}
\hline 0.17 & $0 / 7$ & $x$ & 5 & 1 & 5 & 3 \\
\hline 0.09 & $0 / 7$ & $x$ & 7 & 1 & & 3 \\
\hline 0 & 0,7 & $x$ & 7 & & 5 & 3 \\
\hline 0.22 & 0,7 & $x$ & 5 & 1 & 5 & 3 \\
\hline 0.04 & 0,77 & $x$ & 7 & 1 & 5 & 3 \\
\hline 0.04 & $0 / 7$ & $x$ & 7 & 1 & 5 & 3 \\
\hline 0 & $0 / 7$ & $x$ & 7 & & 5 & 3 \\
\hline 0 & 0,17 & $x$ & 7 & & 5 & 3 \\
\hline 0 & $0 / 7$ & & 5 & & & 3 \\
\hline
\end{tabular}

\begin{tabular}{|c|c|c|c|c|c|c|}
\hline 0 & $0 / 7$ & & 5 & & & \\
\hline 0 & $0 / 7$ & & 7 & & & 3 \\
\hline 0.22 & $0 / 7$ & $x$ & 5 & 1 & 5 & 3 \\
\hline 0 & $0 / 7$ & $x$ & 15 & & 5 & 3 \\
\hline 0.09 & $1 / 7$ & $x$ & 12 & 1 & 5 & 3 \\
\hline 0 & $0 / 7$ & $x$ & 7 & & 5 & 3 \\
\hline 0 & $0 / 7$ & & 7 & & & 3 \\
\hline
\end{tabular}




\begin{tabular}{|c|c|c|c|c|c|c|c|c|c|}
\hline \multirow{2}{*}{ NO. } & \multirow{2}{*}{ PWR SYSTEM, MALFUNCTION (EVENT) } & \multirow{2}{*}{$\begin{array}{l}\text { FREQUENCY } \\
\text { OF } \\
\text { OCCURRENCE }\end{array}$} & \multirow{2}{*}{$\begin{array}{l}\text { CURFENTLY } \\
\text { SIMUILATED }\end{array}$} & \multirow{2}{*}{$\begin{array}{l}\text { ANALYSIS } \\
\text { REQUIRED }\end{array}$} & \multicolumn{4}{|c|}{ JUSTIFICATION } & \multirow{2}{*}{$\begin{array}{l}\text { IMPOR- } \\
\text { TANCE } \\
\text { FACTOP. }\end{array}$} \\
\hline & & & & & A & B & c & D & \\
\hline
\end{tabular}

CHEMICAL AND VOLUME CONTROL (A11 Modes)

\begin{tabular}{|c|c|}
\hline 1 & $\begin{array}{l}\text { VCT radioactive gas release, VCT pressure } \\
\text { failure }\end{array}$ \\
\hline 2 & Charging pump seal failure \\
\hline$\overline{3}$ & Charging pump casing failure \\
\hline 4 & Chemical addition pump failure \\
\hline 5 & Failure of all chemical addition pumps \\
\hline 6 & Loss of charging \\
\hline 7 & Charging pump failure to start \\
\hline 8 & $\begin{array}{l}\text { Charging pump suction piping crack or treak. } \\
\text { Filure }\end{array}$ \\
\hline 9 & Charging line pipe crack or break \\
\hline 10 & $\begin{array}{l}\text { Charging line pipe crack or break fajlure in } \\
\text { containment }\end{array}$ \\
\hline 11 & Letdown to VCT failure \\
\hline 12 & $\begin{array}{l}\text { Letdown header crack or break failure in } \\
\text { containment }\end{array}$ \\
\hline 13 & Loss of letdown \\
\hline
\end{tabular}

\begin{tabular}{|c|c|c|c|c|c|c|c|}
\hline 0.04 & $0 / 7$ & $x$ & 12 & 1 & & 3 & 16 \\
\hline 0.09 & $0 / 7$ & $x$ & 7 & 1 & 5 & 3 & 16 \\
\hline 0.04 & $0 / 7$ & $x$ & 7 & 1 & 5 & 3 & 16 \\
\hline 0.04 & $0 / 7$ & $x$ & 5 & 1 & 5 & 3 & 14 \\
\hline 0 & $0 / 7$ & $x$ & 15 & & 5 & 3 & 23 \\
\hline 0.04 & $7 / 7$ & $x$ & 12 & 1 & 5 & 3 & 21 \\
\hline 0.04 & $7 / 7$ & $x$ & 5 & 1 & 5 & 3 & 14 \\
\hline 0.09 & $0 / 7$ & $x$ & 15 & 1 & 5 & 3 & 24 \\
\hline 0.13 & $3 / 7$ & $x$ & 15 & 1 & 5 & 3 & 24 \\
\hline 0 & $3 / 7$ & $x$ & 7 & & 5. & 3 & 15 \\
\hline 0 & $5 / 7$ & & 7 & & & 3 & 10 \\
\hline 0 & $5 / 7$ & & 7 & & & 3 & 10 \\
\hline 0 & $4 / 7$ & & 7 & & & 3 & 10 \\
\hline
\end{tabular}


ROD CONTROL (A11 Modes, Not Refueling)

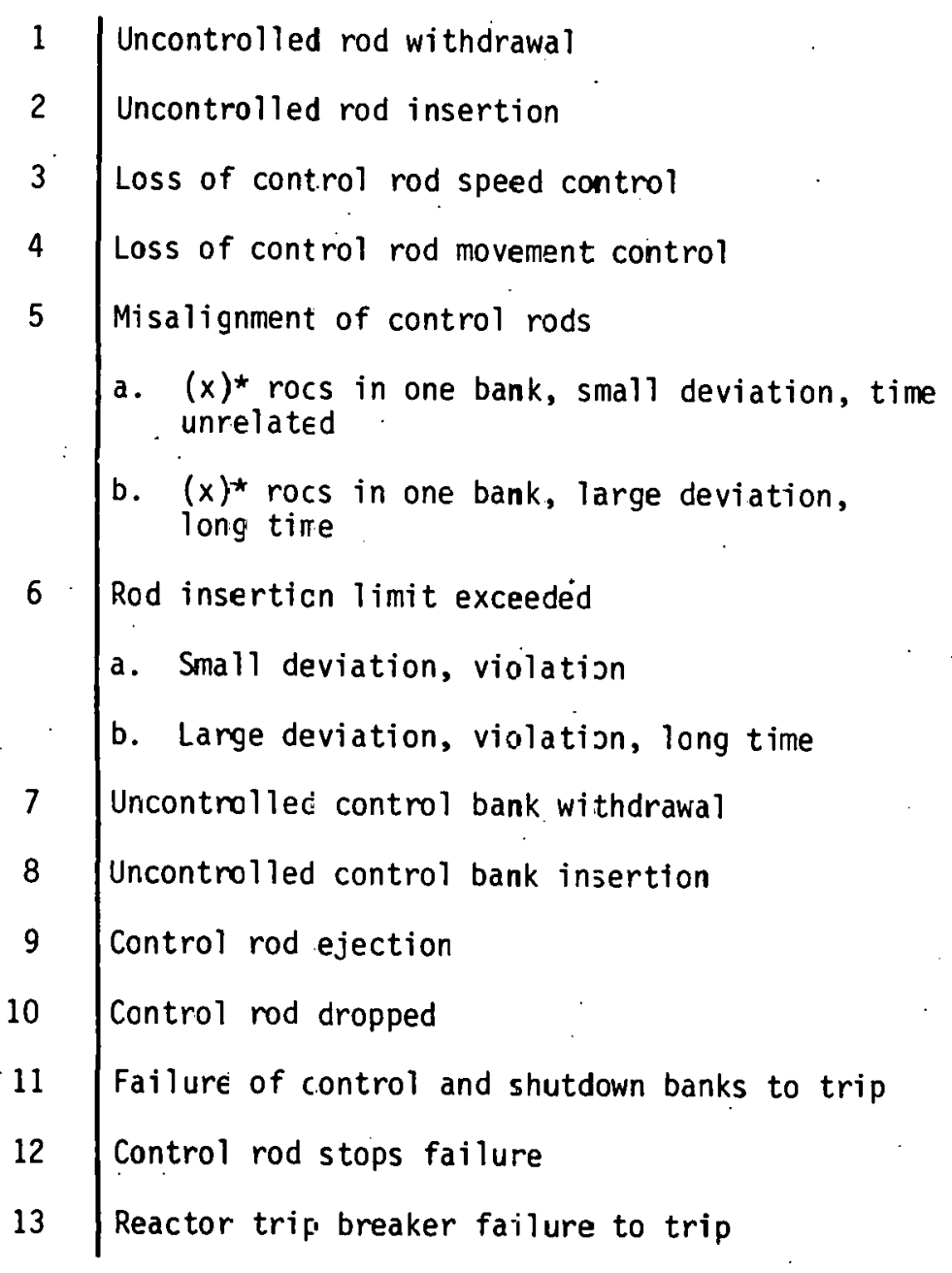

\begin{tabular}{|c|c|c|c|c|c|c|}
\hline 0.09 & $6 / 7$ & $x$ & 12 & 1 & 5 & 3 \\
\hline 0.09 & $6 / 7$ & $x$ & 12 & 1 & 5 & 3 \\
\hline 0.09 & $5 / 7$ & $x$ & 7 & 1 & 5 & 3 \\
\hline 0.04 & $5 / 7$ & $x$ & 7 & 1 & 5 & 3 \\
\hline 0 & $0 / 7$ & $x$ & 5 & & & 3 \\
\hline 0 & $0 / 7$ & $x$ & 12 & & 5 & 3 \\
\hline 0.04 & $0 / 7$ & $x$ & 7 & 1 & 5 & \\
\hline 0 & $0 / 7$ & $x$ & 15 & & 5 & 3 \\
\hline 0 & $0 / 7$ & $x$ & 12 & & 5 & 3 \\
\hline 0 & $0 / 7$ & $x$ & 12 & & 5 & 3 \\
\hline 0 & $4 / 7$ & $x$ & 15 & & 5 & 3 \\
\hline 0.3 & $6 / 7$ & $x$ & 5 & 1 & & \\
\hline 0 & $5 / 7$ & $x$ & 15 & & 5 & 3 \\
\hline 0 & $5 / 7$ & & 7 & & 5 & 3 \\
\hline 0 & $4 / 7$ & $x$ & 7 & & 5 & 3 \\
\hline
\end{tabular}

* $(x)$ rads involved is dependent upon the reactor design and control. rod pattern used-reactor suppliers. 


\begin{tabular}{|c|c|c|c|c|c|c|c|c|c|}
\hline \multirow{2}{*}{ NO. } & \multirow{2}{*}{ PWR SYSTEM, MALFUNCTION (EVENT) } & \multirow{2}{*}{$\begin{array}{c}\text { FREQUENCY } \\
\text { OF } \\
\text { OCCURRENCE }\end{array}$} & \multirow{2}{*}{$\begin{array}{l}\text { CURRENTLY } \\
\text { SIMULATED }\end{array}$} & \multirow{2}{*}{$\begin{array}{l}\text { ANAL YSIS } \\
\text { REQUIRED }\end{array}$} & \multicolumn{4}{|c|}{ JUSTIFICATION } & \multirow{2}{*}{$\begin{array}{l}\text { IMPOR- } \\
\text { TANCE } \\
\text { FACTOR }\end{array}$} \\
\hline & & & & & A. & B & c & D & \\
\hline
\end{tabular}

ROD CONTROL (A11 Modes, Not Refueling) (cont.)

14 Rod drive MG power supply failure

15 Rod drive power voltage failure, high

16 Rod control bus ground

17 Control rods programmed sequence failure

a. Sequence, program violated; small deviation, no time b. Sequence, program violated, large deviation,
long time

18 Control shutdown rods individual position indication failure or drift

19 Manual reactor trip failure

20 Control, shutdown rod failure, broken parts

21 Control, shutdown bank demand, control system position indication failure

22 Rod drive mechanism crack or seal leak

23 Axial power distribution in excess of limits

\section{0}

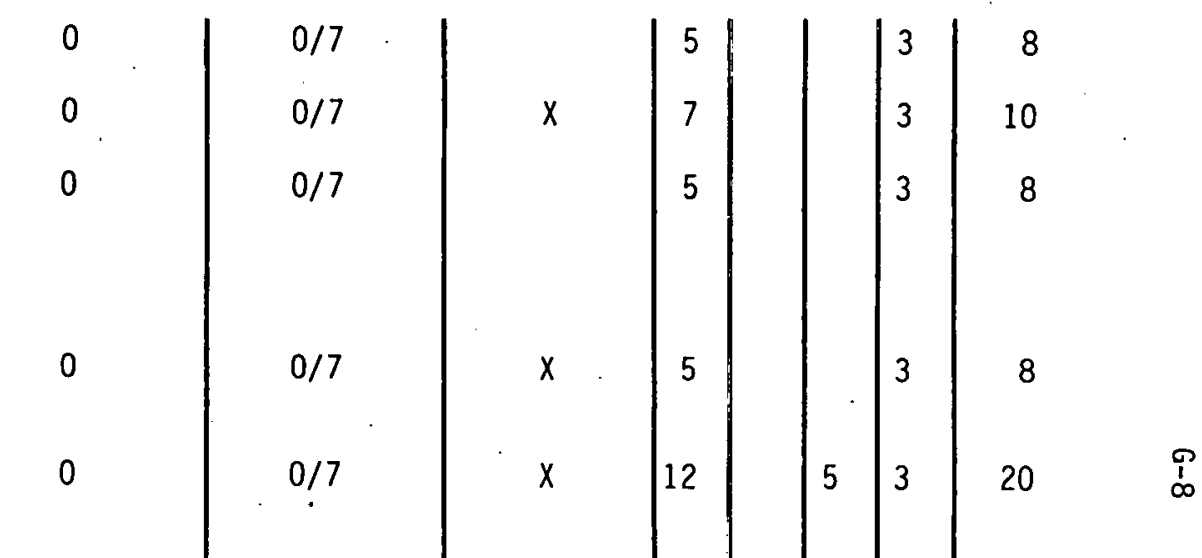

24 Quadrant power tilt in excess of limits

ELECTRICAL DISTRIBUTION (AIT Modes)

1 Reactor coolant pump undervoltage relay failure |

0.04

$0 / 7$

\begin{tabular}{|c|c|c|c|c|c|c|}
\hline 0.35 & $6 / 7$ & $x$ & 5 & 1 & & \\
\hline 0 & $4 / 7$ & $x$ & 15 & & & \\
\hline 0 & $0 / 7$ & $x$ & 7 & & & \\
\hline 0.17 & $0 / 7$ & $x$ & 7 & 1 & & \\
\hline 0.13 & $0 / 7$ & $x$ & 12 & 1 & & \\
\hline 0.04 & $2 / 7$ & $x$ & 5 & 1 & & \\
\hline 0.13 & $2 / 7$ & $x$ & 5 & 1 & & 3 \\
\hline
\end{tabular}




\begin{tabular}{|c|c|}
\hline 2 & $\begin{array}{l}\text { Reactcr coolant pump overload protection failure } \\
\text { (loss of overload protection) }\end{array}$ \\
\hline 3 & Reactcr coolant pump bus overload on pump start \\
\hline 4 & $\begin{array}{l}\text { Reactor coolant pump bus (LVP) low voltage } \\
\text { protection relay failure, RCP restart error }\end{array}$ \\
\hline 5 & Loss of all offsite poner sources \\
\hline 6 & $\begin{array}{l}\text { Main transformer partic̄l failure, selected } \\
\text { phase low voltage }\end{array}$ \\
\hline 7 & $\begin{array}{l}\text { Safeguards buses remairi loaded, failure of } \\
\text { bus stripping to occur, blackout }\end{array}$ \\
\hline 8 & Selected safeguards bus overload trip \\
\hline 9 & Protection channel inverter failure \\
\hline 10 & $\begin{array}{l}\text { Loss of an ESF load ceriter distribution (MCC) } \\
\text { panel, selected ESF auxiliaries }\end{array}$ \\
\hline 11 & Plant battery failure \\
\hline 12 & Reduced battery capacity, availability \\
\hline 13 & Battery charger failure \\
\hline & EMERGENCY DIESEL GENERATOR (Al1 Modes) \\
\hline 1 & ( $\left.\frac{1}{2}\right)$ Diesel generators failure to start \\
\hline 2 & All Diesel generators failure to start \\
\hline 3 & DG loss of control air \\
\hline 4 & $\begin{array}{l}\text { Starting air pressure low, starting not } \\
\text { inhibited }\end{array}$ \\
\hline 5 & Loss of DG lubricating oil, bearing failure \\
\hline
\end{tabular}

\begin{tabular}{l|c|c|c|c|c|c|c}
0 & $0 / 7$ & $x$ & 7 & & & 3 & 10 \\
0 & $4 / 7$ & $x$ & 5 & & & 3 & 8 \\
0 & $0 / 7$ & $x$ & 15 & & 5 & 3 & 23 \\
0.22 & $7 / 7$ & $x$ & 15 & 1 & 5 & 3 & 24 \\
0.04 & $0 / 7$ & $x$ & 7 & 1 & & 3 & 11 \\
0 & $0 / 7$ & $x$ & 12 & & 5 & 3 & 20 \\
0 & $0 / 7$ & $x$ & 12 & & 5 & 3 & 20 \\
0.13 & $0 / 7$ & $x$ & 7 & 1 & & 3 & 11 \\
0.09 & $0 / 7$ & $x$ & 12 & 1 & 5 & 3 & 21 \\
0.04 & $0 / 7$ & $x$ & 12 & 1 & 5 & 3 & 21 \\
0.04 & $0 / 7$ & $x$ & 5 & 1 & & 3 & 9 \\
0.04 & $0 / 7$ & $x$ & 5 & 1 & & 3 & 9
\end{tabular}

\begin{tabular}{l|r|r|r|r|r|r|r}
0 & $0 / 7$ & $x$ & 12 & 1 & 5 & 3 & 21 \\
0 & $0 / 7$ & $x$ & 15 & & 5 & 3 & 23 \\
0.04 & $5 / 7$ & $x$ & 5 & 1 & 5 & 3 & 14 \\
0.09 & $0 / 7$ & $x$ & 5 & 1 & & 3 & 9 \\
0.0 & $0 / 7$ & $x$ & 12 & & 5 & 3 & 20
\end{tabular}




\begin{tabular}{|c|c|c|c|c|c|c|c|c|c|}
\hline \multirow{2}{*}{ NO. } & \multirow{2}{*}{ PWR SYSTEM, MALFUNCTION (EVENT) } & \multirow{2}{*}{$\begin{array}{c}\text { FREQUENCY } \\
\text { OF } \\
\text { OCCURRENCE }\end{array}$} & \multirow{2}{*}{$\begin{array}{l}\text { CURRENTLY } \\
\text { SIMULATED }\end{array}$} & \multirow{2}{*}{$\begin{array}{l}\text { ANALYSIS } \\
\text { REQUIRED }\end{array}$} & \multicolumn{4}{|c|}{ JUSTIFICATION } & \multirow{2}{*}{$\begin{array}{l}\text { IMPOR- } \\
\text { TANCE } \\
\text { FACTOR }\end{array}$} \\
\hline & & & & & $A$ & 8 & C & D & \\
\hline
\end{tabular}

EMERGENCY DIESEL GENERATOR (A11 Modes) (corit.)

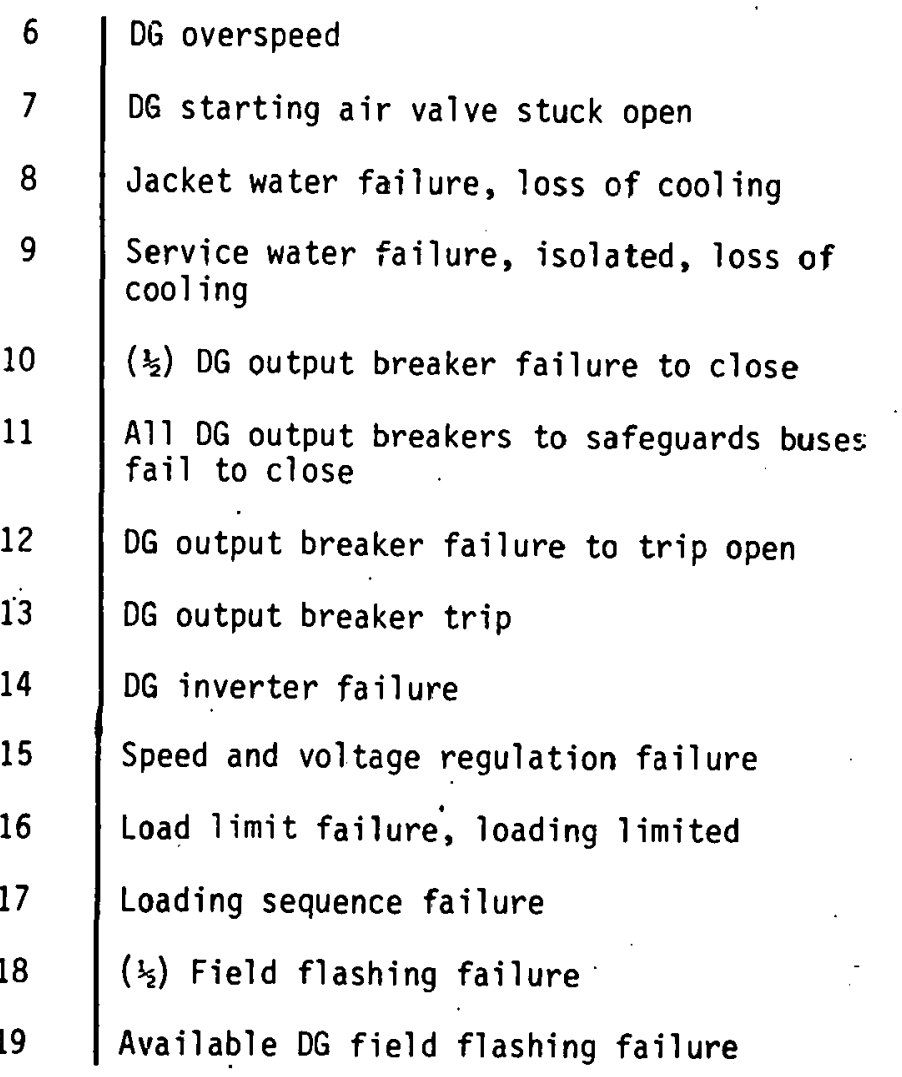

MAIN STEAM AND TURBINE (Modes 1-3)

$1 \quad$ Main steam line flow protection channel setpoint drift or failure

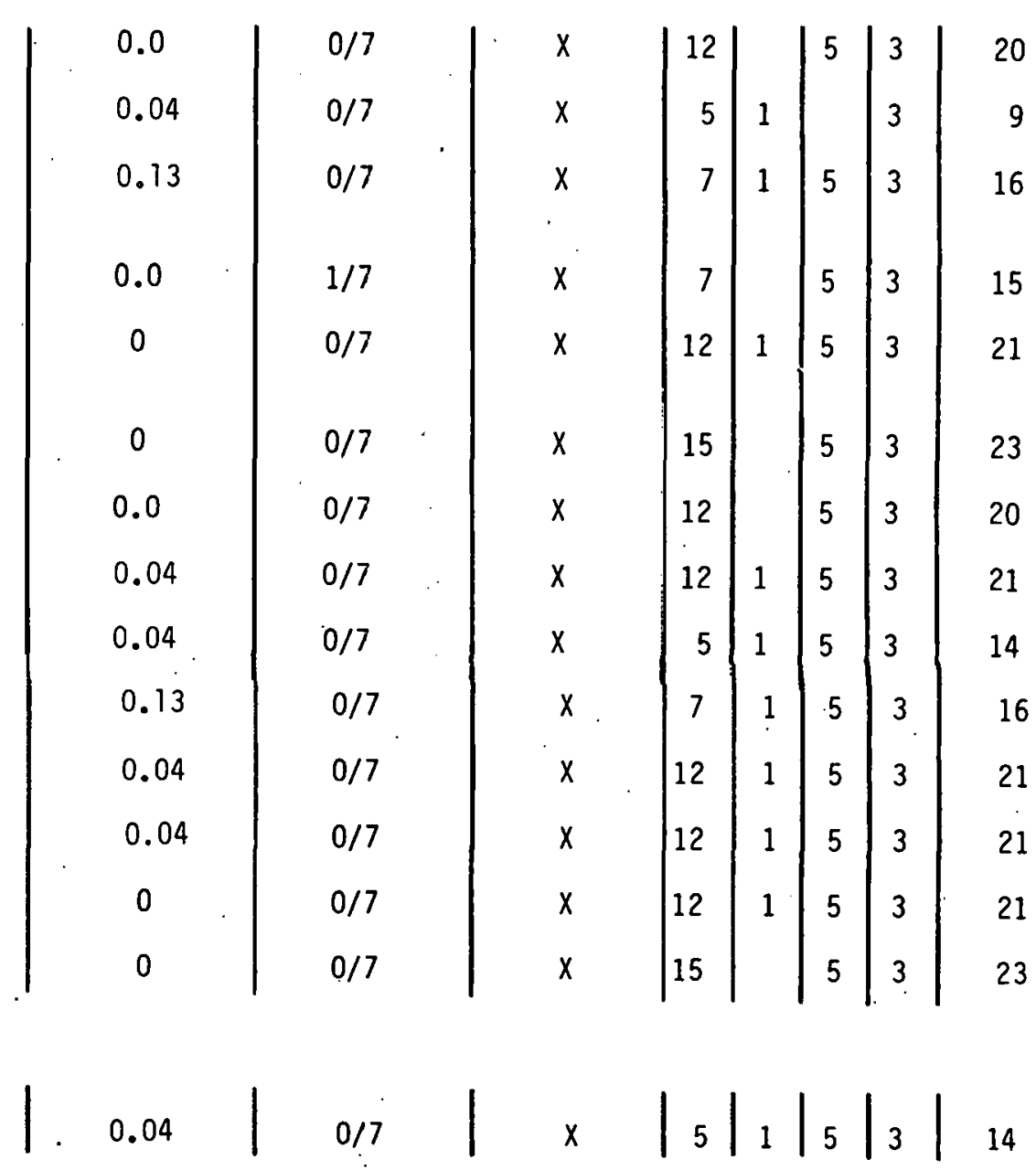


2 Main steam line flow transmitter failure or drift

3 Main steam line pressure protection channel setpoint drift or failure

4 Main steam line pressure transmitter drift or failure

5 Main stean line isolation valve failure to close hydraulically

6 Main stearn line isolation valve failure to trip Main steam line isolation valve trip circuit channel fajlure

8 Failure of all main steam line isolation trip circuits Main steam line safety valve failure, open Automatic steam dump valve(s) =ail, closed Automatic stean dump valve(s) iailure, open Moisture separator reheater (MSR) tube rupture Main steam line differential pressure alarm and status indication failure, constant indication Main turbine bearing failure

Main turbine first stage pressure (impulse pressure) control channel drift or failure CONDENSATE (A11 Modes)

1 Condensàte storage tank levell below limit for power operation

\begin{tabular}{|c|c|c|c|c|c|c|}
\hline 0.13 & $0 / 7$ & $X$ & 5 & 1 & 5 & 3 \\
\hline 0.04 & $0 / 7$ & $x$ & 5 & 1 & 5 & 3 \\
\hline 0.09 & $0 / 7$ & $x$ & 5 & 1 & 5 & 3 \\
\hline 0.17 & $0 / 7$ & & & 1 & & 3 \\
\hline 0 & $1 / 7$. & $x$ & 7 & & 5 & 3 \\
\hline 0 & $1 / 7$ & $x$ & 12 & & 5 & 3 \\
\hline 0 & $0 / 7$ & $x$ & 15 & & 5 & 3 \\
\hline 0 & $2 / 7$ & $x$ & 15 & & 5 & 3 \\
\hline 0 & $6 / 7$ & $x$ & 12 & & 5 & 3 \\
\hline 0 & $6 / 7$ & $x$ & 12 & & 5 & 3 \\
\hline 0 & $0 / 7$ & $x$ & 7 & & 5 & 3 \\
\hline 0.13 & $0 / 7$ & $x$ & 5 & 1 & 5 & 3 \\
\hline 0. & $0 / 7$ & & & & & 3 \\
\hline 0 & $5 / 7$ & & 7 & & 5 & 3 \\
\hline
\end{tabular}




\begin{tabular}{|c|c|c|c|c|c|c|c|c|c|}
\hline \multirow{2}{*}{ NO. } & \multirow{2}{*}{ PWR SYSTEM, MALFUNCTION (EVENT) } & \multirow{2}{*}{$\begin{array}{c}\text { FREQUENCY } \\
\text { OF } \\
\text { GCCURRENCE }\end{array}$} & \multirow{2}{*}{$\begin{array}{l}\text { CURRENTLY } \\
\text { SIMULATED }\end{array}$} & \multirow{2}{*}{$\begin{array}{l}\text { ANALYSIS } \\
\text { REQUIRED }\end{array}$} & \multicolumn{4}{|c|}{ JUSTIFICATION } & \multirow{2}{*}{$\begin{array}{l}\text { IMPOR- } \\
\text { TANCE } \\
\text { FACTOR }\end{array}$} \\
\hline & & & & & A & B & C & 0 & \\
\hline
\end{tabular}

CONDENSATE (A11 Modes) (cont.)

\begin{tabular}{l|l|}
2 & $\begin{array}{l}\text { Condensate booster pump failure } \\
\text { Condensate booster pump failure to trip }\end{array}$ \\
4 & $\begin{array}{l}\text { Condensate booster pump loss of suction } \\
\text { hotwell pumps loss of suction }\end{array}$ \\
5 & $\begin{array}{l}\text { Loss of condensate - pipe break } \\
6\end{array}$ \\
7 & $\begin{array}{l}\text { Condenser hotwell makeup control failure } \\
\text { Heater drain pump failure }\end{array}$ \\
8 & $\begin{array}{l}\text { Failure of turbine auxiliary cooling water } \\
\text { (TACW) cooling or isolated }\end{array}$ \\
9 & $\begin{array}{l}\text { Feedwater heaters bypassed - loss of feedwater } \\
\text { and condensate heating }\end{array}$
\end{tabular}

\begin{tabular}{|c|c|c|c|c|c|}
\hline 0 & $5 / 7$ & & 5 & 5 & \\
\hline 0.04 & $0 / 7$ & & 5 & 5 & \\
\hline 0 & $0 / 7$ & & 7 & 5 & 3 \\
\hline 0 & $2 / 7$ & & 7 & 5 & 3 \\
\hline 0 & $5 / 7$ & & 7 & 5 & 3 \\
\hline 0 & $4 / 7$ & . & 5 & & 3 \\
\hline 0 . & $0 / 7$ & & 7 & 5 & 3 \\
\hline 0 & $3 / 7$ & $x$ & 7 & 5 & 3 \\
\hline
\end{tabular}

FEEDWATER (Modes 1-3)
1 Feedwater line flow obstruction
2 S.G. water level feedwater flow channel setpoint drift or failure
3 Steam flow/feedwater flow feedwater instrument drift or failure
4 Feedwater isolation channel failure or setpoint drift
Main feedwater pump failure to trip

\begin{tabular}{l|l|l|l|l|l|l|l}
0.04 & $0 / 7$ & $x$ & 7 & 1 & 5 & 3 & 16 \\
0.17 & $0 / 7$ & $x$ & 5 & 1 & 5 & 3 & 14 \\
0.04 & $0 / 7$ & $x$ & 5 & 1 & 5 & 3 & 14 \\
0 & $0 / 7$ & $x$ & 5 & & 5 & 3 & 13 \\
0 & $0 / 7$ & $x$ & 7 & & 5 & 3 & 15
\end{tabular}




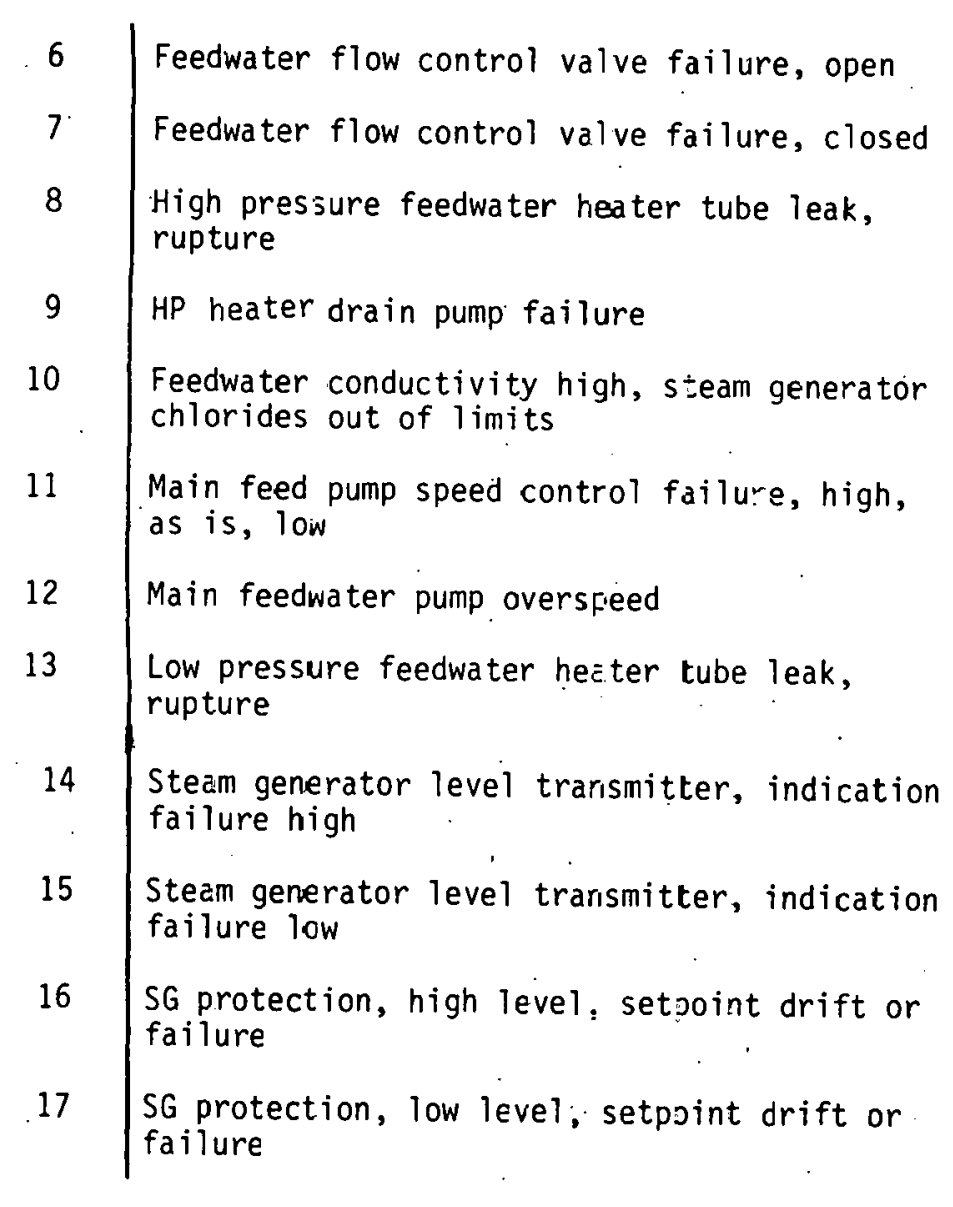

AUXILIARY FEEDWATER (Modes 1-气)
1 TD aux feed pump failure to start
2 Motor driven aux feed pumf failure to start
3 TD aux feed pump speed, control failure

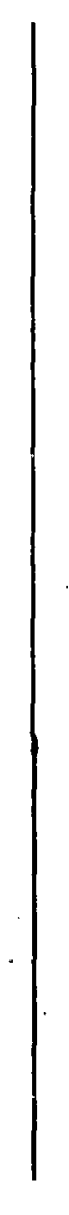

\begin{tabular}{l|}
0 \\
0 \\
0 \\
0 \\
0.09 \\
0 \\
0 \\
0 \\
0.17 \\
0 \\
0 \\
0.09
\end{tabular}

\begin{tabular}{l}
$4 / 7$ \\
$4 / 7$ \\
$6 / 7$ \\
$4 / 7$ \\
$2 / 7$ \\
$0 / 7$ \\
$0 / 7$ \\
$0 / 7$ \\
$6 / 7$ \\
$5 / 7$ \\
$0 / 7$ \\
$0 / 7$ \\
\hline
\end{tabular}

\begin{tabular}{rr|r|r|r|r|r}
$x$ & 7 & & 5 & 3 & 15 \\
$x$ & & 7 & & 5 & 3 & 15 \\
$x$ & & 7 & & 5 & 3 & 15 \\
$x$ & 5 & & & 3 & 8 \\
$x$ & & 5 & 1 & & 3 & 9 \\
$x$ & & 5 & & 5 & 3 & 13 \\
$x$ & 5 & & 5 & 3 & 13 \\
$x$ & & 5 & & & 3 & 8 \\
$x$ & 5 & 1 & 5 & 3 & 14 \\
$x$ & 5 & & 5 & 3 & 13 \\
$x$ & & 5 & & 5 & 3 & 13 \\
$x$ & 5 & 1 & 5 & 3 & 14
\end{tabular}

$\frac{P}{\omega}$ 


\begin{tabular}{|c|c|c|c|c|c|c|c|c|c|}
\hline \multirow{2}{*}{ No. } & \multirow{2}{*}{ PWR SYSTEM, MALFUNCTION (EVENT) } & \multirow{2}{*}{$\begin{array}{c}\text { FREQUENCY } \\
\text { OF } \\
\text { OCCURRENCE }\end{array}$} & \multirow{2}{*}{$\begin{array}{l}\text { CURRENTLY } \\
\text { SIMULATED }\end{array}$} & \multirow{2}{*}{$\begin{array}{l}\text { ANALYSIS } \\
\text { REQUIRED }\end{array}$} & \multicolumn{4}{|c|}{ JUSTIFICATION } & \multirow{2}{*}{$\begin{array}{l}\text { IMPOR- } \\
\text { TANCE } \\
\text { FACTOR }\end{array}$} \\
\hline & & & & & $A$ & B & $C$ & 0 & \\
\hline
\end{tabular}

AUXILIARY FEEDWATER (Modes 1-3) (cont.)

\begin{tabular}{c|l|l|}
4 & $*\left(\frac{1}{x}\right)$ Aux feedwater discharge supply isolation \\
5 & Available aux feedwater discharge supply isolated \\
6 & $*\left(\frac{1}{x}\right)$ Aux feedwater discharge pipe rupture, failure \\
7 & $\begin{array}{l}\text { Available aux feedwater discharge pipe rupture } \\
\text { failure }\end{array}$ \\
8 & Turbine aux feed pump steam supply failure \\
9 & Loss of normal (condensate) water supply tc \\
10 & $\begin{array}{l}\text { Auxiliary feedwater pumps } \\
\text { full open fedwater supply valves failure, as is, }\end{array}$
\end{tabular}

NUCLEAR INSTRUMENTATION (AII Modes)

\begin{tabular}{l|l}
1 & Source range instrument failure low or drift \\
2 & Source range channel inoperable during startup \\
3 & Loss of all source range channels \\
4 & Source range instrument failure, high \\
5 & Power range channel failure, low \\
6 & Power range channel failure, high
\end{tabular}.

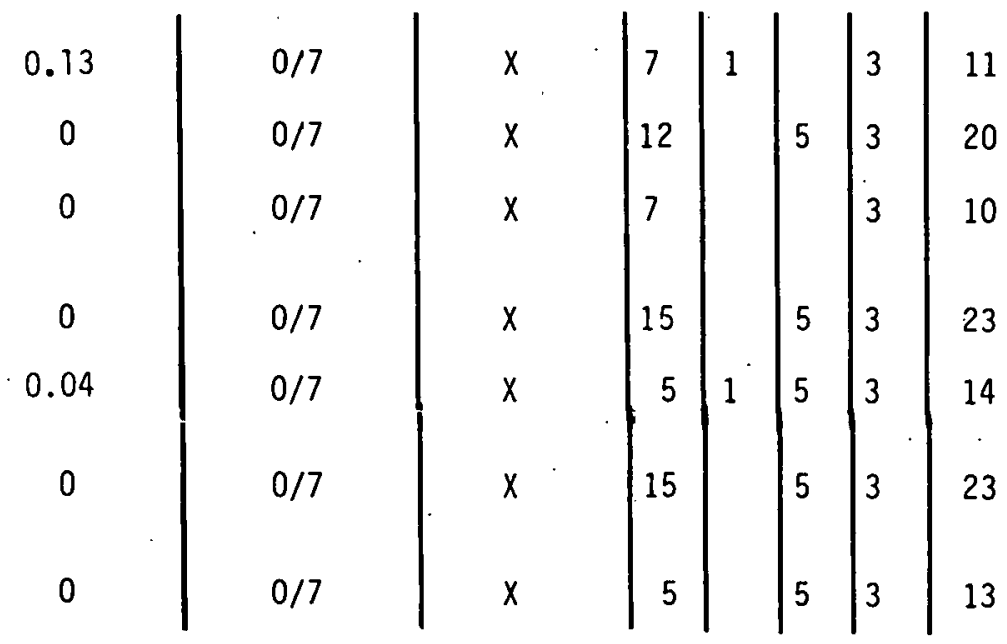

* Degree of malfunction attributed to particular plant design and normal equipment compliment.

\begin{tabular}{l|l|l|l|l|l|l|l}
0.09 & $6 / 7$ & $x$ & 5 & 1 & 5 & 3 & 14 \\
0.04 & $6 / 7$ & $x$ & 5 & 1 & 5 & 3 & 14 \\
0.04 & $0 / 7$ & $x$ & 7 & 1 & 5 & 3 & 16 \\
0 & $6 / 7$ & $x$ & 5 & & 5 & 3 & 13 \\
0.13 & $6 / 7$ & $x$ & 5 & 1 & 5 & 3 & 14 \\
0.09 & $6 / 7$ & $x$ & 5 & 1 & 5 & 3 & 14
\end{tabular}




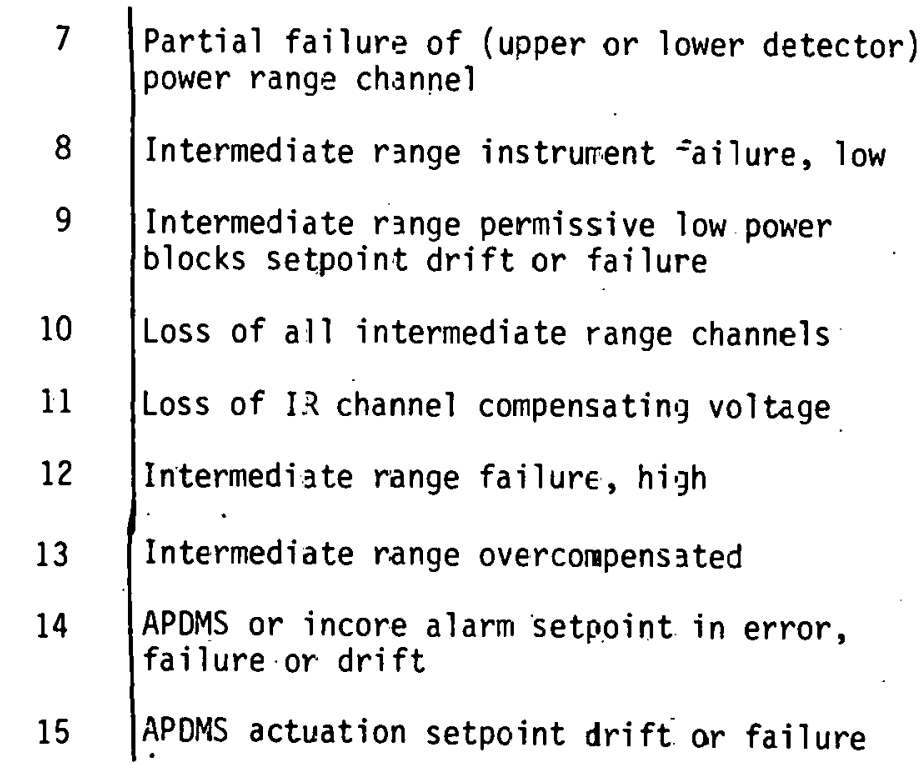

RESIDUAL heAT REMOVAL (Modes 4-6)

\begin{tabular}{l|l}
1 & RHR system inadvertent isolation \\
2 & RHR system pressure interlock failure to isolate \\
3 & RHR pumps excessive seal leakage \\
4 & RHR system leakage or pipe rupture \\
5 & RHR pump failure \\
6 & $\begin{array}{l}\text { Loss of all RHR pumps } \\
7\end{array}$ \\
$8 H R$ system temperature increase above \\
8 & $\begin{array}{l}\text { Rode limits } \\
\text { RHR system cause of inadivertent dilution }\end{array}$ \\
9 & RHR flow indication failure
\end{tabular}

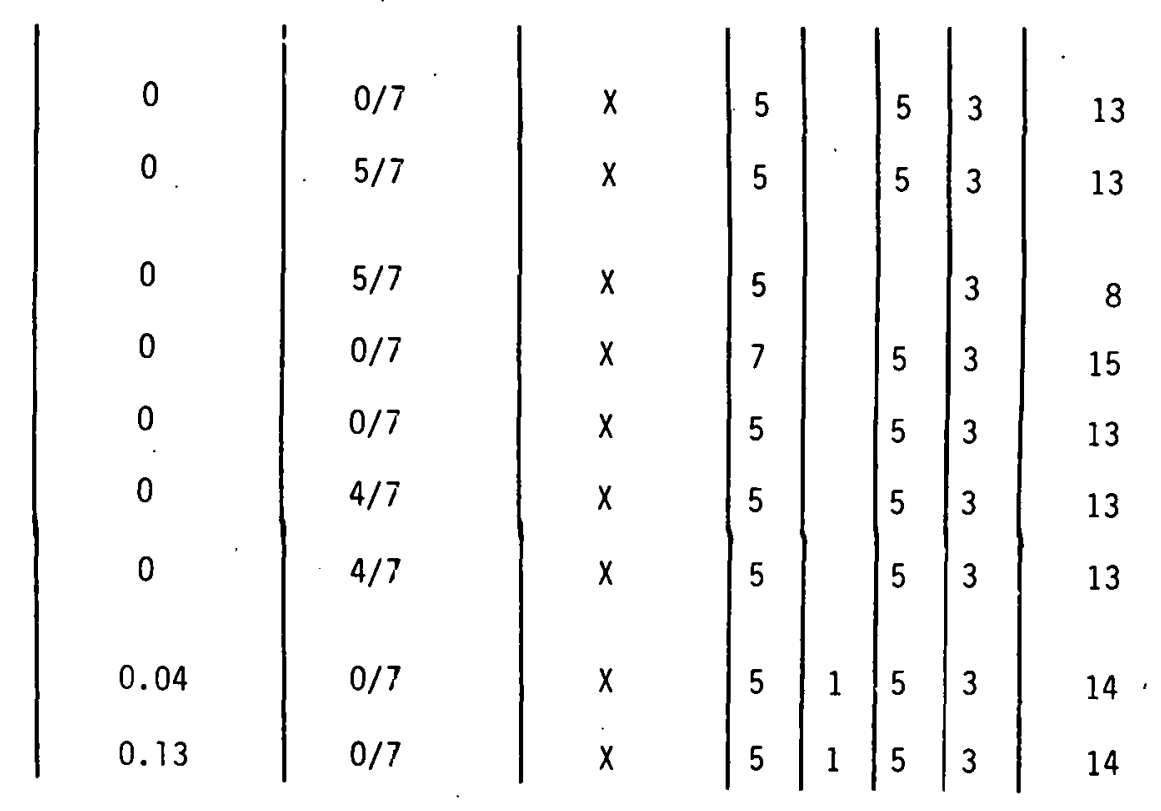

$\frac{P}{G}$

\begin{tabular}{|c|r|r|r|r|r|r|r}
0 & $0 / 7$ & $x$ & 5 & & & 3 & 8 \\
0 & $0 / 7$ & $x$ & 15 & & & 3 & 18 \\
0.04 & $0 / 7$ & & 5 & 1 & & 3 & 9 \\
0.09 & $0 / 7$ & $x$ & 15 & 1 & 5 & 3 & 24 \\
0.04 & $5 / 7$ & $x$ & 5 & 1 & & 3 & 9 \\
0.22 & $0 / 7$ & $x$ & 12 & 1 & 5 & 3 & 21 \\
0 & $3 / 7$ & $x$ & 7 & & 5 & 3 & 15 \\
0 & $0 / 7$ & $x$ & 7 & & 5 & 3 & 15 \\
0 & $0 / 7$ & & 5 & & & 3 & 8
\end{tabular}




\begin{tabular}{|c|c|c|c|c|c|c|c|c|c|}
\hline \multirow{2}{*}{ NO. } & \multirow{2}{*}{ PWR SYSTEM, MALFUNCTION (EVENT) } & \multirow{2}{*}{$\begin{array}{l}\text { FREQUENCY } \\
\text { OF } \\
\text { OCCURRENGE }\end{array}$} & \multirow{2}{*}{$\begin{array}{l}\text { CURRENTLY } \\
\text { SIIYULATED }\end{array}$} & \multirow{2}{*}{$\begin{array}{l}\text { ANALYSIS } \\
\text { REQUIRED }\end{array}$} & \multicolumn{4}{|c|}{ JUSTIFICATION } & \multirow{2}{*}{$\begin{array}{l}\text { IMPOR- } \\
\text { TANCE } \\
\text { FACTOR }\end{array}$} \\
\hline & & & & & $A$ & B & $c$ & 0 & \\
\hline
\end{tabular}

RESIDUAL HEAT REMOVAL (Modes 4-6) (cont.)

10 Decay heat mode inadvertent blowdown to containment recirc. sump

11. RHR heat exchanger tube leak or failure

PLANT VENTILATION (AIT Modes)

1 Control room air conditioning dampers failure, ESF dampers

2 Control room air condition unit failure

3 Loss of control room air conditioning

4 Auxiliary building and containment ventilation plant stack instrument flow drift or failure

5 ESF ventilation dampers failure

6 ESF ventilation units auto start failure

7 Containment cooling units failure, damper failure, temperature contral failure

Containment hydrogen control (skimmer) fans failure

Containment hydrogen control (skimmer) dampers failure

10 Containment hydrogen recombiner failure.

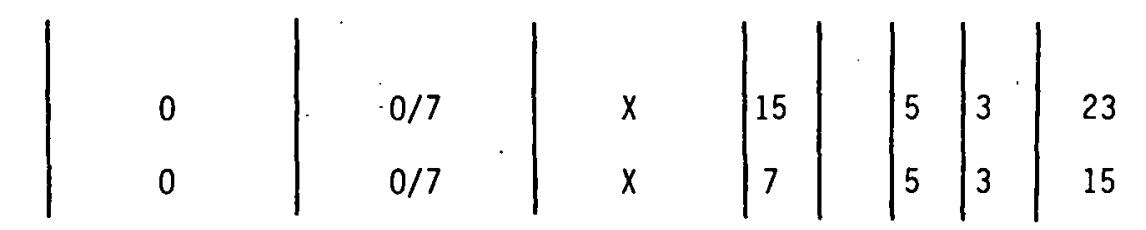
15

\begin{tabular}{|c|c|c|c|c|c|c|c}
0.13 & $0 / 7$ & $x$ & 5 & 1 & 5 & 3 & 14 \\
0.09 & $0 / 7$ & $x$ & 5 & 1 & & 3 & 9 \\
0 & $0 / 7$ & $x$ & 7 & & 5 & 3 & 15 \\
0 & $0 / 7$ & $x$ & 5 & & 5 & 3 & 13 \\
0.04 & $0 / 7$ & $x$ & 5 & & 5 & 3 & 13 \\
0.04 & $0 / 7$ & $x$ & 7 & & 5 & 3 & 15 \\
0.04 & $0 / 7$ & $x$ & 7 & & 5 & 3 & 15 \\
0.09 & $0 / 7$ & $x$ & 15 & 1 & 5 & 3 & 24 \\
0 & $0 / 7$ & $x$ & 15 & & 5 & 3 & 23 \\
0 & $0 / 7$ & $x$ & 15 & & 5 & 3 & 23
\end{tabular}


RADIATION MONITORING (4T1 Modes)

\begin{tabular}{|c|c|}
\hline 1 & $\begin{array}{l}\text { Containment purge with high radiation contain- } \\
\text { ment purge iso. signal bypassed }\end{array}$ \\
\hline 2 & Fuel building area radiation monitor failure \\
\hline 3 & Contaiment particulate monitor failure \\
\hline 2 & Flant vent stack monitor failure \\
\hline 5 & $\begin{array}{l}\text { Containment post accident radiation monitor } \\
\text { failure }\end{array}$ \\
\hline 0 & $\begin{array}{l}\text { Containment gaseous and particulate monitors } \\
\text { sampling plugged or isolated }\end{array}$ \\
\hline 7 & Component cooling water high activity levei \\
\hline 8 & Component cooling water rad. monitor failure \\
\hline 9 & Service water high act ${ }^{-}$ity level \\
\hline 10 & Service water rad. monitor failure \\
\hline 1 & S.G. tlowdown monitor drift and failure \\
\hline 12 & S.G. t.lowdciwn monitor high activity \\
\hline 13 & Fuel randling area radiation high level \\
\hline 14 & Containment area radia sion monitor high level \\
\hline 1 & $\begin{array}{l}\text { Charging pump area radiation monitor drift } \\
\text { or failure }\end{array}$ \\
\hline 16 & $\begin{array}{l}\text { Waste handling fasility radiation monitor } \\
\text { high level }\end{array}$ \\
\hline
\end{tabular}

\begin{tabular}{|c|c|c|c|c|c|c|}
\hline 0.04 & $4 / 7$ & $x$ & 7 & 1 & 5 & 3 \\
\hline 0.04 & $0 / 7$ & $x$ & 5 & 1 & 5 & 3 \\
\hline 0.17 & $4 / 7$ & $x$ & 5 & 1 & 5 & 3 \\
\hline 0.22 & $4 / 7$ & $x$ & 5 & 1 & 5 & 3 \\
\hline 0.22 & $4 / 7$ & $x$ & 15 & 1 & 5 & 3 \\
\hline & & & & & & \\
\hline 0.17 & $4 / 7$ & $x$ & 5 & 1 & 5 & 3 \\
\hline 0 & $0 / 7$ & $x$ & 5 & & 5 & 3 \\
\hline 0 & $0 / 7$ & $x$ & 5 & & 5 & 3 \\
\hline 0 & $0 / 7$ & $x$ & 7 & & 5 & 3 \\
\hline 0 & $0 / 7$ & $x$ & 5 & & 5 & 3 \\
\hline 0.04 & $0 / 7$ & $x$ & 5 & 1 & 5 & 3 \\
\hline 0 & $0 / 7$ & $x$ & 7 & & 5 & 3 \\
\hline 0 & $0 / 7$ & $x$ & 7 & & 5 & 3 \\
\hline 0 & $0 / 7$ & $x$ & 7 & & 5 & 3 \\
\hline 0 & $0 / 7$ & $x$ & 5 & & & 3 \\
\hline 0 & $0 / 7$ & $x$ & 5 & & 5 & 3 \\
\hline
\end{tabular}




\begin{tabular}{|c|c|c|c|c|c|c|c|c|c|}
\hline \multirow{2}{*}{ No. } & \multirow{2}{*}{ PWR SYSTEM, MALFUNCTION (EVENT) } & \multirow{2}{*}{$\begin{array}{c}\text { FREQUENCY } \\
\text { OF } \\
\text { OCCURRENCE }\end{array}$} & \multirow{2}{*}{$\begin{array}{l}\text { CURRENIILY } \\
\text { SIMULATED }\end{array}$} & \multirow{2}{*}{$\begin{array}{l}\text { ANALYSIS } \\
\text { REQUIRED }\end{array}$} & \multicolumn{4}{|c|}{ JUSTIFICATION } & \multirow{2}{*}{$\begin{array}{l}\text { IMPOR- } \\
\text { TANCE } \\
\text { FACTOR }\end{array}$} \\
\hline & & & & & $A$ & $B$ & C & $D$ & \\
\hline
\end{tabular}

REACTOR PROTECTION (Modes 1-3)

\begin{tabular}{l|l}
1 & $\begin{array}{l}\text { Reactor trip breakers failure to trip } \\
\text { Reactor trip system failure to trip, primary } \\
\text { input relays failure }\end{array}$ \\
3 & $\begin{array}{l}\text { Reactor trip system secondary output relays } \\
\text { failure }\end{array}$ \\
& $\begin{array}{l}\text { Reactor trip, main turbine trip; main turbine } \\
\text { trip failure; excessive cooldown }\end{array}$
\end{tabular}

\begin{tabular}{l|l|l|l|l|l|l|l}
0.04 & $0 / 7$ & $x$ & 15 & 1 & 5 & 3 & 24 \\
0 & $0 / 7$ & $x$ & 12 & 5 & 3 & 20 \\
0 & $0 / 7$ & $x$ & 12 & 5 & 3 & 20 \\
0. & $0 / 7$ & $x$ & 15 & 5 & 3 & 23
\end{tabular}

COntainment (A11 Modes)

\begin{tabular}{l|l|}
1 & $\begin{array}{l}\text { Containment isolation actuation channel } \\
\text { failure to isolate, first phase }\end{array}$ \\
2 & $\begin{array}{l}\text { Selected containment isolation valves inoperable } \\
\text { failure to isolate }\end{array}$ \\
3 & $\begin{array}{l}\text { Selected containment isolation valves leak } \\
4\end{array}$ \\
5 & $\begin{array}{l}\text { False actuation of containment isolation } \\
\text { Containment isolation actuation channel failure }\end{array}$ \\
6 & $\begin{array}{l}\text { Containment casing cooling inoperable } \\
7\end{array}$ \\
8 & $\begin{array}{l}\text { Containment casing cooling limit exceeded } \\
\text { Containment pressure channel failure, high, low. }\end{array}$
\end{tabular}

\begin{tabular}{l|l|l|l|l|l|l|l}
0.04 & $0 / 7$ & $x$ & 15 & 1 & 5 & 3 & 24 \\
0.61 & $0 / 7$ & $x$ & 15 & 1 & 5 & 3 & 24 \\
0.26 & $0 / 7$ & $x$ & 15 & 1 & 5 & 3 & 24 \\
0 & $3 / 7$ & $x$ & 5 & & 5 & 3 & 13 \\
0 & $0 / 7$ & $x$ & 15 & & 5 & 3 & 23 \\
0.09 & $0 / 7$ & $x$ & 7 & 1 & 5 & 3 & 16 \\
0.17 & $0 / 7$ & $x$ & 5 & 1 & 5 & 3 & 14 \\
0 & $0 / 7$ & $x$ & 5 & - & 5 & 3 & 13
\end{tabular}




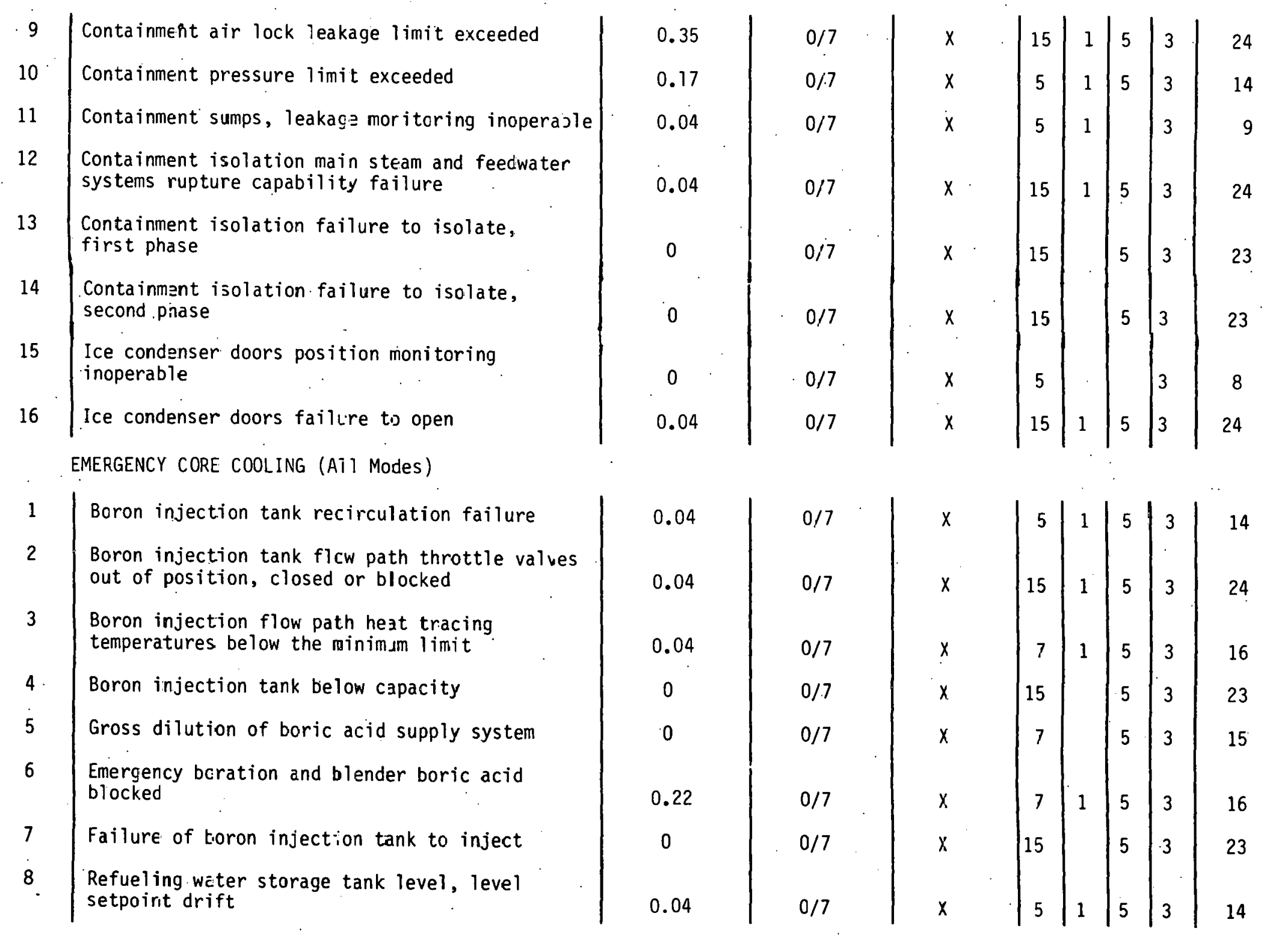




\begin{tabular}{|c|c|c|c|c|c|c|c|c|c|}
\hline \multirow{2}{*}{ NO. } & \multirow{2}{*}{ PWR SYSTEM, MALFUNCTION (EVENT) } & \multirow{2}{*}{$\begin{array}{c}\text { FREQUENCY } \\
\text { OF } \\
\text { OCCURRENCE }\end{array}$} & \multirow{2}{*}{$\begin{array}{l}\text { CURRENILY } \\
\text { SIIULATED }\end{array}$} & \multirow{2}{*}{$\begin{array}{l}\text { ANALYSIS } \\
\text { REQUIRED }\end{array}$} & \multicolumn{4}{|c|}{ JUSTIFICATION } & \multirow{2}{*}{$\begin{array}{l}\text { IMPOR- } \\
\text { TANCE } \\
\text { FACTOR }\end{array}$} \\
\hline & & & & & A & B & c & D & \\
\hline
\end{tabular}

EMERGENCY CORE COOLING (A11 Modes) (cont.)

\begin{tabular}{|c|c|}
\hline 9 & Refueling water storage tank level below limit \\
\hline 10 & $\begin{array}{l}\text { Refueling water storage tank bypass ESF } \\
\text { circuit failure }\end{array}$ \\
\hline 11 & ESF sequencer timer failure \\
\hline 12 & LOCA blowdowr analysis in error \\
\hline 13 & Containment sump valve failure \\
\hline 14 & Containment spray pump failure to start \\
\hline 15 & Containment spray pump auto start failure \\
\hline 16 & $\begin{array}{l}\text { ESF auxiliary relay cabinet selected relays } \\
\text { failure, valves, pumps }\end{array}$ \\
\hline 17 & Failure of high head safety injection pump \\
\hline 18 & All high head safety injection pumps inoperable \\
\hline 19 & Safety injection system leakage, pipe failure \\
\hline 20 & $\begin{array}{l}\text { All intermediate or low head safety injection } \\
\text { pumps inoperable }\end{array}$ \\
\hline 21 & $\begin{array}{l}\text { Upper head injection accumulator pressure } \\
\text { failure }\end{array}$ \\
\hline 22 & Safety injection tank check valves failure \\
\hline
\end{tabular}

\begin{tabular}{l|l|l|l|l|l|l|l}
0.04 & $0 / 7$ & $x$ & 7 & 1 & 5 & 3 & 16 \\
0.04 & $0 / 7$ & $x$ & 15 & 1 & 5 & 3 & 24 \\
0.04 & $0 / 7$ & $x$ & 12 & 1 & 5 & 3 & 21 \\
0.04 & $0 / 7$ & $x$ & 15 & 1 & 5 & 3 & 24 \\
0.09 & $0 / 7$ & $x$ & 15 & 1 & 5 & 3 & 24 \\
0.04 & $0 / 7$ & $x$ & 15 & 1 & 5 & 3 & 24 \\
0.04 & $0 / 7$ & $x$ & 12 & 1 & 5 & 3 & 21 \\
0 & $0 / 7$ & $x$ & 12 & & 5 & 3 & 20 \\
0 & $1 / 7$ & $x$ & 12 & 5 & 3 & 20 \\
0.04 & $0 / 7$ & $x$ & 15 & 1 & 5 & 3 & 24 \\
0 & $3 / 7$ & $x$ & 12 & 5 & 3 & 20 \\
0 & $0 / 7$ & $x$ & 15 & & 5 & 3 & 23 \\
0.04 & $1 / 7$ & $x$ & 15 & 1 & 5 & 3 & 24 \\
0.04 & $0 / 7$ & $x$ & 15 & 1 & 5 & 3 & 24
\end{tabular}




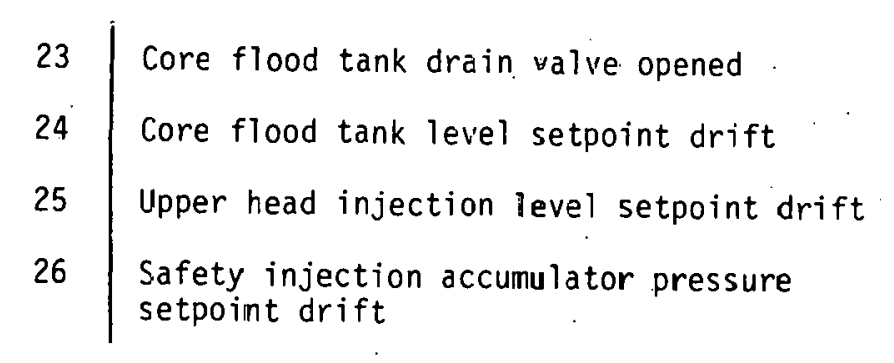

\begin{tabular}{|c|c|c|c|c|c|}
\hline 0 & $0 / 7$ & $x$ & 15 & 5 & 3 \\
\hline 0.13 & $0 / 7$ & $x$ & 5 & 5 & 3 \\
\hline 0 & $0 / 7$ & $x$ & 5 & 5 & 3 \\
\hline 0 & $0 / 7$ & $x$ & 5 & 5 & 3 \\
\hline
\end{tabular}

EMERGENCY PLAN (A11 Modes)

\begin{tabular}{|c|c|}
\hline 1 & Atmosphere temperature $\Delta T$ instruments failure \\
\hline 2 & Fedundant wind direction instrument failure \\
\hline 3 & Gaseous release trip ve.lve failure \\
\hline 4 & Accidental release of righ activity gas tark \\
\hline 5 & Chlorine tank car leak or rspture \\
\hline 6 & Waste gas area explosicn \\
\hline & MODE STATUS REQUIREMENTS (A11 Modes) \\
\hline 1 & $\begin{array}{l}\text { High head ECCS component surveillance test } \\
\text { failure mode change }\end{array}$ \\
\hline 2 & $\begin{array}{l}\text { Emergency diesel generator surveillance } \\
\text { failure for mode change }\end{array}$ \\
\hline 3 & $\begin{array}{l}\text { Low head ECCS components surveillance test } \\
\text { failure or in cool down mode for power operztion } \\
\text { mode }\end{array}$ \\
\hline 4 & $\begin{array}{l}\text { Passive component accumslatcir or core flood } \\
\text { injection iodated for power operation mode }\end{array}$ \\
\hline 5 & $\begin{array}{l}\text { Containment purge system operation beyond } \\
\text { limiting condition (LCO) }\end{array}$ \\
\hline 6 & $\begin{array}{l}\text { Auxiliary feedwater surveilliance requirements } \\
\text { failure for mode change }\end{array}$ \\
\hline
\end{tabular}

\begin{tabular}{l|l|l|l|l|l|l|l}
0.04 & $0 / 7$ & $x$ & 7 & 1 & 5 & 3 & 16 \\
0 & $0 / 7$ & $x$ & 7 & & 5 & 3 & 15 \\
0 & $3 / 7$ & $x$ & 7 & & 5 & 3 & 15 \\
0 & $3 / 7$ & $x$ & 7 & & 5 & 3 & 15 \\
0 & $0 / 7$ & & & & 5 & 3 & 8 \\
0 & $0 / 7$ & $x$ & 12 & & 5 & 3 & 20
\end{tabular}




\begin{tabular}{|c|c|c|c|c|c|c|c|c|c|}
\hline \multirow{2}{*}{ NO. } & \multirow{2}{*}{ PWR SYSTEM, MALFUNCTION (EVENT) } & \multirow{2}{*}{$\begin{array}{c}\text { FREQUENCY } \\
\text { OF } \\
\text { OCCURRENCE }\end{array}$} & \multirow{2}{*}{$\begin{array}{l}\text { CURRENTLY } \\
\text { SIMULATED }\end{array}$} & \multirow{2}{*}{$\begin{array}{l}\text { ANALYSIS } \\
\text { REQUIRED }\end{array}$} & \multicolumn{4}{|c|}{ JUSTIFICATION } & \multirow{2}{*}{$\begin{array}{l}\text { IMPOR- } \\
\text { TANCE } \\
\text { FACTOR }\end{array}$} \\
\hline & & & & & $A$ & B & $c$ & 0 & \\
\hline
\end{tabular}

FIRE (A11 Modes)

\begin{tabular}{c|l}
1 & Loss of $\frac{1}{2}$ diesel fire pumps \\
2 & Loss of all diesei fire pumps \\
3 & Loss of $\frac{1}{2}$ motor driven fire pumps \\
4 & Loss of all motor driven fire pumps \\
5 & Diesel fire pumps auto start failure \\
6 & Motor driven fire pumps auto start failure \\
7 & Fire system pressure actuation instruments \\
8 & drift or failure \\
9 & Header remote isolation valves failure: \\
10 & Fire protection alarm spurious \\
11 & MSIV enclosure area fire \\
12 & Reactor coolant pump area fire \\
13 & Main turbine area fire \\
14 & Main generator fire \\
15 & Emergency diesel fire \\
16 & Fire header pipe rupture \\
\end{tabular}

\begin{tabular}{|c|c|c|c|c|c|c|c|}
\hline 0.17 & $0 / 7$ & $x$ & 5 & 1 & 5 & 3 & 14 \\
\hline 0 & $0 / 7$ & $x$ & 12 & & 5 & 3 & 20 \\
\hline 0.04 & $0 / 7$ & $x$ & 5 & 1 & & 3 & 9 \\
\hline 0 & $0 / 7$ & $x$ & 12 & & 5 & 3 & 20 \\
\hline 0.04 & $0 / 7$ & $x$ & 5 & 1 & 5 & 3 & 14 \\
\hline 0.04 & $0 / 7$ & $x$ & 5 & 1 & 5 & 3 & 14 \\
\hline 0.04 & $0 / 7$ & $x$ & 5 & 1 & 5 & 3 & 14 \\
\hline 0 & $0 / 7$ & $x$ & 12 & & $5^{\circ}$ & 3 & 20 \\
\hline 0 & $0 / 7$ & $x$ & & & & 3 & 3 \\
\hline 0 & $0 / 7$ & $x$ & 5 & & & 3 & 8 \\
\hline 0 & $0 / 7$ & $x$ & 12 & & 5 & 3 & 20 \\
\hline 0 & $0 / .7$ & $x$ & 15 & & 5 & 3 & 23 \\
\hline 0 & $0 / 7$ & $x$ & 12 & & 5 & 3 & 20 \\
\hline 0 & $0 / 7$ & $x$ & 12 & & 5 & 3 & 20 \\
\hline 0 & $0 / 7$ & $x$ & 15 & & 5 & 3 & 23 \\
\hline 0.04 & $0 / 7$ & $x$ & 12 & 1 & 5 & 3 & 21 \\
\hline
\end{tabular}


17 Carbon dioxide $\left(\mathrm{CO}_{2}\right)$ fire protection system auto actuation faifure

18 Carbon dioxide $\left(\mathrm{CO}_{2}\right)$ auto actiation Main transfomer fire

\begin{tabular}{|l|r|r|r|r|r|r|r}
0 & \\
0 & $0 / 7$ & $x$ & 15 & & 5 & 3 & 23 \\
0 & $0 / 7$ & $x$ & & & & 3 & 3 \\
$0 / 7$ & $x$ & 12 & & 5 & 3 & 20
\end{tabular}


In Chapter 5 of this report procedures are offered for selecting the most important equipment malfunctions for simulation during operator training programs. To illustrate the procedures, we have applied them to a group of typical malfunctions gathered from LERs and other sources. In each case the malfunction is ranked in the following four areas:
A. Whether it constitutes a safety-related event.
B. How frequently it occurs.
C. Whether it is a safety-related precursor.
D. Whether it results in significant plant outage.

A numerical evaluation is given to each of these categories, and their sum is identified as the "importance factor" for the malfunction. The maximum importance factor possible is 27 .

This appendix presents the results of applying the proposed procedures to BWR malfunctions. The frequency of occurrence given in the third column represents the number of such events per reactor year of operation for all BWRs based on a six-month operating period in 1978; the information.listed in the fourth column (as $x / y$ ) indicates the number of simulators surveyed that simulate that particular malfunction $(x)$ and the total number of simulators included in the survey at the time the analysis was completed for that malfunction $(y)$; and the fifth column indicates whether the malfunction represents an event that must be analyzed in safety analysis reports. (For additional information, see Chapter .5.) 


\begin{tabular}{|c|c|c|c|c|c|c|c|c|c|}
\hline \multirow{2}{*}{ NO. } & \multirow{2}{*}{ BWR SYSTEM, MALFUNCTION (EVENT) * } & \multirow{2}{*}{$\begin{array}{c}\text { FREQUENCY } \\
\text { OF } \\
\text { OCCURRENCE }\end{array}$} & \multirow{2}{*}{$\begin{array}{l}\text { CURRENTLY } \\
\text { SIMULATED }\end{array}$} & \multirow{2}{*}{$\begin{array}{l}\text { ANAL YSIS } \\
\text { REQUIRED }\end{array}$} & \multicolumn{4}{|c|}{ JUSTIFICATION } & \multirow{2}{*}{$\begin{array}{l}\text { IMPOR- } \\
\text { TANCE } \\
\text { FACTOR }\end{array}$} \\
\hline & & & & & $A$ & B & C & $D$ & \\
\hline
\end{tabular}

REACTOR COOLANT (Any Mode)

\begin{tabular}{c|l|}
1 & Reactor water level instrument failure \\
2 & Pressure relief valve set point out of cal. \\
3 & Pressure relief valve fails open/leaks (actual) \\
4 & RWCU system failure - mechanical \\
5 & RWCU system failure - chemistry \\
6 & RWCU system failure - piping leak/rupture \\
7 & Heatup/cooldown rates exceeded \\
8 & Reactor pressure instrumentation out of cal \\
9 & Recirc pump trip (actual) \\
10 & Recirc instrumentation out of calibration \\
11 & $\begin{array}{l}\text { Coolant leaks into drywell (See "Containinent" - } \\
\text { leakage into drywell out of spec) }\end{array}$
\end{tabular}

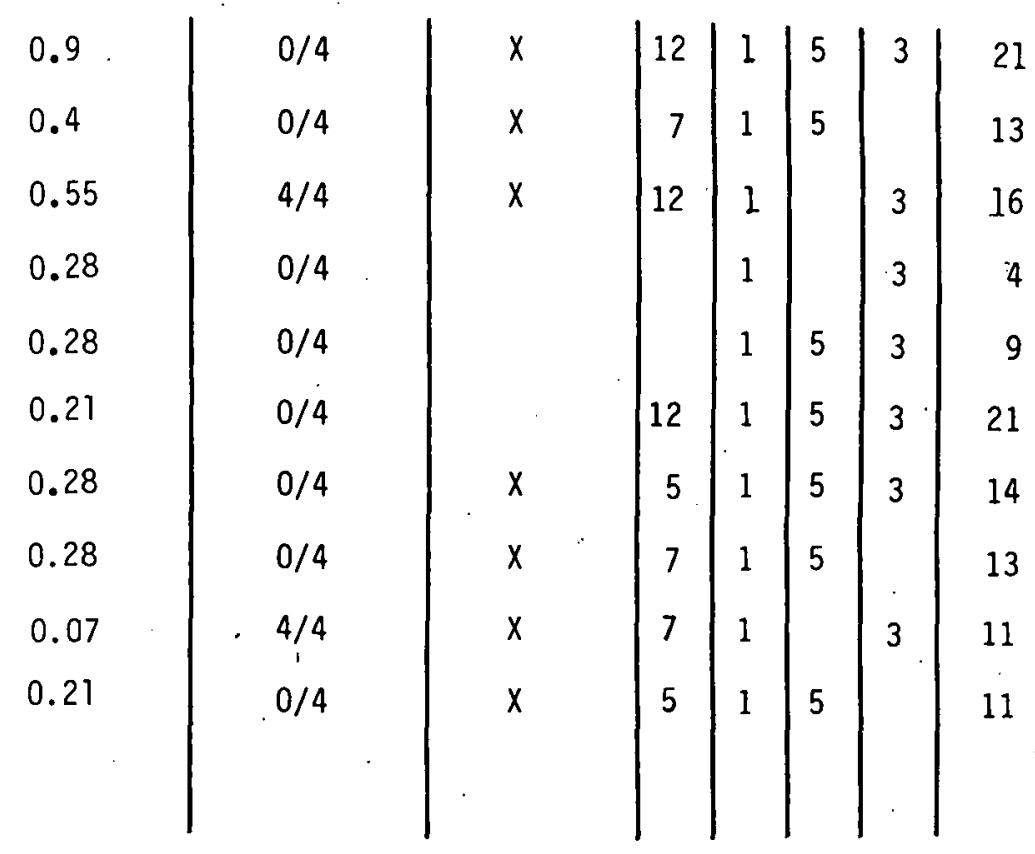

STANDBY LIQUID CONTROL SYSTEM (Any Mode)

\begin{tabular}{l|l}
1 & System inoperative - valve alignment \\
2 & System inoperative - valve failure \\
3 & Pressure instrument failure \\
4 & SLC system inadvertently initiates \\
\hline
\end{tabular}

\begin{tabular}{l|l}
0.14 & $0 / 4$ \\
0.07 & $0 / 4$ \\
0.21 & $0 / 4$ \\
0 & $0 / 4$
\end{tabular}

$x$
$x$
$x$
$x$

\begin{tabular}{|r|r|r|r|r}
5 & 1 & 5 & & 11 \\
5 & 1 & 5 & & 11 \\
& 1 & 5 & $\cdot$ & 6 \\
12 & & & 3 & 15
\end{tabular}.

*See Appendix I for definitions of acronyms. 
REACTOR CONTROLS (Any Mode)

\begin{tabular}{l|l}
1 & Control rod drive piping leaks/ruptured \\
2 & Control rod drive accumulator failure \\
3 & Control rod inoperative \\
4 & Scran discharge volume misaligned \\
5 & Pattern control system failure \\
6 & Critical power ratio exceeded
\end{tabular}

\begin{tabular}{|r|r|r|r|r|r|r|r|r|}
0.34 & $0 / 4$ & $x$ & 12 & 1 & 5 & 3 & 21 \\
0.21 & $2 / 4$ & $x$ & 5 & 1 & 5 & 3 & 14 \\
0.34 & $3 / 4$ \\
0.07 & $0 / 4$ & $x$ & 5 & 1 & & 3 & 9 \\
0.14 & $1 / 4$ & & & 5 & 1 & 5 & 3 & 14 \\
0.07 & $0 / 4$ & $x$ & & 12 & 5 & & 6 \\
& $x$ & & & & & \\
0.32 & & 5 & 3 & 21
\end{tabular}

ELECTRICAL (Any Mode)

\begin{tabular}{l|l}
1 & Station batteries out of service \\
2 & Loss of off-site power \\
3 & $\begin{array}{l}\text { Reduced power operations (degraded elec. } \\
\text { system) }\end{array}$
\end{tabular}

\begin{tabular}{r|r|r|r|r|r|r|r}
0.28 & $0 / 4$ & $x$ & & 1 & 5 & & 6 \\
0.28 & $0 / 4$ & $x$ & 12 & 1 & & 3 & 16 \\
0.55 & $2 / 4$ & $x$ & 12 & 1 & 5 & 3 & 21
\end{tabular}

DIESEL GENERATOR (Any Mode)

\begin{tabular}{l|l}
1 & D. G. fails to start \\
2 & D. G. trips while running \\
3 & D. G. would not trip \\
4. & D. G. placed inop (mechanical \& elec. fail) \\
5 & D. G. fuel system malfunction
\end{tabular}

\begin{tabular}{l|ll|l|l|l|l|l|l}
0.34 & $2 / 4$ & $x$ & 5 & 1 & & 6 \\
0.41 & $0 / 4$ & $x$ & 5 & 1 \\
0.07 & $0 / 4$ & & & & & \\
0.55 & $0 / 4$ & $x$ & 5 & 1 \\
0.14 & $0 / 4$ & $x$ & 5 & 1 & &
\end{tabular}

MAIN STEAM AND TURBINE (Any Mode)

1 Main steam line temperature high

2 Main steam line rad monitor inoperative

\begin{tabular}{l|l|}
0.34 & $0 / 4$ \\
0.41 & $0 / 4$
\end{tabular} \begin{tabular}{|l|l|l|l|l}
5 & 1 & 5 & 3 & 14 \\
5 & 1 & 5 & 3 & 14
\end{tabular} 


\begin{tabular}{|c|c|c|c|c|c|c|c|c|c|}
\hline \multirow{2}{*}{ NO. } & \multirow{2}{*}{ BWR SYSTEM, MALFUNCTION (EVENT) } & \multirow{2}{*}{$\begin{array}{c}\text { FREQUENCY } \\
\text { OF } \\
\text { OCCURRENCE }\end{array}$} & \multirow{2}{*}{$\begin{array}{l}\text { CURRENTLY } \\
\text { SIMULATED }\end{array}$} & \multirow{2}{*}{$\begin{array}{l}\text { ANALYSIS } \\
\text { REQUIRED }\end{array}$} & \multicolumn{4}{|c|}{ JUSTIFICATION } & \multirow{2}{*}{$\begin{array}{l}\text { IMPOR- } \\
\text { TANCE } \\
\text { FACTOR }\end{array}$} \\
\hline & & & & & A & B & $C$ & $D$ & \\
\hline
\end{tabular}

MAIN STEAM AND TURbine (Any Mocie) (cont.)

\begin{tabular}{l|l}
3 & MSIV isolation switch fails \\
4 & MSIV fails to operate \\
5 & Valve response time out of spec
\end{tabular}.

\begin{tabular}{l|l|l|l|l|l|l|l|l}
0.83 & $0 / 4$ \\
0.14 & $0 / 4$ & & \\
0.34 & $1 / 4$ & & 5 & 1 & 5 & & 11 \\
& & & & 3 & 11 \\
& & 5 & & 6
\end{tabular}

CONDENSATE AND FEEDWATER (AII Modes)

\begin{tabular}{l|l}
1 & Condensate storage tank low level \\
2 & Feedwater leak/ruptured. \\
3 & Condensate conductivity out of spec.
\end{tabular}

\begin{tabular}{l|l|l|l|l|l|l|l}
0.14 & $0 / 4$ & $x$ & 5 & 1 & 5 & & 11 \\
0.07 & $0 / 4$ & $x$ & 12 & 1 & 5 & 3 & 21 \\
0.07 & $0 / 4$ & $x$ & & 1 & & & 1
\end{tabular}
NUCLEAR INSTRUMENTATION (Any Mode).

\begin{tabular}{l|l}
1 & IRM monitor failed \\
2 & IRM out of calibration (drift) \\
3 & SRM failed \\
4 & SRM out of calibration (drift) \\
5 & APRM failed \\
6 & APRM out of calibration (drift) \\
7 & LPRM out of calibration (drift) \\
8 & Rod block monitor out of calibration (drift) \\
9 & TIP system mechanical failure
\end{tabular}

\begin{tabular}{|c|c|c|c|c|c|}
\hline 0.47 & $4 / 4$ & $x$ & 5 & 1 & 3 \\
\hline 0.07 & $0 / 4$ & $x$ & & 1 & 3 \\
\hline 0.07 & $4 / 4$ & $x$ & 5 & 1 & 3 \\
\hline 0 & $.0 / 4$ & $x$ & $\cdot$ & 0 & 3 \\
\hline 0.07 & $4 / 4$ & $x$ & 5 & 1 & 3 \\
\hline 0.14 & $0 / 4$ & $x$ & & 1 & 3 \\
\hline 0.07 & $0 / 4$ & $x$ & & 1 & \\
\hline 0.14 & $0 / 4$ & & & $i$ & \\
\hline 0.14 & $0 / 4$ & $x$ & 5 & 1 & \\
\hline
\end{tabular}


10 TIP system instrumert fäilure (out of calibration) (drift)

CONTAINMENT (AII Modes)

1 Containment oxygen/hydrogen inst fail

2 Containment integrity violated/broken

3

Containment atmosphere radiction monitor failinop

4

Drywe 1: pressure insturment failure

Primary containment isolaticn valves fail

Excessive drywell leakage-failed indication

Excessive drywell ieakage-various packing/seal leaks

\section{Contairment vacuum breakers fail/inop} (Torus-RB/Torus-drywe1l)

Torus level instrument iailure

Torus level out of spec-actual-valve failure

* $\quad$ Clearly identified as instrument failure.

OFF GAS;STANDBY GAS TREATMENT (SBGT) (Any Moje)

\begin{tabular}{l|l}
1 & Stack monitor inoperative \\
2 & SBGT system failure \\
3 & Air ejector system instrument failure \\
4 & Off-gas system leaks/ruftures
\end{tabular}

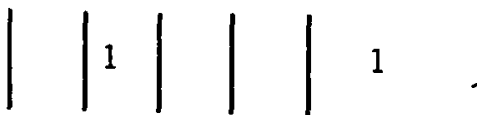

\begin{tabular}{|c|c|c|c|c|c|c|}
\hline 2.0 & $0 / 4$ & & & 2 & 5 & \\
\hline 0.62 & $0 / 4$ & & 7 & 1 & 5 & \\
\hline 0.62 & $0 / 4$ & & & 1 & 5 & \\
\hline 0.34 & $0 / 4$ & $x$ & & 1 & 5 & \\
\hline 0.34 & $0 / 4$ & & 7 & 1 & 5 & \\
\hline 0.07 & $0 / 4$ & & & 1 & 5 & \\
\hline 0.28 & $0 / 4$ & $x$ & 12 & 1 & 5 & 3 \\
\hline 0.48 & $0 / 4$ & $x$ & & 1 & & \\
\hline 0.34 & $0 / 4$ & & 5 & 1 & 5 & \\
\hline 0.07 & $0 / 4$ & & 5 & 1 & 5 & $n$ \\
\hline
\end{tabular}

\begin{tabular}{r|r|r|r|r|r|r|r}
0.83 & $0 / 4$ & $x$ & 7 & 1 & 5 & 3 & 16 \\
0.62 & $0 / 4$ & $x$ & 5 & 1 & 5 & 3 & 14 \\
0.21 & $0 / 4$ & $x$ & & 1 & 5 & & 6 \\
0.07 & $0 / 4$ & $x$ & 15 & 1 & 5 & 3 & 24
\end{tabular}




\begin{tabular}{|c|c|c|c|c|c|c|c|c|c|}
\hline \multirow{2}{*}{ NO. } & \multirow{2}{*}{ BWR SYSTEM, MALFUNCTION (EVENT) } & \multirow{2}{*}{$\begin{array}{c}\text { FREQUENCY } \\
\text { OF } \\
\text { OCCURRENCE }\end{array}$} & \multirow{2}{*}{$\begin{array}{l}\text { CURRENTLY } \\
\text { SIMULATED }\end{array}$} & \multirow{2}{*}{$\begin{array}{l}\text { ANALYSIS } \\
\text { REQUIRED }\end{array}$} & \multicolumn{4}{|c|}{ JUSTIFICATION } & \multirow{2}{*}{$\begin{array}{l}\text { IMPOR- } \\
\text { TANCE } \\
\text { FACTOR }\end{array}$} \\
\hline & & & & & A & $B$ & $C$ & $D$ & \\
\hline
\end{tabular}

EMERGENCY CORE COOLANT - CORE SPRAY (Any Mcde)

1 Core spray instrumentation failure

2 Core spray inoperative

3 Core spray system leaks/rupture

EMERGENCY COPE COOLANT - HIGH-PRESSURE COOLANT INJECTION (Mode: Above Required Pressure Set Point)

\begin{tabular}{l|l|}
1 & HPCI fails to start \\
2 & HPCI flow insufficient \\
3 & HPCI turbine exhaust press high \\
4 & HPCI trips after starting \\
5 & HPCI turbine steam flow indication failure \\
6 & HPCI made inoperative-valve/component malfunction \\
7 & HPCI area temperature high \\
8 & HPCI area temperature instrument failure
\end{tabular}

\begin{tabular}{|c|c|c|c|c|}
\hline 0.07 & $0 / 4$ & $x$ & 5 & \\
\hline 0.34 & $0 / 4$ & $x$ & 5 & . \\
\hline 0.21 & $0 / 4$ & & & 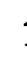 \\
\hline 0.14 & $0 / 4$ & $x$ & 5 & 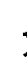 \\
\hline 0.14 & $0 / 4$ & $x$ & 5 & 1 \\
\hline 0.76 & $0 / 4$ & $x$ & 5 & \\
\hline 0.14 & $0 / 4$ & $x$ & 5 & \\
\hline 0.14 & $0 / 4$ & $x$ & 7 & \\
\hline
\end{tabular}

EMERGENCY CORE COOLANT - LOW-PRESSURE COOLANT INJECTION (Any Mode)

\footnotetext{
1 LPCI inoperable - mechanical malfunction $2 \int \begin{aligned} & \text { LPCI inoperable - electrical/instrument } \\ & \text { malfunction }\end{aligned}$
}

\begin{tabular}{l|r|r|r|r|r|r|r}
0.21 & $0 / 4$ & $x$ & 5 & 1 & 5 & & 11 \\
0.14 & $0 / 4$ & $x$ & 5 & 1 & & 3 & 9 \\
0.14 & $0 / 4$ & $x$ & 7 & 1 & 5 & 3 & 16
\end{tabular}

\begin{tabular}{l|l|l|l|l|l|l|l}
0.34 & $0 / 4$ & $x$ & 5 & 1 & & 3 & 9 \\
0.14 & $0 / 4$ & $x$ & 5 & 1 & & 3 & 9
\end{tabular}


EMERGENCY CCRE COOLANT - ISOLATION CONDENSER (Any Mode).

1 Isolation condenser made inaperative

2 Isolation condenser level out of spec

\begin{tabular}{l|l|ll|l|l|l|l|l}
0.14 & $0 / 4$ & $x$ & 5 & 1 \\
0.14 & $0 / 4$ & $x$ & 3 & 9 &
\end{tabular}

EMERGENCY CCIRE COOLANT - REACTOR CORE ISOLA-ION COOLING (Mcde: Above Required Pressure Set Point)

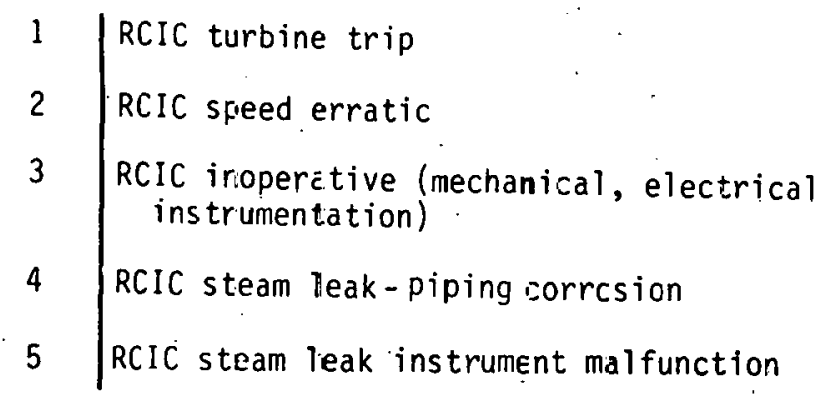

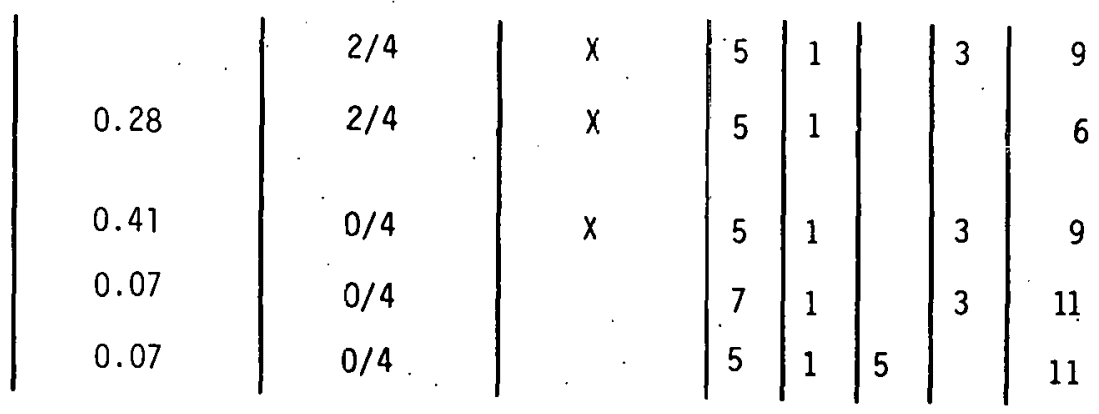

EMERGENCY CORE COOLANT - RESIDUAL HEAT REMOVAL/ SHUTDOWN COOLING (Any libde)

$1 \quad$ RHR system instrumentation failure

2 RHR system inoperative (mechanical)

3 RHR sys.tem leaks/rupture

FIRE PROTECTION (Any Mode)

\begin{tabular}{l|l}
1 & Fire/heat detection sys tem failure \\
2 & Fire sy'stem inoperable-i.pump fail/valve/etc.)
\end{tabular}

\begin{tabular}{|c|c|c|c|c|c|c|c|}
\hline 0.21 & $0 / 4$ & $k$ & 7 & 1 & 5 & & 13 \\
\hline 0.41 & $0 / 4$ & $x$ & 5 & 1 & & 3 & 9 \\
\hline 0.14 & $0 / 4$. & $x$ & 7 & 1 & 5 & 3 & .16 \\
\hline 0.48 & $0 / 4$ & $x$ & 5 & 1 & 5 & & \\
\hline 0.34 & $0 / 4$ & $x$ & 5 & 1 & & 3 & 9 \\
\hline
\end{tabular}


Appendix I

DEFINITIONS OF ACRONYMS 


\begin{tabular}{|c|c|c|c|}
\hline AC & Alternating Current & HPCI & $\begin{array}{l}\text { High Pressure Coolant Injection } \\
\text { (System) }\end{array}$ \\
\hline APDMS & $\begin{array}{l}\text { Axial Power Distribution Monitoring } \\
\text { System }\end{array}$ & HPCS & High Pressure Charging System \\
\hline APRM & $\begin{array}{l}\text { Average Power Range Monitoring } \\
\text { (System) }\end{array}$ & HPFW & High Pressure Feedwater (System) \\
\hline AUX & Auxiliary & HPI & High Pressure Injection \\
\hline BIT & Boron Injection Tank & $H X$ & Heat Exchanger \\
\hline BKRS & Circuit Breakers & IC & Initial Conditions \\
\hline BOP & Balance of Plant & IRM & $\begin{array}{l}\text { Intermediate Range Monitoring } \\
\text { (System) }\end{array}$ \\
\hline BWR & Boiling Water Reactor & KV & Kilovolt \\
\hline$C B$ & Control'Building & LCO & Limiting Conditions for Operation \\
\hline CCW & $\begin{array}{l}\text { Component Cooling Water (PWR): } \\
\text { Closed cooling Water (BWR) }\end{array}$ & LCD & Load Control Dispatcher \\
\hline CEDM & Control Element Drive Mechanism & LER & Licensee Event Report \\
\hline CRD & Control Rod Drive & LOCA & Loss of Coolant Accident \\
\hline CS & Core Spray & LP & Low Pressure \\
\hline CTS & Containment Spray System & LPCI & $\begin{array}{l}\text { Low Pressure Coolant Injection } \\
\text { (System) }\end{array}$ \\
\hline $\mathrm{CV}$ & Control Valve & LPCS & Low Pressure Charging System \\
\hline CVCS & Chemical Volume Control System & LPFW & Low Pressure Feedwater (System) \\
\hline $\mathrm{DG}$ & Diesel Generator & LPRM & Local Power Range Monitoring (System) \\
\hline DP & Differential Pressure & LPT & Low Pressure Turbine \\
\hline DRN & Drain & LVP & Low Voltage Protection \\
\hline DT & Differential Temperature & MCC & Motor Control Center \\
\hline ECC & Emergency Core Cooling & MCR & Main Control Room \\
\hline ECCS & Emergency Core Cooling System & MDAFP & Motor Driven Auxiliary Feedwater Pump \\
\hline EGTS & Emergency Gas Treatment System & $M / G$ & Motor Generator \\
\hline $\mathrm{EH}$ & Electro-Hydraulic & MS & Main Steam (System) \\
\hline $\mathrm{EHC}$ & Electro-Hydraulic Control (System) & MSIV & Main Steam Isolation Valvé \\
\hline ESF & Engineered Safety Feature & NI & Nuclear Instrumentation (System) \\
\hline ESW & Essential Service Water (System) & NR & Non-regenerative \\
\hline FSAR & Final Safety Analysis Report & NSAC & Nuclear Safety Advisory Committee \\
\hline $\mathrm{FW}$ & Feedwater & NSSS & Nuclear Steam Supply System (Vendor) \\
\hline$H / L$ & $\mathrm{High} / \mathrm{Low}$ & PORV & Pilot Operated Relief Valve \\
\hline HP & High Pressure & PRM & Power Range Monitoring (System) \\
\hline
\end{tabular}




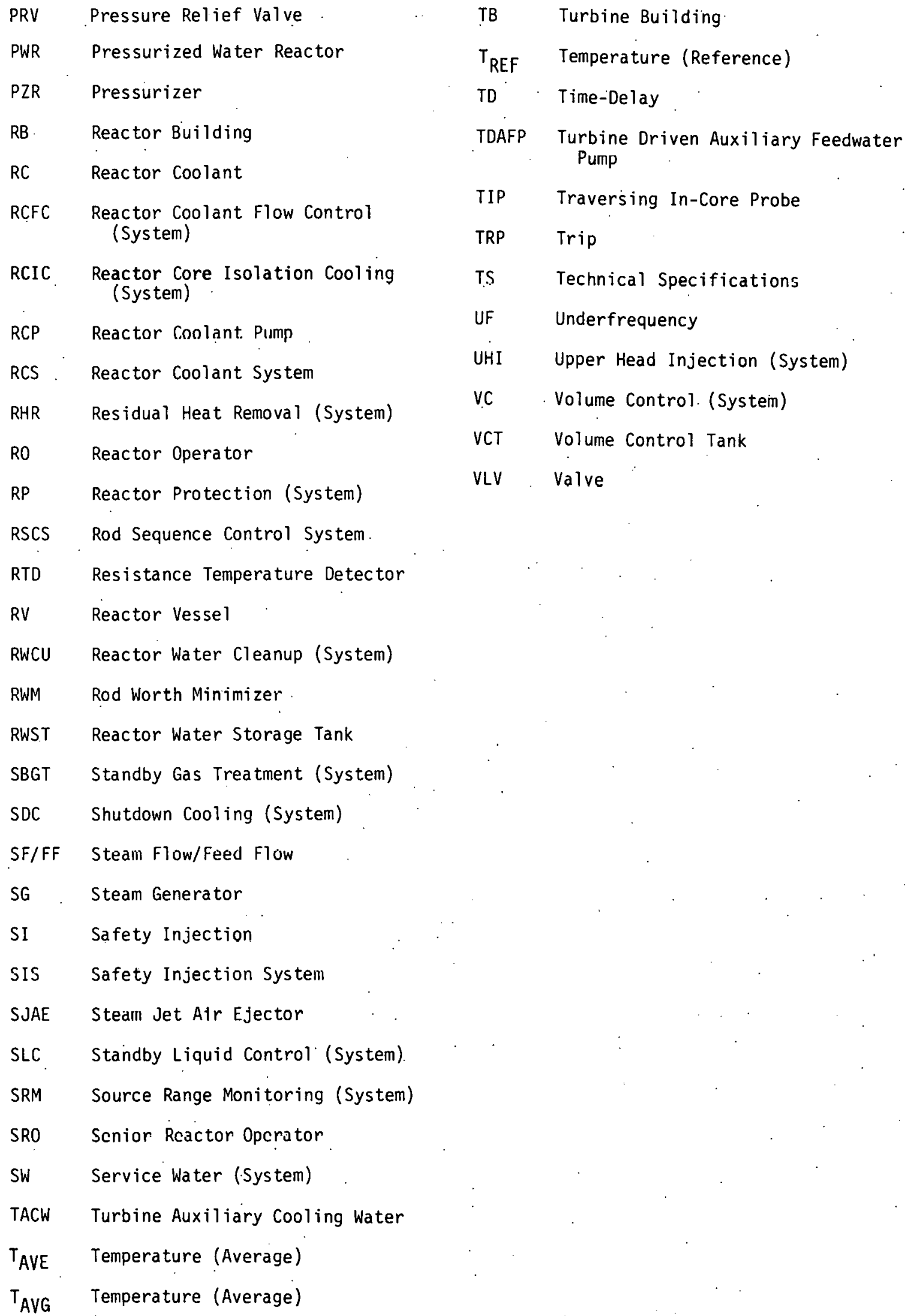


INTERNAL DISTTRIBUTION

$\begin{array}{ll}\text { 1. } & \text { L. S. Abbott } \\ \text { 2. J. L. Anderson } \\ \text { 3. } & \text { D. E. Bartine } \\ \text { 4. } & \text { F. Binford } \\ \text { 5. } & \text { J. B. Bullock } \\ \text { 6. } & \text { W. Casto } \\ \text { 7. } & \text { W. B. Cottrell } \\ \text { 8. G. F. Flanagan } \\ \text { 9. } & \text { H. Goldstein (Consultant) } \\ \text { 10-14. P. M. Haas } \\ \text { 15. T. Hamrick } \\ \text { 16. S. D. Hudson } \\ \text { 17. } \\ \text { 18. H. Jordan } \\ \text { 19. A. H. Kisner } \\ \text { H. E. Knee }\end{array}$
20. F. C. Maienschein
21. J. J. Manning
22. F. R. Mynatt
23. L. C. Oakes
24. W. H. Sides, JR.
25. R. Stone
26. D. B. Trauger
27. A. Zucker
28. P. Greebler (Consultant)
29. W. B. Lowenstein (Consultant)
30. R. Wilson (Consuit tant)
31. Central Research Library
32. $Y-12$ Document Reference Section
33. Laboratory Records - ORivL, RC
34. ORNL Patent Office

EXTERNAL DISTRIBUTION

35-36. Director, Division of Reactor \& Technology, USDOE, Washington, DC 20545

37. Office of Assistant Manager for Energy Research \& Development, USDOE, ORO, Oak Ridge, Tenn. 37830

38-42. D. W. Jones, Memphis State University, Memphis, Tenn.

43. A. D. Swain, Sandia Laboratories, Albequerque, NM 87115

44. E. Kozinsky, General Physics Corp., One Northgate Park, Chattanooga, TN 37415

45. A. Ri Buhl, Technology for Encrgy Corp., 10431 Lexinylun Dr., Concord, TN

46. J. Paris, EPRI, P.0. Box 10412, Palo Alto, California 94303

47. G. Bennett, USDOE, Washington, DC

48. Z. Sabri, Iowa St. University; Ames, Iowa

49-50. USDOE Tẹchnical Informationn rẹnter, Dak. Ridge, TN 37830

51-350. Given distribution as shown. in Category RI, Basic (NTIS-10)

351-425. Extra Copies requested by NRC for special distribution 